NBER WORKING PAPER SERIES

DETERRENCE AND COMPELLENCE IN THE PARLIAMENT

\author{
Duha T. Altindag \\ Naci H. Mocan \\ Jie Zhang \\ Working Paper 28532 \\ http://www.nber.org/papers/w28532 \\ NATIONAL BUREAU OF ECONOMIC RESEARCH \\ 1050 Massachusetts Avenue \\ Cambridge, MA 02138 \\ March 2021, Revised July 2021
}

We thank Rafael Di Tella, Gianmarco Daniele, Marcel Garz, Chris Vickers, Aditi Sengupta, Randy Beard, Gilad Sorek, Giuseppe Di Vita, Pelin Akyol, Nicolas Ziebarth, Francesco Trebbi, Philip Marx, Paolo Pinotti, Manoel Gehrke, Semih Tümen, Samuel Cole, and the participants of the CLEAN Seminar Series of Bocconi University, the 8th Economic Analysis of Litigation Workshop in Paris, France, the Annual Conference of the Spanish Association of Law and Economics at University Pompeu Fabra for helpful comments. The views expressed herein are those of the authors and do not necessarily reflect the views of the National Bureau of Economic Research.

NBER working papers are circulated for discussion and comment purposes. They have not been peerreviewed or been subject to the review by the NBER Board of Directors that accompanies official NBER publications.

(C) 2021 by Duha T. Altindag, Naci H. Mocan, and Jie Zhang. All rights reserved. Short sections of text, not to exceed two paragraphs, may be quoted without explicit permission provided that full credit, including $(\odot$ notice, is given to the source. 
Deterrence and Compellence in the Parliament

Duha T. Altindag, Naci H. Mocan, and Jie Zhang

NBER Working Paper No. 28532

March 2021, Revised July 2021

JEL No. D02,K0,P48

\begin{abstract}
In most countries, Parliamentary immunity protects lawmakers from civil or criminal charges while in office, and it shields them from prosecution for their political speech or political actions. This paper presents the first empirical analysis in the literature of the impact of Parliamentary immunity on the behavior and performance of politicians. Leveraging a Constitutional Amendment, the adoption of which lifted the immunity of 24 percent of the Members of the Turkish Parliament (MPs), we find that immunity from prosecution impacts how the MPs act and perform their duties in the Parliament. Losing immunity pacifies the MPs of the opposition parties, who become less diligent in the Parliament (drafting fewer pieces of legislation, initiating fewer investigation inquiries, delivering fewer and shorter speeches) and become less aggressive (interrupting other MPs less frequently). They also reduce their tendency to cast dissenting votes against the government. These MPs are less likely to get re-nominated by their parties in the next election, and they are less likely to get re-elected. We find no evidence that more outspoken and active opposition MPs or those who are more valuable for their parties have been targeted for immunity revocation. The results are robust to limiting the analysis to the sample of opposition MPs who had the same intensity of pre-treatment Parliamentary activity. There is no evidence that the MPs, who retained immunity, have increased their Parliamentary efforts in reaction to their same-party colleagues losing immunity. We find that laws are passed faster after the Constitutional Amendment was adopted, possibly as a consequence of reduced opposition and deliberation. Using Eurobarometer surveys, we find that citizens' reactions to the revocation of MP immunity are polarized. An individual's trust in the Parliament is lower or higher based on whether an MP from the individual's province lost immunity and if that MP subscribes to the same or opposing ideology as the individual.
\end{abstract}

Duha T. Altindag

Auburn University

Department of Economics

136 Miller Hall

Auburn AL, 36849

altindag@auburn.edu

Naci H. Mocan

Department of Economics

Louisiana State University

2439 BEC

Baton Rouge, LA 70803-6306

and NBER

mocan@1su.edu

\author{
Jie Zhang \\ The Center for Economics \\ Finance and Management Studies (CEFMS) \\ Hunan University \\ Changsha, Hunan \\ China \\ jiezhangtz@hnu.edu.cn
}




\section{Deterrence and Compellence in the Parliament}

\section{Introduction}

Politicians’ free speech has been protected by law in most countries. ${ }^{1}$ Specifically, elected politicians are provided with non-liability to guard them against arrest and prosecution in matters related to their mandate, such as expression of opinions and casting votes, in an effort to make sure that politicians serve the best interest of their constituents without fear of retribution. This privilege typically starts after the politician is elected, and in most countries it is valid for perpetuity; i.e., it is not restricted to the term in office. In addition, elected politicians are typically covered by inviolability during their time in office, which provides wider protections and eliminates the possibility of any civil or criminal complaint, investigation, search, and seizure. $^{2}$

Although a large literature in economics has focused on the investigation of the behavior and performance of politicians, ${ }^{3}$ there has been no empirical investigation of how politicians' performance on the job is influenced by legal immunity from prosecution bestowed upon them. ${ }^{4}$ This is because, the existence of political immunity varies only between countries, i.e., in a given country, immunity applies either to all politicians or to none. There have been cases where the

\footnotetext{
${ }^{1}$ The origin of protecting politicians from incrimination related to expression of an opinion, can be traced back to Article 9 of the Bill of Rights of 1689 in England. Reddy et al. (2020) point out that "more than 70 percent of democratic countries have some legal provision that protects elected politicians-to varying degrees- from apprehension, prosecution or indictment” (Reddy et al. 2020, p. 531). The authors describe the history of immunity provisions in Section 2 of their paper, and in Table 1 they provide the details of legislative immunity across countries.

2 There is concern that Parliamentary immunity of politicians may lead to abuse of power and corruption (Wigley 2009, 2003), and Reddy, Schularick, and Skereta (2020) show that in a cross-section of countries, variations in immunity levels between countries explain variations in country-level corruption.

${ }^{3}$ These analyses include the investigation of how the performance and legislative activities of politicians are influenced by peer effects and connections (Harmon et al. 2019, Saia 2018), by salaries (Mocan and Altindag 2013, Kotakorpi and Poutvaara 2011), term lengths (Dal Bo and Rossi 2011), political scandals (Daniele et al. 2020, Ferraz and Finan 2008), the impact of the media (Garz and Sörensen 2017, Snyder and Strömberg 2010), and even the sex of politicians’ offspring (Washington 2008).

${ }^{4}$ Dal Bó, Dal Bó, and Di Tella (2006) construct a model where interest groups influence politicians both through bribes and by threats of smear campaigns, legal harassment and violence. The authors introduce immunity to the model as a method to insulate politicians from threats, and analyze the impact of immunity on politician corruption. Reddy, Schularick, and Skereta (2020) modify this model by making the decision to be corrupt binary and by making the bribery and treat decisions of the pressure group a sequential one, as opposed to ones that can be pursued simultaneously.
} 
Parliament of a country has revoked the immunity of some politicians following a charge related to a serious criminal offense or a public scandal such as exposed corruption. Yet, these cases are rare, and they do not lend themselves to a systematic investigation of the impact of immunity revocation. Our paper presents the first empirical analysis in the literature of the effect of Parliamentary immunity on the behavior and performance of lawmakers.

As detailed in Section II, a well-defined legal threat was initiated by the Turkish Parliament in May 2016 towards some of its members. Following the enactment of a constitutional amendment, state prosecutors were empowered to initiate arrest warrants, pursue indictments, and file lawsuits against 132 of the 550 Members of the Parliament (MPs), the majority of whom were members of the opposition parties. We analyze the extent to which the opposition MPs, who lost their immunity, are compelled to vote in tandem with the government and the extent to which they are deterred from engaging in Parliamentary activities that could be construed as detrimental for the government.

According to an original article of the Turkish Constitution, no MP could be questioned, arrested, detained, or brought to trial unless the Parliament lifted her/his immunity based on the recommendation of a Parliamentary Committee. The amendment of May 2016, which was enacted after a bi-partisan vote and with more than 2/3 support of the Parliament, modified the Constitution and suspended (for one term of the Parliament) this inviolability of some MPs. Specifically, the amendment permitted prosecutors to pursue indictments and to press charges against those MPs who had a criminal or civil charge filed against them as of May 2016. The relevant article of the constitution continued to provide legal protection to other MPs as long as they had no charges brought against them when the amendment was enacted by the Parliament. The Constitution also continued to protect the MPs with respect to their political speeches and other Parliamentary activities. That is, non-liability is continued to be provided to all MPs. The related details, including the justification of the Amendment as described by the lawmakers who drafted it and the political environment, are described in Section II below.

This event enables us to analyze the extent to which lifting Parliamentary immunity of the MPs has altered their actions and legislative activities in the Parliament vis-à-vis other MPs who are not impacted by the amendment. It is expected that those MPs, who faced the risk of legal action due to the removal of their immunity, would keep a lower profile and avoid activities in the Parliament that would displease the government if they believed that their opposition 
activities in the Parliament might trigger prosecution. ${ }^{5}$ Examples of such activities include delivering speeches on the Parliament floor, submitting formal queries addressed to the government, filing investigation inquiries into the actions of the government or into the activities of the members of the cabinet, and showing aggression by interrupting the speakers who are members of the government bloc. Thus, the effect (intended or unintended) of the constitutional amendment would be a reduction in the intensity of the opposition activities of these MPs.

In addition to being a deterrent, lifting the immunity could also be a vehicle for compellence, or “a threat intended to make an adversary to do something” (Schelling 1980, p. 195). In this context, the compellence effect would manifest itself by MPs' actions that reflect their improved support of the government. An example is voting in tandem with the governing party to support the bills and legislation proposed by the government as opposed to casting dissenting votes in the Parliament. ${ }^{6}$

Our paper is also related to the literature on the quality of governance, which analyzed the importance of institutional structure on the actions of elected representatives, and on political and economic outcomes. For example, Persson et al. (1997) emphasize the importance of the

\footnotetext{
${ }^{5}$ Prosecutors, who can bring charges against the MPs, are employed by the Department of Justice, but their decisions regarding whether or not to bring charges against a person or an entity should not be influenced by the agenda of the government. Whether this de jure independence of the Department of Justice translates into de facto independence is difficult to determine. More importantly, it is not possible to ascertain whether the MPs believed that the prosecutors could not be influenced by the government. That a Justice Department would act under the direction of the government is not surprising, and there are many examples of this behavior both in developing and developed countries. A recent example is the firing of Geoffrey Berman, the US Attorney in Manhattan, by the U.S. Attorney General William Barr, on June 20, 2020, an action which is widely believed to suppress the investigation of Rudy Giuliani, Donald Trump's personal lawyer. On October 8, 2020, President Trump, through tweets and interviews on cable news networks, openly put pressure on Attorney General William Barr to indict his political opponent former Vice President Joe Biden and former President Barack Obama. We assume that Turkish MPs, whose immunities have been lifted, considered this event as a credible threat which increased their probability of prosecution.

${ }^{6}$ It can be argued that the difference between deterrence and compellence is semantic in this context. For example, using the analogy from the crime literature, one can argue that while an increase in the arrest rate or the rise in the police force is a deterrence to crime (Di Tella and Schargrodsky 2004, Corman and Mocan 2000), an increase in the arrest rate or an increase in the number of police officers can be thought of as a tool to compel individuals not to commit crime. In our particular case, it is clear that the MPs may be deterred from activities that could be construed as detrimental for the agenda of the government. These include initiating inquiries into the actions of the government and delivering formal speeches on the floor of the Parliament to criticize the government. On the other hand, we consider voting in tandem with the government as having been compelled to openly support the government because supporting a bill on a roll call is not the opposite of casting a dissenting vote. This is because, the MPs have always the option to abstain or not to be present in the session for the vote.
} 
separation of powers between the legislative and executive branches to curb the abuse of power. Persson and Tabellini (2004) show that presidential systems result in smaller governments than parliamentary democracies. Lizzeri and Persico (2001) present a model that demonstrates electoral rules impact the provision of public goods. Lizzeri and Persico (2005) show that it might be efficient to have an institutional structure that restricts electoral competition. Acemoglu et al. (2013) show that voters may prefer to weaken the checks and balances on politicians, thereby allowing them to extract higher rents in order to limit the impact of interest groups on politicians. Along these lines, our paper analyzes the influence of a particular dimension of an institutional structure -the protection of the legislators through Parliamentary immunity- on the behavior of politicians.

Our identification strategy relies on the comparison of Parliamentary activities of the MPs who lost their immunity to those who retained it before and after the enactment of the constitutional amendment (which triggered the revocation of immunity). A threat to the validity of this strategy is that the revocation of immunity may be a function of past Parliamentary activities or personal attributes of the MPs. We show, in an event study analysis, that the trends in Parliamentary activities were not different between those who lost their immunity and those who retained it before the date on which the immunity status of some MPs is revoked. We also show that the MPs who lost their immunity are not different from the ones who continued to be protected by Parliamentary immunity in observable characteristics such as their age, sex, and education. The only difference is that those MPs who are members of the opposition parties are more likely to have their immunity revoked. Thus, we focus on the MPs of the opposition parties. In these analyses, the treatment group includes the MPs who are members of the opposition parties and who lost their immunity. The control group consists of the MPs who are also members of the same opposition parties but retained their immunity.

To investigate further whether selected MPs of the opposition parties have been targeted to have their immunity stripped off, we perform a number of analyses. For example, using the rank of each MP on their party’s candidate list before the election, we show that the revocation of immunity is not targeted to those opposition MPs who were more valuable to their parties (who were ranked higher on their party ticket) ${ }^{7}$ We also analyze the intensity of the

\footnotetext{
${ }^{7}$ In the proportional representation election system used in Turkey, voters cast their votes in general elections for political parties and not for individual MP candidates. Each party submits a list of candidates in a given election district (which is a province). Those candidates who are ranked higher on
} 
Parliamentary activity of each MP before the enactment of the Constitutional Amendment. We find that the loss of immunity is not concentrated among the opposition MPs who were more active and outspoken in the Parliament before the revocation of their immunity and that immunity revocation is not correlated with being active in the Parliament before the Constitutional Amendment. This result casts doubt about the potential of targeting "troublemaker and outspoken MPs.”

Furthermore, when we analyze the group of opposition MPs who were most active (in the top 25 percent of all MPs) in the Parliament before the constitutional amendment, we find that although they were all similarly highly active ex-ante, those of the group who subsequently lost their immunity changed their behavior in comparison to those who retained immunity. These analyses and the fact that the Constitutional Amendment received the endorsement of the leader of the main opposition party, that the amendment received bi-partisan support in the Parliament, and that 32 MPs of the government bloc also lost their immunity indicate that the amendment was not the result of a polarized partisan battle.

We find that revoking the Parliamentary immunity muffles the MPs. Specifically, MPs are less likely to interrupt the speeches delivered by the members of the government party when they no longer have legal immunity from prosecution. We also find that lifting their immunity reduces the efforts of the MPs regarding scrutinizing and criticizing the government. Such MPs initiate fewer investigation inquiries against the government and draft fewer pieces of legislation. They also reduce their tendency to vote against the government during roll call votes. The same results are obtained when we analyze the sample of opposition MPs who were highly active and outspoken before the enactment of the constitutional amendment or those who are top-ranked on their party’s pecking order. Losing immunity has no impact on the behavior of government bloc MPs.

It is conceivable that members of the same party, who retained their immunity, picked up the slack and increased their own efforts to compensate for the decline in job effort of their colleagues who lost immunity. Alternatively, the revocation of their colleagues' immunity may have galvanized the MPs who retained their immunity, and as a result, they may have increased their effort in Parliament. We perform two complementary analyses to investigate whether MPs who lost their immunity "outsourced” their jobs in the Parliament to their colleagues of the same

their party's list are more likely to get elected from that province. Therefore, parties rank their more senior, important/valuable candidates higher on their list. 
party and find no evidence for such spillover effects. We also show that the increase in the proportion of a party's MPs who lost immunity leads to a decrease, rather than an increase, in the overall legislative activity of that party. This finding is inconsistent with the conjecture that political parties may have been energized and became more active in the Parliament after some of its members lost immunity.

A faction of the Turkish armed forces that was loyal to the exiled cleric Fethullah Gulen attempted a coup d'état in July 2016. It is important to note that this coup attempt was a completely unforeseen event, not expected or predicted by either the government or the opposition parties. Neither was it foreseen by any other entity, including the media. This coup attempt failed, and the government declared a state of emergency in late July 2016. Our results may be confounded by the impact of this state of emergency that followed the coup attempt because the post-amendment period mostly overlapped with the post-coup period. However, considering the enactment of the constitutional amendment and the declaration of the state of emergency as two distinct events reveals that the impact on the treatment group is due to the former event. We also show that accounting for executive orders issued by the government during the post-coup period to provide extraordinary powers to the law enforcement and the prosecutors has no impact on the results. ${ }^{8}$ Importantly, we present evidence indicating that the effect of lifting immunity is observed immediately after the enactment of the constitutional amendment in May 2016 and not after the declaration of the state of emergency in July $2016 .{ }^{9}$

When an MP's immunity is revoked, she/he can be arrested, detained, and brought to trial. In these circumstances, those MPs would need to spend time defending themselves against the alleged offenses. As a result, their time available for legislative activities would be reduced. We show that this channel is not the driver of the decrease in legislative activities. First, we show that losing immunity does not lead to a decrease MPs’ Parliamentary attendance. Second, MPs who faced a greater number of investigations (which would require the MPs to spend more time in their legal defense) did not alter their legislative activities differently in comparison to those

\footnotetext{
${ }^{8}$ These executive orders provided special authority to the government to unleash the powers of law enforcement and the legal system in order to detect, detain and prosecute individuals who are suspected to be collaborators or supporters of the coup attempt.

${ }^{9}$ In additional analyses, we also show the Parliamentary activity, measured by the number of days in which the Parliament was in session, was not different in the months of May and June in comparison to other months, demonstrating that the impact of lifting immunity is not attributable to some unusually low workload of the Parliament.
} 
who faced fewer investigations. Third, we show that the results are not driven by the 16 MPs who have not completed their term in the Parliament. More specifically, the results do not change when we drop from the analysis those MPs who were ultimately arrested, indicted, and/or convicted and thus lost their MP status and therefore stopped attending the Parliament, or stopped attending for some other reason such as death or resignation.

Losing Parliamentary immunity may impact MPs' re-election chances for a number of reasons. To the extent that voters value MPs' effort and effectiveness in the Parliament, the loss of immunity would reduce MPs' appeal to voters because the loss of immunity leads to reduced effort and effectiveness in the Parliament. Similarly, voters may consider the loss of immunity as a negative signal for the character of the MP, regardless of the MP's Parliamentary activity. If losing Parliamentary immunity tarnishes an MP's reputation, voters may find the MP unappealing for re-election. ${ }^{10}$ Although voters in Turkish general elections vote for the party ticket and not for particular candidates, these concerns nevertheless may motivate voters to switch away from the party of the politician who lost immunity. Along the same lines, the leadership of parties may decide not to nominate such MPs in the following election because of these concerns.

We find that opposition MPs whose immunities are revoked in the $26^{\text {th }}$ Parliamentary term are less likely to get re-elected to the $27^{\text {th }}$ term compared to their counterparts who retain their Parliamentary immunity. We further show that this is because the MPs whose immunities are revoked are less likely to be re-nominated by their parties as MP candidates in the next election. Losing immunity has no impact on either re-nomination or re-election probability of the MPs of the government bloc. We also show that holding constant immunity status, the number of charges levied against the MPs has no impact on re-nomination probability, suggesting that it is the effectiveness in the Parliament, but not the perceived loss of reputation due to the number of charges that is the driver of re-nomination.

To investigate the impact of the regime with no immunity protection, we analyze the speed with which the legislators passed laws. Utilizing the Parliamentary records pertaining to each legislation enacted, we find that laws are passed more quickly after the Constitutional

\footnotetext{
${ }^{10}$ Dal Bó, Dal Bó and Di Tella (2006) also highlight this point and write that "[A]lthough a legal attack will not full convince the public that the accused person is guilty, it will increase the perception that he is, relative to the no accusation scenario. Thus a legal attack can still be painful for example by lowering reelection chances (Dal Bó et al. 2006, p. 48).
} 
Amendment. Specifically, after the revocation of MP immunities, the average days it took to pass a law (from the introduction to the Parliament to the vote) went down by about 1.5 days (where the average duration is 2.2 days). While this result suggests an increase in efficiency, the increase in the speed with which legislation is enacted could be detrimental to the quality of the legislation.

Finally, we investigate whether lifting MPs’ immunity had an impact on citizens' trust in the Parliament. Using data from two waves of the Eurobarometer Survey and leveraging the fact that the Constitutional Amendment and the ensuing immunity revocation took place between the two survey waves and before the military coup attempt, we find that people's reactions were polarized. Survey respondent's trust in the Parliament is enhanced (diminished) if an MP from the respondent's province lost immunity and if that MP is a member of the opposing ideology (same ideology) as the respondent. ${ }^{11}$ This effect is driven by citizens who are supporters of the government bloc.

In Section II, we provide the background information of the Turkish Parliament, the immunity provided by the Constitution, the 2016 amendment to the Constitution, and the political power structure of the $26^{\text {th }}$ Parliament, which faced this "treatment" generated by the temporary amendment. Section III describes the data. Section IV presents the Empirical Framework, the main results, as well as the results of robustness analyses. Section $\mathrm{V}$ is the Summary and Conclusion.

\section{Political Parties in the Parliament and the Amendment to the Constitution}

We consider the $26^{\text {th }}$ Parliament of the Republic of Turkey and investigate the behavior of the Members of the Parliament (MPs) in this parliamentary term because the constitutional amendment, which lifted the immunity of some of the MPs, applied only to this term. The Parliament consisted of 550 elected members who represented 81 provinces of the country that had a population of 70 million in 2015. ${ }^{12}$ MPs serve 4-year terms, and there are no term limits. The $26^{\text {th }}$ Parliament, however, lasted shorter than four years. Specifically, following the national

\footnotetext{
${ }^{11}$ Using the same Eurobarometer survey and the same empirical specification, we show that the Constitutional Amendment had no impact on citizens' trust in the EU or in the United Nations.

${ }^{12}$ After our sample period ended, starting with the $27^{\text {th }}$ Parliamentary term in July 2018, the number of MPs in the Parliament has increased to 600.
} 
elections, the $26^{\text {th }}$ Parliament convened in November 2015 and concluded in June 2018 because the government decided to hold snap elections in Summer 2018.

Four political parties were represented in Parliament during this term. AKP (Justice and Development Party) had the majority with 317 seats, and it formed the government. This party has been in the government continuously since 2002. The Nationalist Movement Party (MHP) had 40 seats. Although MHP was not a coalition partner to the government party AKP (AKP had more than 50 percent of the seats in the Parliament), MHP has been a political ally of AKP, and it has been a supporter of the policies and positions of AKP. The two parties are not very different ideologically, and their MPs vote in tandem on most issues. MHP and AKP even collaborated during the local elections by nominating joint candidates in several districts. ${ }^{13}$ CHP and HDP are the two opposition parties. CHP (Republican People’s Party) is a center-left party representing social democrats with 134 MPs. HDP (People’s Democratic Party) is a pro-Kurdish left-wing party, which had 59 seats in the Parliament. These two parties are fiery opponents of the governing party, AKP.

\section{Parliamentary Immunity and the 2016 Constitutional Amendment}

To protect elected politicians’ freedom of speech, Article 83 of the Turkish Constitution provides MPs with general Parliamentary immunity, which has two attributes. First, MPs have absolute and permanent Parliamentary non-liability. This means that MPs can never be held accountable for their legislative activities (i.e., neither during nor after their term in the Parliament). This attribute of the immunity eliminates any possibility of prosecution or retaliation related to an MP's voting record, the contents of her/his speeches, or any other Parliamentary activity. The second attribute of MP immunity is Inviolability, which puts a stop to any legal proceedings or investigations against the MP during her/his term in Parliament. In other words, MPs who are alleged to have committed a crime, either before or after the elections, cannot be detained, interrogated, arrested, or tried (Neziroğlu 2015). This attribute of immunity provides MPs the ability to conduct their Parliamentary business with no disruption. The Parliament could lift the immunity of an MP, provided that law enforcement authorities officially

\footnotetext{
${ }^{13}$ Although both of these parties pursue a conservative agenda, MHP’s political platform is arguably more nationalistic.
} 
file with a Joint Judiciary Committee of the Parliament the charges brought against the MP and that the Joint Committee moves the case to the Parliament after its investigation. ${ }^{14}$

\section{The Standard Process of Lifting Immunity}

If an MP has a civil or criminal charge filed against her/him, the Joint Judiciary Committee of the Turkish Parliament evaluates the file of that MP. If the Committee decides to bring the case to the Parliament, the case is put on the Parliamentary agenda, but it may still be tabled. If the Parliament decides to make a decision on the case, the charges are discussed, and the Parliament votes to revoke or retain the immunity of that MP. Between 1923 and 2016, a total of only 40 MPs lost immunity (all are subsequently convicted by the courts). ${ }^{15}$

Before the general election of November 2015, there were accumulated charges on the docket of the Judiciary Committee pertaining to MPs of the previous Parliamentary terms. After the election, when the new Parliament was convened, charges were brought against some of the

\footnotetext{
${ }^{14}$ As in Turkey, many countries around the world grant non-liability and inviolability to their elected politicians, although there is variation in the details between countries. For example, in Austria and Finland non-liability is granted only for the duration of the politicians' mandate but it cannot be waived in the former country, whereas it can be waived in the latter. In contrast, non-liability is provided for perpetuity in Denmark and the Netherlands, but it can be waived. In Belgium and Italy, non-liability cannot be waived, and its duration is unlimited. Similarly, the extent of inviolability varies between countries. For example, in Ireland, the protection of politicians from a lawsuit is restricted only to the duration of their mandate, but this protection cannot be waived. In France, Germany and Spain, such inviolability is limited to the duration of the mandate of the elected politician and it can be waived. In Greece, Belgium and Finland, inviolability is limited to the days when the Parliament is in session and it can be waived. Specific details for the European Union countries can be found in McGee (2001). In the U.S., the First Amendment provides protection of free speech for all citizens, which covers political speech. However, politicians in the U.S. are not protected from prosecution for alleged crimes. Over the years a number of U.S. Congressmen have been indicted, tried and convicted while in office. The same is true for politicians in the U.K., Canada, and Australia.
}

${ }^{15}$ The historical reluctance of the Parliament to revoke MP immunity has, at times, created frustration. For example, an MP of the social democratic opposition party (CHP) had two separate law suits filed against him (before he was elected in 2002) for insulting a civilian person and a public official. Both cases were suspended because he gained Parliamentary immunity after having been elected. Both cases were referred by the courts to the Joint Judiciary Committee with the request of lifting immunity. The Committee rejected the request. The MP unsuccessfully appealed the decision and asked his immunity be lifted in order for him to defend himself and clear his name in court. The MP got elected to the Parliament again in 2007 and the same process repeated. The MP took his case to the European Court of Human Rights arguing that the refusal of the Turkish Parliament to lift his parliamentary immunity had denied him of his right to access to a court and to a fair trial. By a 13-4 decision the European Court of Human Rights ruled on December 3, 2009 that the MP may not renounce his Parliamentary immunity in order to stand trial voluntarily. (European Court of Human Rights; Case Kart v. Turkey, Application No:8917/05) KART v. TURKEY (coe.int) 
newly-elected MPs. These new charges, as well as the existing ones (from previous years) against some re-elected MPs, constitute the stock of total charges on the docket of the Committee.

Some of these charges were terrorism-related, and the government wanted the prosecutors to pursue them. The legislation, submitted to the Parliament on April 12, 2016, to introduce the Constitutional Amendment, explicitly stipulates that a goal of the Amendment was to make it feasible to investigate the charges against terrorism, but that it was important not to single out specific MPs. It was stipulated that, therefore, it was important to investigate all charges against all MPs. The text of the legislation stated that there were 562 charges accumulated over time against the MPs waiting to be investigated at the Judiciary Committee of the Parliament. The legislation further stipulated that it would take 94 days to discuss all of these charges at the Parliament and that this would translate into more than 30 weeks of Parliamentary sessions (almost eight months) as the Parliament meets three days per week. Thus, this legislation proposed a Constitutional Amendment to lift the immunity of all MPs who had at least one charge against them. ${ }^{16}$

In May 2016, this legislation received bipartisan support and was enacted by a secret ballot vote, and it amended Article 83 of the Constitution. The Amendment was proposed by the governing party (AKP). The ally of the governing party, MHP, was also in favor of the amendment. These two parties of the government bloc (AKP and MHP) had 357 seats between them, which was not sufficient to reach the 2/3 majority needed to rectify the Constitution (which translates into 367 votes). The support of the opposition allowed the amendment to pass with 376 votes. This means that at least 19 MPs of the opposition parties have voted in favor of the amendment. If the 32 government bloc MPs, who lost their immunity, voted against the amendment, this would imply that 51 opposition bloc MPs voted in favor. This is not surprising because the leader of the Social Democratic Party (the main opposition) publicly supported the amendment and said he would vote in favor. There was also public support for the Amendment.

\footnotetext{
${ }^{16}$ Five hundred -sixty two charges pertain to 132 MPs. However, some MPs have a large number of charges against them that have been accumulated over time. For example, the leader of the Social Democrat Party (CHP) had 39 charges against him, while another important politician of that party, had 12 charges. The leader of the pro-Kurdish party (HDP) faced 71 charges, and another MP from the same party had 48 charges. In fact, nine MPs of HDP faced a total of 243 charges between them.
} 
This amendment, which is designed to apply only to the $26^{\text {th }}$ term of the Parliament (i.e., the Parliament that was in session), lifted the immunity of some MPs by revoking their inviolability privilege. Those MPs who had criminal or civil charges filed against them at the Joint Judicial Committee had their immunity lifted. As a result, these MPs would not be inviolable for those alleged offenses, and the police and the prosecutors could continue their investigations and legal actions against these MPs. Put differently, after the amendment became effective, these MPs could be interrogated, arrested, detained, and prosecuted. MPs who did not face a pending investigation at the time of the enactment of the amendment continued to be covered with full immunity of Article 83 of the Constitution. It is important to note that all MPs continued to have immunity related to their Parliamentary actions and behavior. In other words, all MPs continued to be protected by non-liability with respect to their Parliamentary activities.

One hundred and thirty-two of the 550 MPs, or approximately 1 out of every 4, have lost their Parliamentary immunity in May 2016. In Table 1, we present the distribution of MPs by their immunity status and political party. AKP was the governing party that had the majority in the Parliament with 317 seats. Twenty five of its MPs (eight percent) had their immunity revoked. The second political party listed in Table 1 is the pan-Turkish MHP, which is an ally of the AKP. MHP had 40 MPs in the Parliament, and eight of them lost immunity. CHP and HDP are the two opposition parties, and as Table 1 demonstrates, 40 percent and 76 percent of their MPs, respectively, lost Parliamentary immunity.

Although we know the number of charges against each of the 132 MPs who lost their immunity, with the exception of a few cases that leaked to the media or went to trial, we don't have information about the nature of the charges against specific MPs, or the specific date on which a charge was filed because that information is protected for privacy. However, based on a speech of the Justice Minister on May 17, 2016, delivered in the Parliament in response to a formal inquiry, we know that these MPs had a variety of accusations filed against them, ranging from violation of election laws to simple battery, from vandalism and criminal damage to slander and defamation, from assault to forgery, from sedition to terrorism.

\section{Data}

Our data set includes information on the Parliamentary activities of each Member of the Parliament (MP), obtained from the official minutes of the meetings that are published online at 
the website of the Turkish Parliament. ${ }^{17}$ The top section of Table 2 provides the definitions and descriptive statistics of the outcome variables analyzed. The unit of observation is an MPmonth. ${ }^{18}$ Ignoring the months in which the Parliament was in recess, there are 28 observations per MP.

On average, MPs delivered about 6.7 Speeches each month on the Parliament floor. The minutes of the meetings are very detailed, and each spoken word is recorded. This allows us to measure the length of each speech by counting the number of words spoken in a month, represented by the variable Words. Speeches in the Parliament are transcribed in such a way that identifies the MPs who delivered speeches as well as the MPs who interrupted these speeches. We counted the number of times an MP interrupted a speech delivered on the podium by another MP by cutting off the speaker through interjections, comments, and other verbal disruptions. The official minutes allow us to identify the disrupters. Such interference and interruptions of a colleague’s speech are measures of aggression and harassment. The number of interruptions, displayed in Table 2, could be the result of interrupting a particular speaker multiple times or interrupting different speakers on different occasions. The variable Interruptions Targeting Speeches of Gov. MPs represents the number of times per month the MPs interrupted speeches of other MPs who were members of the governing party. We also measured the number of interruptions targeted at non-government MPs (Interruptions Targeting Speeches of Non-Gov. MPs). These infractions could be committed by an opposition MP against an MP who is a member of another opposition party or by a government party-MP against an opposition MP.

We have data on the votes cast by the MPs in roll calls. These voting data are also publicly available from the Turkish Parliament website. The variable \% Votes Against Government measures the percentage of votes the MP has cast against the bills and motions proposed by the governing party (AKP). To construct this variable, we first determined how the overwhelming majority of the MPs of the governing party voted on each issue. If at least 90 percent of the members of the government party voted to support (object) a particular motion, then we postulate that the government party's position was to accept (reject) the motion on the

\footnotetext{
${ }^{17}$ https://www.tbmm.gov.tr/tutanak/tutanaklar.htm

${ }^{18}$ Some Parliaments, such as the European Union Parliament, define a Plenary Session as a session consisting of 2 to 4 consecutive working days. Turkish Parliament has no such classification. The classification scheme of the Turkish Parliament consists of Meetings and Sessions, where Meetings are 12-hour long, and a Session includes all Meetings in a day. There is no official classification for multiple days.
} 
floor. ${ }^{19}$ We then compared each individual MP's vote to this position and generated \% Votes Against the Government, which measures the extent to which the MP voted against the proposals of the government.

Other outcome variables are formal inquiries submitted to the Parliament to initiate an investigation regarding the activities of the government or a member of the cabinet (Investigation Inquiries Filed), the number of proposals drafted or co-sponsored for legislation (Drafts of Legislation), and formal, written queries posed by the MP to the government through the Parliament (Formal Queries). MPs drafted (or sponsored) 0.13 pieces of legislation per month, which is equivalent to about one-and-a-half legislation drafted or co-sponsored per year. MPs posed 1.8 formal queries to a member of the government each month on average, and they filed an investigation inquiry about the activities of the government 0.17 times per month, which translates into two inquiries per year (Investigation Inquiries Filed). ${ }^{20}$

We augment our data set with the personal characteristics of the MPs, as reported in their profiles on the Parliament website. ${ }^{21}$ At the bottom of Table 2, we present the sample means of MP attributes. The average age of the MPs was about 52 when the constitutional amendment was passed in May 2016. Fourteen percent of the MPs are female, and 41 percent have a graduate degree. About half of the MPs are re-elected in the following election.

To test whether the MPs who lost their immunity are different from those who retained it, we conducted randomization tests where we regressed the indicator for whether MP's immunity was rescinded (Immunity Lifted) on each MP attribute (Age in May 2016, MA/PhD, Female, and whether the MP is a member of the opposition). The results are displayed in column (1) of Appendix Table A1 for all MPs. MPs' education, age, and sex are not related to whether or not their Parliamentary immunity has been lifted. On the other hand, an opposition MP is more likely to have her/his immunity lifted. This is consistent with the information displayed in Table 1, which reveals that opposition parties are hit substantially more strongly with the loss of Parliamentary immunity. In column (2) of Table A1, we repeat the same exercise within the

\footnotetext{
19 The results are not sensitive to different thresholds.

${ }^{20}$ These investigations are conducted by committees which have the power to subpoena documents and collect testimony.

${ }^{21}$ https://www.tbmm.gov.tr/develop/owa/milletvekillerimiz_sd.mv_liste_eskiler?p_donem_kodu=26
} 
opposition MPs and again find no evidence of a systematic difference between the treated and control groups in terms of their personal attributes.

\section{Empirical Analysis}

Panel A of Appendix Table A2 presents the means of the outcome variables for the MPs whose immunity is rescinded (treatment group) versus retained (control group), both before and after the enactment of the constitutional amendment. Column (7) displays the difference in the differences and indicates that losing Parliamentary immunity has muted the activities of the MPs in the Parliament, and it decreased the MPs' tendency to cast votes against the positions of the government. We also generated three summary measures. Specifically, we created the first principal component (PC) of the four performance measures related to speeches and interruptions, the PC of the other four performance measures (\%Votes Against the Government, Investigation Inquiries Filed, Drafts of Legislation, Formal Queries), as well as the PC of all eight performance indicators. These three Principal Components are employed as aggregate indicators of Parliamentary performance. Column (7) of Panel A in Appendix Table A2 shows that the intensity of MPs’ Parliamentary activities has declined after May 2016 (the month in which the immunity of some MPs was lifted), but that the decline was more substantial for those MPs who have lost their immunity.

Panel B of Appendix Table A2 repeats the same exercise for the MPs of the opposition parties. It shows that the decrease in the extent of Parliamentary activities was more significant for the opposition MPs who lost their immunity in comparison to opposition MPs who retained their immunity.

More formally, we implement a difference-in-differences strategy to estimate the impact of legal immunity on the legislative activities of the MPs. The treatment group consists of the 132 MPs whose immunities were rescinded in May 2016. We consider the remaining MPs as constituting the control group. We also consider an alternative, and arguably more relevant, formulation. As shown in Table 1 and also in Appendix Table A1, opposition party MPs are significantly more likely to have lost their immunity. Furthermore, opposition MPs (those who are members of CHP and HDP) constitute a more homogenous group in comparison to all MPs with respect to their political positions regarding their opposition to the government. Thus, we focus on the MPs of the opposition parties and analyze the impact of losing Parliamentary 
immunity among this group of opposition MPs. This group consists of 193 opposition MPs, 99 of whom lost their Parliamentary immunity.

In this framework, we estimate:

$$
Y_{i t}=\beta_{0}+\beta_{1} \text { Immunity Lifted }_{i} \times \text { Post }_{t}+\mu_{i}+m_{t}+u_{i t}
$$

where the subscripts $i$ and $t$ represent MPs and the time periods (months of the $26^{\text {th }}$ Parliament), respectively. The outcome variable, $Y$, measures various legislative activities of the MPs, displayed in Table 2. The variable Immunity Lifted stands for whether an MP has lost her/his immunity, and Post indicates the post-treatment period, which starts in May 2016. ${ }^{22}$ Equation (1) controls for MP fixed effects, $\mu_{i}$, and month-by-year fixed effects, $m_{t}$. Standard errors are clustered at the MP level. The coefficient $\beta_{1}$ represents the difference-in-differences estimate.

\section{Baseline Results}

Estimates obtained from Equation (1) are displayed in Table 3. The time period of the analysis is December 2015 to May 2018. Excluding the months in which the Parliament was in recess, there are 28 observations per MP. Because we run regressions with 11 different dependent variables that aim to gauge similar outcomes, we also report in brackets [p-values] adjusted for multiple-hypothesis testing using the improved Benforroni method of Simes (Newson 2010, Benjamini and Yekutieli 2001, Simes 1986). Panel A presents the results where the outcomes are related to speeches in Parliament.

Losing Parliamentary immunity has a large and statistically significant effect on MPs’ tendency to interrupt the members of the governing party (Panel A, column 3). Losing immunity reduces the number of speeches delivered each month (column 1) and shortens these speeches (column 2), although these effects are not statistically significant. Columns (1)-(3) of Panel B reveal that revoking the immunity reduces the propensity to vote against the government by 3.8 percentage points; it reduces the number of inquiries filed per month by 0.3 and cuts the number of legislation drafts sponsored by 0.37. The first principal components of the outcomes in Panels A and B are used as dependent variables in regressions reported in columns 2 and 3 of Panel C, and the result pertaining to the principal component of all eight outcomes is displayed

\footnotetext{
${ }^{22}$ Although the Amendment was enacted on May 20, 2016, the bill of the amendment was introduced to the Parliament on April 12, 2016. By the end of April, it became clear that it was going to pass by bipartisan support.
} 
in column 1 of Panel C. Consistent with Panels A and B, the results in Panel C (where the dependent variables are the first principal components) show that losing immunity reduced MPs' Parliamentary effort, but that the impact on speech-related activities was not estimated with precision.

Although personal attributes of the MPs are not correlated with the probability of losing Parliamentary immunity (see Appendix Table A1), MPs of the opposition parties are more likely to have lost their immunity. Of all MPs who lost their immunity, 75 percent are members of these two opposition parties (99 of 132). ${ }^{23}$ Therefore, we estimated the models among the sample of MPs who belong to opposition bloc parties: CHP and HDP. In this design, the treatment group consists of those MPs who are members of these opposition parties and who lost their Parliamentary immunity. The control group contains MPs who are from the same parties but who retained their immunity. The results, displayed in Table 4, are consistent with the ones reported in Table 3, but there is stronger evidence that lifting immunity muffles the interruptions of other MPs' speeches. Specifically, the impact is statistically significant not only in interruptions targeting government MPs (column 3 of Panel A) but also in interruptions targeting non-government MPs (column 4 of Panel A). The impacts on the number of speeches and the total number of words spoken per month are larger among the opposition MPs (columns 1 and 2 of Panel A), although the estimates are not significant at conventional levels. As was the case in Table 3, Panels B and C of Table 4 demonstrate that Parliamentary immunity impacts legislative activities (Panel B) and that its effect is registered on aggregate indicators as well (Panel C). These results are confirmed when we estimated the models using negative binomial regressions. The opposition bloc consists of two political parties: the social democrats (CHP) and the left-wing, pro-Kurdish Peoples’ Democratic Party (HDP). Fourteen of HDP’s 59 MPs (almost

\footnotetext{
${ }^{23}$ The political rivalry and the animosity between the governing party AKP, and the two opposition parties (CHP and HDP) can also be seen in Appendix Table A3, which displays the distribution of all speech interruptions during the $26^{\text {th }}$ Parliament by the party of the speaker and the interrupter. For example, column (1) and row (2) show that 27.5 percent of all interruptions in the Parliament took place when an MP of the governing party (AKP) was delivering a speech, and she/he was interrupted by an MP of the social democrats (CHP). Similarly, column (1) and row (4) shows that about eight percent of interruption incidents took place when an AKP speaker was on the podium, interrupted by an MP of the center-left pro-Kurdish party (HDP). Columns (2) and (4) of row (1) show that 27 percent, and 20 percent of all interruptions in the Parliament are committed by the members of the AKP delegation when an MP from CHP, or an MP from HDP was delivering a speech, respectively. Thus, 82 percent of all interruptions committed between the MPs of the government party (AKP) and the opposition parties (CHP and HDP).
} 
24 percent) lost immunity. ${ }^{24}$ To ensure that the results are not driven by the behavior of the MPs of this party, we dropped the MPs of the HDP, and estimated the models using only the MPs of the social democratic opposition party, CHP. The results are presented in Table 5. They are similar to the ones displayed in earlier tables, but here immunity has a statistically significant impact on the number of speeches and the number of words as well. As column (1) of Panel A in Table 5 shows, losing Parliamentary immunity reduced the number of speeches delivered in a month by five and reduced the total number of spoken words in a month by 301 among the MPs of the main opposition: the social democratic party, CHP. ${ }^{25}$

In Table 6, we present the results obtained from the MPs of the government bloc. This sample consists of the MPs who are members of the governing party (AKP) and members of MHP, which is a center-right, pan-Turkish party and a political ally of the AKP. The point estimates obtained from the sample of government bloc MPs of Table 6 are dramatically smaller than the corresponding estimates in Table 4 (the opposition sample), and they are never statistically significant. This indicates that lifting Parliamentary immunity has no impact on the activities of the MPs if they are members of the governing party or the political ally of the governing party.

In supplementary analyses, we investigated the propensity of having been interrupted while delivering speeches on the podium of the Parliament. We found that the MPs of the opposition parties are significantly less likely to get interrupted by the government bloc after they have lost their immunity (see Appendix Table A4). This result is, in part, a reflection that opposition MPs deliver fewer and shorter speeches after losing their immunity. Consequently, they face a lower risk of being interrupted. But it could also be a reflection of the government bloc MPs' diminished enthusiasm to interrupt the opposition MPs whose immunity has been revoked because such MPs may be more careful in the tenor of their speeches after losing immunity. ${ }^{26}$

\footnotetext{
${ }^{24}$ As mentioned earlier, the accusations against the MPs which led to their loss of immunity varied in their severity, ranging from violation of election laws to vandalism and criminal damage, from slander and defamation to assault, from forgery to terrorism.

${ }^{25}$ This translates into an approximately 3.3-minute reduction in total duration of speeches delivered in a month for an MP.

${ }^{26}$ We also tried a sentiment analysis using the contents of the speeches. We tried to identify words that may represent a particular world view and political ideology. The government party (AKP) has a religious identity, and words such as "God" and "God Willing” are used frequently by the governing 
If there is no treatment effect, but if there exist parallel downward trends for both the treatment and control groups which continue after the constitutional amendment, all MPs would experience the same percentage reduction in their activity. Because the treatment group tends to have bigger pre-treatment mean values for most outcomes, this could produce a spurious negative effect of the treatment. To investigate this possibility, we took the logarithms of the outcomes (after adding +1 , as there are zero values) rather than using them in levels. The results provided by this functional form provide the same inference (see Appendix Table A5.)

\section{Parallel Pre-Trends and Potential Post-Treatment Impacts}

To investigate whether the treatment and the control groups followed differential pretrends, we conduct an event study analysis by estimating the regression below:

$$
Y_{i t}=\sum_{j \in t} \alpha_{j} \text { Immunity Lifted }_{i} \times m_{t}+\mu_{i}+m_{t}+\varepsilon_{i t}
$$

This specification is identical to Equation (1), except, instead of the interaction of Immunity Lifted and Post, we include time dummies' interactions with Immunity Lifted. These interaction terms identify whether the treated group deviates from the trends common to both groups in each time period. To present the results in a concise manner, we show the estimates obtained from principal components. Figure 1 displays the estimated coefficients obtained from the sample of all MPs, where the dependent variable is the first principal component of all eight outcomes. Figure 2 presents the same information obtained from the sample of opposition MPs (the Social Democratic Party, CHP, and the pro-Kurdish party, HDP), and Figure 3 displays the estimates obtained from the sample of the MPs who are members of the government bloc (the majority party AKP and its ally MHP). In other words, Figures 1, 2, and 3 correspond to the samples used in Tables 3, 4, and 6, respectively. The bars in the figures represent the point estimates of the interactions of time dummies with the Immunity Lifted variable, and the capped lines are the 95\% confidence intervals.

In Figures 1 and 2, no consistent pattern is observed in the coefficients before the start of the treatment, but the post-treatment impacts are negative. This picture supports the parallel pretrends assumption, i.e., the difference in behaviors between the treatment and the control groups

party MPs in their speeches. We analyzed if the opposition MPs switched to such phrases after losing their immunity. We also analyzed the frequency of curse words and rough language, but no clear results emerged in either case. 
is not statistically significant in the pre-treatment period, but the divergence occurred after the initiation of the treatment. Figure 3 reveals that in the sample of AKP and MHP (the governing party and the supporting party), there is no impact to speak of.

To provide more information about the variation driving the results, we also present the raw means of the first principal component of all legislative activities for the treated and untreated groups within both the opposition and government parties. Figure 4, which displays this information among the opposition MPs, shows that before the constitutional amendment (to the left of the vertical line in the graph) those opposition MPs who ended up losing their immunity (represented by dots) were more active in the Parliament in comparison to the opposition MPs who retained their immunity (represented by triangles). However, with the enactment of the constitutional amendment, the activity level of those who lost immunity went down and became almost indistinguishable from the activity level of the MPs who retained their immunity. Figure 5 presents the same information for the MPs of the government bloc. Here too, the MPs who ended up losing immunity were more active before the enactment of the amendment compared to those who retained their immunity. But this pattern, for the most part, remained the same during the post-amendment period among these government bloc MPs.

All of the 132 MPs who are in the treatment group experienced the treatment at the same time in May 2016. That is, there is no variation in the timing of the treatment. While this avoids some complications related to heterogeneous effects that might emerge in the case of staggered treatment (de Chaisemartin and D’Haultfoeuille 2020, Goodman-Bacon 2021), it can be argued that the treatment in our case may be capturing some other differential trend related to the attributes of the MPs. For example, if some characteristic of the treated MPs, other than the fact that they are treated, caused their performance in the Parliament to change after May 2016, then the coefficient of Immunity Lifted Im $_{i}$ Post $_{t}$ could pick this differential trend, and it would incorrectly attribute it to the impact of revoking an MP's immunity. Although we have shown in Appendix Table A1 that there are no differences in observable attributes of the treated and untreated MPs, to guard against this possibility, we nevertheless estimated an augmented version of Equation (1). In this alternative specification, we included the interactions of MP attributes with Post $_{t}$ as additional variables. ${ }^{27}$ These interactions will isolate the Dif-in-Dif effect from

\footnotetext{
${ }^{27}$ Recall that time-invariant attributes, such as Female and $M A / P h D$, were not included in the baseline regressions because of the inclusion of MP fixed effects. But in this alternative specification, the interactions of these time-invariant variables and Post $_{t}$ can be included.
} 
other possible differential trends that may be generated by MPs' age, sex, or education. The coefficient estimates obtained from these regressions are shown in Appendix Table A6. The results reveal that our findings, reported in previous tables, are robust to this alternative specification. If anything, the impact of lifting the immunity is more precisely estimated in these regressions.

\section{Deterrence/Compellence or a Time Constraint?}

It can be argued that the decline in Parliamentary activities of the MPs after they have lost their immunity is not because of a deterrence or compellence effect, but simply because of the change in MPs' time constraint. The MPs are prone to investigation, prosecution, and litigation when their immunity is lifted. This means that the results may be driven by particular MPs who stopped attending the Parliamentary sessions if they faced investigations and court hearings subsequent to losing their immunity. To investigate if the results are driven by the absenteeism of the MPs who have lost their immunity, we conducted three complementary analyses. First, we analyzed if the immunity status had an impact on attendance to the Parliament. We do not have data on the actual number of Parliamentary sessions attended. But we tallied the days on which the MPs cast a vote in the Parliament. Using the number of days present in the Parliament as the dependent variable, we ran the same model, the results of which are reported in Appendix Table A7. Column (2) shows that immunity status has no impact on the number of days present in the Parliament among the MPs of the opposition parties. Column (1) shows that in the sample of all MPs, losing the immunity status leads to an increase, rather than a decrease, in the number of days attended. Thus, the decline in Parliamentary performance cannot be attributed to absenteeism due to losing the immunity status.

We investigated this question in a different way, using the number of charges against each MP. Recall that the constitutional amendment permitted the revocation of the immunity of an MP if the MP had an official investigation pending at the time when the amendment was enacted. We have information on the number of charges filed against each MP before the enactment of the constitutional amendment. There exists variation in the number of charges among the MPs whose immunity is revoked (mean=4.78 std=8.92). A larger number of charges should lead to a bigger devotion of time and effort on the part of the MP to defend herself/himself against these charges. Thus, the number of charges levied against the MPs who lost their immunity is a reasonable proxy for time spent outside of the Parliament. 
Figure 6 presents the distribution of charges among the opposition MPs. Ninety-four opposition MPs had no charges filed against them when the constitutional amendment was passed. Thus, these MPs have retained their immunity. The rest of the opposition MPs have a varying number of charges against them. For example, 27 MPs whose immunities are revoked had only one investigation about them. Thirty-three MPs were facing 2 or 3 investigations, and the remaining 39 MPs had at least four investigations or charges. Only in a handful of cases, we know the contents of these investigations or the indictments/sentences to which they ultimately led. Nevertheless, MPs who were subject to a large number of investigations are expected to allocate more time to their potential defense, leaving less time for Parliamentary activities. Consequently, we ran the same model with the addition of the number of charges against the MPs (Charges) interacted with the Post dummy. The results, displayed in Table 7, are consistent with the ones reported earlier and demonstrate that the impact of revocation of immunity is not attributable to the number of charges faced by the MPs who lost their immunity. This suggests that the results are unlikely to be driven by MPs’ reduced time allocation to the Parliament.

Finally, we analyzed the sample of MPs who participated in the $26^{\text {th }}$ Parliament continuously. There are 16 MPs who stopped their Parliamentary activities before the end of their term. The reason for this type of cease-of-action is either the death of the MP, her/his resignation, her/his arrest while waiting for a trial, or losing the MP status due to the conviction after a trial. Of the 16 MPs who have not completed their term in Parliament, all but one are members of the opposition parties. Dropping these 16 MPs from the sample of opposition MPs and re-estimating the models did not alter the results, which are reported in Appendix Table A8.

\section{The Coup Attempt}

As mentioned in the Introduction, there was a failed coup d'état in Turkey in July 2016. It is important to underline that this coup attempt was orchestrated and implemented by a small faction of the armed forces, who are led by the followers of a cleric, Fethullah Gulen, who was in self-exile in the U.S. This coup attempt was not anticipated by anyone in the country, including the government and the opposition parties. Importantly, the coup attempt is unrelated to the constitutional amendment or the identities of particular MPs who lost their Parliamentary immunity.

Following this coup attempt, martial law was declared in the country, and there was increased public support for the government in the aftermath of the coup attempt. Thus, it is 
conceivable that the results might reflect the impact of the coup attempt rather than the impact of the loss of Parliamentary immunity. To disentangle the potential impact of this coup attempt from the impact of the loss of immunity, we ran the benchmark models with the addition of a second indicator (Post-Coup) that is interacted with the indicator for the loss of Parliamentary immunity. The results, summarized in Appendix Table A9 for the sample of opposition MPs, show that the Post-Coup period has no impact on legislative activities of the MPs and that the effect of the loss of Parliamentary immunity remains significant. The results presented in Appendix Table A9 are based on clustering standard errors by month since it can be argued that errors are correlated within months. Computing the wild t bootstrap p-values did not alter the inference. The p-values associated with these bootstrapped standard errors are provided in \{curly brackets\} in Appendix Table A9.

During the period following the attempted coup, the government has issued a number of executive orders. These executive orders provided extraordinary powers to the law enforcement agencies and to the judiciary in an effort to locate and prosecute the collaborators or the culprits of the attempted coup. ${ }^{28}$ Appendix Figure AF1 presents the time-series behavior of the monthly number of executive orders. To the extent that executive orders provided more power and flexibility to the prosecutors to press charges, it is reasonable to assume that the MPs who have lost their Parliamentary immunity would keep an even lower profile during periods in which executive orders are being issued.

We added the number of executive orders, interacted with the Immunity Lifted indicator, to the models. The results are presented in Appendix Table A10. Executive orders have no statistically significant impact on the behavior of opposition MPs, but consistent with previous results, losing Parliamentary immunity has a negative effect on the outcomes analyzed.

We also estimated the models for the time period up to the coup attempt, which took place on July 15, 2016. Thus, we considered only the months of May and June 2016 as the posttreatment periods. Although doing so substantially limits the variation in the data, the estimates obtained from this short sample are not subject to potential confounding due to the coup attempt. The results are presented in Table 8 for the opposition MPs and in Appendix Table A11 for the

\footnotetext{
${ }^{28}$ These executive orders (called "Kanun Hukmunde Kararname” in Turkish) instituted new laws and regulations ranging from extending the time period in which suspects can be held in custody to new procedures regulating the termination of employment of government workers and the military personnel, to providing financial help to the victims who lost their lives or who were injured while resisting the coup attempt in the streets.
} 
entire Parliament (all 550 MPs). They reveal that lifting the immunity generated a decline in the extent to which speeches of the government MPs are interrupted (Panel A), as well as a decrease in the proportion of votes cast against the government, a decrease in the investigations filed against the government and legislation drafted (Panel B). Models in Panel C, where the first principal components are the dependent variables, confirm those results reported in Panels A and B. In summary, the findings of the paper based on the entire duration of the $26^{\text {th }}$ Parliament are verified using the pre-coup time period, indicating that the coup attempt is not the driver of the findings.

\section{Extensions and Robustness}

The estimates in the previous section have a causal interpretation if the MPs in the control group are counterfactuals to those in the treatment group. That average MP characteristics, such as age, sex, education, do not depend on their immunity status (see Appendix Table A1) is reassuring. However, as shown in Panels A and B of Appendix Table A2, those MPs who lost their immunity were more active in the Parliament before the enactment of the Constitutional Amendment. It can be argued that the MPs who were more outspoken and more active in the Parliament could have been targeted for having their immunity lifted. Note that, in this scenario, some MPs have unobservable attributes that make them formidable and fiery opposition members (who speak more and interrupt others more frequently, who file investigation inquiries against the government more often, and so on). At the same time, these attributes make them more likely targets for immunity revocation. In this case, we would underestimate the impact of immunity on MPs' activities, and the estimated impact of immunity revocation would be biased towards zero. However, the analyses detailed in the Appendix show that opposition MPs who are more active, aggressive, and outspoken before the Constitutional Amendment was enacted were not targeted for lifting their immunity. Furthermore, the results hold among this group of highly active MPs. More specifically, when we analyze the sample of MPs who had similar pre-treatment levels of Parliamentary activity, we find that among this group, those who subsequently lost immunity reduced their effort in comparison to those who retained their immunity. (See the description provided in Section 2 of the Appendix and Appendix Tables A12, A13 in that same section.)

Similarly, we find no evidence for more valuable MPs being targeted. We show in Section 2 of the Appendix that MPs, who are ranked higher on their party tickets when they were 
elected in their respective provinces, are not more likely to lose immunity. Also, these highlyranked and valuable MPs respond to the loss of immunity no differently than other MPs (see Appendix Tables A14 and A15, and the explanations provided in Section 2 of the Appendix.)

To analyze the sensitivity of the results to the pre-treatment activity level of the MPs, we ran the main model depicted in Equation (1) with the following modification. We considered the pre-treatment Parliamentary activity of each opposition MP as summarized in Appendix Table A12. Each MP is classified into one of the quartiles of the pre-treatment activity distribution. We interacted these quartile dummies with the post-amendment dummy (Post) and added them to Equation (1). The results are presented in Appendix Table A16. The impact of losing immunity is the same as before.

We also investigated whether the months of May and June of 2016 (the two months between the Constitutional Amendment and the coup attempt) were different from previous years' May and June in terms of the workload of the Parliament. We identified no drop in the workload in May or June 2016. Analyzing seasonality more generally, we found that the workload of the Parliament is rather evenly distributed throughout the year. The details of these analyses are also provided in Section 4 of the Appendix and displayed in Appendix Figure AF2.

\section{Potential SUTVA Violations}

It may be the case that the opposition MPs, who retained their immunity, may have been nevertheless impacted by the Constitutional Amendment. For example, these control-group MPs may also have reduced their Parliamentary efforts and tamed their aggressiveness and determination. If this is true, the impacts we identified in the paper would be underestimates of the true effect of losing immunity.

Could the MPs, who are stripped of their immunity, have outsourced their Parliamentary activities to their colleagues who retained their immunity? It may be implausible for those who lost their immunity to convince their colleagues to interrupt other MPs' speeches more frequently, and the case is even less convincing for casting votes in tandem with the government (because each MP has one vote). It is, however, conceivable for colleagues to pick up the slack and exert more effort to compensate for the reduced effort of those who lost immunity in such dimensions as delivering additional speeches on the Parliament floor, speaking longer, or drafting extra pieces of legislation. 
A related conjecture is that the MPs, who retained immunity, may have been energized due to the revocation of their colleagues' immunity, and they may therefore have increased their legislative efforts when those who lost immunity did not change their behavior. Under this scenario, the effect we identify would be driven by such increased effort of immunity-intact MPs in reaction to their colleagues' loss of immunity.

Detailed analyses, presented in Appendix Section 3 and Appendix Tables A17 and A18, show that there is no evidence for the MPs who are in the control group (those who retained their immunity) to have been impacted by their colleagues’ losing immunity.

To shed additional light on this question, we also ran regressions at the party-level where the unity of observation is the party-level average of the outcomes in each month. The regressions control for party fixed effects and party-specific trends. The key variable is \% Immunity Lifted, which is the percentage of the MPs in each party who lost immunity. Under the assumption of complete outsourcing, the proportion of MPs who lost immunity from a party should have no impact on that party's Parliamentary activity. Similarly, under the hypothesis that MPs who lose immunity do not alter their behavior, but that their immunityintact peers increase their effort, the impact of \% Immunity Lifted should be positive. But the results, displayed in Appendix Table A19, show that a higher proportion of MPs who have lost immunity is associated with a reduction of the party's effort and performance in the Parliament. Thus, consistent with the results presented in Tables A17 and A18, the results of Appendix Table A19 also indicate that there is no compelling evidence of a notable shift of Parliamentary activities from immunity-losing to immunity-retaining MPs.

\section{The Impact of Immunity Revocation on Parliamentary Efficiency}

Finally, we analyzed whether the Constitutional Amendment, which led to the revocation of MP immunities, had an impact on the speed with which legislation is enacted. As shown in Section 5 of the Appendix, after the Parliamentary action which lifted the immunity of some MPs, laws were passed 1.5 days faster than before, presumably because of shorter and/or fewer debates in the Parliament (see Appendix Figures AF3, AF4, Appendix Table A20 and the associated discussion in Section 5 of the Appendix). Although the increase in the speed with which legislators passed laws makes the Parliament more efficient, if the quality of these laws is lower (in their comprehensiveness or in the propensity to be challenged in courts) in comparison 
to the quality that would have been observed had these laws been enacted slower, and with more deliberation, the welfare implications are unclear.

\section{The Impact on Re-Election Probability}

The results in previous sections show that losing Parliamentary immunity has an impact on the behavior of the MPs who are members of the opposition bloc in the Parliament. Losing immunity quieted down these MPs and reduced their efforts in the Parliament. To the extent that these behavioral changes, triggered by the loss of immunity, rendered these MPs less effective in the eyes of the voters, these MPs are less likely to be re-elected in the next election. Recall that voters in Turkish general elections cast votes for the party ticket and not for particular candidates. Nevertheless, these concerns may motivate voters to switch away from the party of the politician who lost immunity. Along the same lines, party leaders may consider these MPs as being no longer effective. In this case, these MPs would be less likely to be re-nominated by their parties in the next election. Alternatively, voters or party leaders may consider the reputations of these MPs as being tarnished, which may impact the MPs' re-nomination or reelection chances.

We ran a regression where the unit of observations is an MP. The dependent variable is an indicator that takes the value of one if the MP is re-elected to the Parliament in the next election. The right-hand side variables include the indicator for whether the MP's immunity is lifted and personal attributes, as well as the party fixed-effects. Also included is the number of charges that were brought against the MP.

Table 9, which presents the results, shows that female MPs are less likely to get renominated and re-elected. The same is true for older MPs. The results, presented in column (1) of Table 9, reveal that losing Parliamentary immunity has no impact on the probability of reelection of the government bloc MPs. In contrast, column (2) shows that losing immunity leads to 19 percentage points (48 percent) decrease in the probability of re-election among the opposition bloc MPs (The group of 16 MPs who are arrested, convicted, resigned, or died after losing their immunity are not included in these regressions). ${ }^{29}$

\footnotetext{
${ }^{29}$ Previous research analyzed the impact of corruption accusations and convictions on incumbents' reelection chances. Peters and Welch (1980) do not find a significant impact of corruption charges on reelection probability of U.S. House of Representatives between 1968 and 1978, but voter reaction is stronger during 1982-1990 (Welch and Hibbing 1997). Chang, Golden and Hill (2010) analyze political careers of Italian legislatures between 1948 and 1994 and find that investigations about alleged offenses
} 
Columns (3)-(4) of Table 9 display the regression results where the dependent variable is whether the MP has been re-nominated by her/his party as a candidate in the next election. Once again, column (3) reveals that immunity has no impact on the probability of re-nomination among the members of the government bloc (AKP and MHP). On the other hand, column (4) shows that the loss of immunity reduces the chances of re-nomination of opposition MPs by 16 percentage points (a 31 percent decline from the base of 52 percent re-nomination rate). ${ }^{30}$ Table 9 also shows that holding constant immunity status, the number of charges levied against the MPs has no impact on their re-election or re-nomination probability. This suggests that the lack of effectiveness in the Parliament is the primary factor that impacts the probability of re-election and re-nomination of the opposition MPs, and not the perceived loss of reputation due to the number of charges.

\section{The Impact on Citizens' Trust in the Parliament}

In this last section of the paper, we analyze whether lifting the Parliamentary immunity of the MPs had an impact on citizens' trust in the Parliament. To investigate this question, we utilize two waves of the Eurobarometer survey, which were registered before and after the revocation of Parliamentary immunity. ${ }^{31}$ The election, which formed the $26^{\text {th }}$ Parliament analyzed in the paper, was held on November 1, 2015. The first wave of the Eurobarometer survey was registered after the election, between Nov 7 and November 17, 2015. This means that the respondents knew the identities of the MPs and the composition of the Parliament when they took the survey in November 2015. The second survey was conducted between May 21 and May 31, 2016. The Constitutional Amendment was enacted on May 20, 2016. Thus, the second

did not influence re-election chances until the early 1990s. The authors attribute the shift in voter behavior to public awareness triggered by the media coverage of well-publicized corruption investigations in 1992. Similarly, Ferraz and Finan (2008) find that the audit reports of corruption in local governments of Brazil had a negative impact on incumbents' likelihood of re-election and that the impact was bigger in municipalities with local radio stations.

\footnotetext{
${ }^{30}$ We cannot identify whether these MPs tried to run in the next election but their party chose not to nominate them, or whether they themselves decided not to be a candidate.

${ }^{31}$ Standard Eurobarometer, conducted by the European Commission, monitors public opinion in European Union member countries, as well as candidate and accession countries. The surveys are conducted typically twice a year, one in May and the other in November. In each wave, representative samples of the countries are drawn. The respondents are asked about their opinions on the EU, its institutions, policies, and goals.
} 
wave of the survey was given right after the revocation of MPs' immunity. It is important to note that the second wave of the survey was completed before the military coup attempt on July 15, 2016. Thus, the answers of the survey respondents are not confounded by their reactions to the coup attempt.

The Eurobarometer survey includes only Turkish citizens; no refugees are surveyed. It is a repeated cross-section that includes information about a host of respondent attributes. It also contains questions about people's trust in institutions. As the outcome of this analysis, we use the question: "Do you trust the National Parliament?” which can be answered as "Yes” or "No.” We ran a regression where the dependent variable is an indicator that equals one if the individual trusts the Turkish Parliament. The sample mean of this variable is 0.58 ( $\mathrm{sd}=0.49)$. The model controls for personal characteristics such as age, sex, education, marital status, household size, employment status, income and wealth proxies (difficulty in paying bills, ownership of a house or car), fixed effects for 26 provinces in which the respondents reside, and dummy variable to account for whether the survey was taken in November 2015 versus May 2016. The key explanatory variable is a dichotomous indicator which takes the value of 1 if at least one MP from the respondent's province has lost her/his Parliamentary immunity. ${ }^{32}$

Column (1) of Table 10 reveals that if an MP, who represents the province, has lost her/his Parliamentary immunity, this has no statistically significant impact on the extent to which individuals from that province trust the Parliament, although as we demonstrate below, this is not the correct inference. To analyze in more detail people's reaction to the Parliament's move that revoked the immunity of some MPs, we recognize that Turkey is a politically polarized country. Citizens on the right and on the left of the political spectrum have distinct and strong views on a number of issues, including the other group’s identity (Aydin-Duzgit 2019). Thus, we investigate whether people's trust in the Parliament is a function of whether the action of the Parliament (lifting MPs’ immunity) has helped or hurt "their side.”

The Eurobarometer survey includes a question gauging citizens’ self-identification on the political spectrum. Specifically, the respondents are asked the following question: "In political matters, people talk of 'the left' and 'the right.' How would you place your views on this scale?” They are then shown a ten-unit scale, one denoting the most left, and the most right. We classify

\footnotetext{
${ }^{32}$ Each province is also an election district. This means that the residents of a province vote to elect their MPs for the Parliament. The number of MPs from each province is proportional to the province population.
} 
people as being on the left (right) of the political spectrum if they chose 1-5 (6-10) on this scale. After dropping respondents who did not answer this question, we have a sample of 1,677 individuals between the two waves of the survey. One thousand forty-one of the sample (62 percent) self-identify as being on the right of the political spectrum.

Using this information, we estimated the following model:

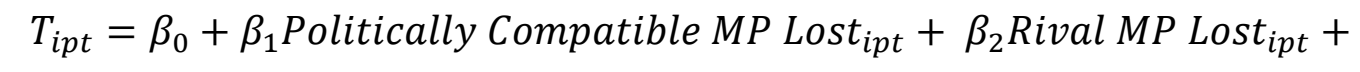

$\beta_{3}$ Left $_{i p t}+\beta_{4}$ Post $_{t}+\beta_{5} X_{i p t}+\beta_{6}$ Left $_{i p t} \times$ Post $_{t}+\pi_{p}+\beta_{7} L e f t_{i p t} \times \pi_{p}+v_{i p t}$,

where the dependent variable is the same as before (=1 if the individual trusts the Parliament), $\pi_{\mathrm{p}}$ stands for province fixed effects, and Post represents a dummy that identifies whether the individual was surveyed before or after the enactment of the Constitutional Amendment (November 2016 or May 2016), and X stands for a vector of personal attributes of the respondents. Leftipt is an indicator that takes the value of one if individual (i), who resides in province (p) and surveyed in period (t) self-identifies as being politically on the left, and zero if she/he is on the right. There are two key explanatory variables: Politically Compatible MP Lost and Rival MP Lost. The former variable is equal to one if at least one MP from the province of the respondent lost her/his Parliamentary immunity and if this MP supports the same political position as the individual (i). For example, if the respondent is ideologically on the left (on the right), and if an opposition bloc MP (government bloc MP) from that province lost immunity, Politically Compatible MP Lost Immunity takes the value of 1, and it is zero otherwise. Similarly, Rival MP Lost equals one if an opposition bloc MP (a government bloc MP) from the province lost immunity and if the respondent self-describes as being on the right (left) of the political spectrum. ${ }^{33}$ The baseline is the case where both Friendly MP Lost and Rival MP Lost are equal to zero, which means that no MP from that province lost immunity. Standard errors are clustered at the province level, and they are bootstrapped because there are only 26 provinces surveyed. Appendix Figure AF5 presents a map of Turkey, which displays the variation in opposition and government bloc MPs' loss of immunity between the regions. Appendix Table A21 presents the same information for each of the provinces.

\footnotetext{
${ }^{33}$ Recall that the government bloc parties (AKP and MHP) are right-wing parties, and the opposition bloc (CHP and HDP) are left-wing parties.
} 
Column (2) of Table 10 shows that if an MP, who is ideologically compatible with the respondent, has lost her/his immunity (Politically Compatible MP Lost=1), the likelihood that the Parliament is trusted is reduced, but the estimated impact is not statistically significant. On the other hand, if an MP, who is an ideological rival, loses immunity (Rival MP Lost=1), the probability of trusting the Parliament goes up by 22 percentage points (45 percent). This result indicates that people's perception of the appropriateness of an institutional change (the enactment of the Constitutional Amendment and the resultant revocation of MP immunity) depends on whether they believe that the change has helped or hurt their side politically.

Column (3) of Table 10 presents a specification which investigates the same hypothesis depicted by Equation (3) in an alternative way. In this specification we divide individuals into four categories based on whether their own ideology is Left or Right and whether the province in which they reside experienced a loss of immunity by a government bloc MP (right-wing parties) or by an opposition bloc MP (left-wing parties). The results are consistent with those reported in column (2), but they suggest that they are driven by individuals who are on the right of the political spectrum. A right-wing person in a province loses trust in the Parliament if a rightwing MP from that province loses immunity, but a right-wing person's propensity to trust the Parliament goes up if a left-wing MP loses immunity. Thus, the results of Table 10 reveal that the evolution of trust in the Parliament depends on whether the Parliamentary move (revocation of immunity) helps or hurts the side with which the citizens associate themselves. ${ }^{34}$

We also conducted a falsification exercise to demonstrate that the results reported in columns (2) and (3) of Table 10 are not an artifact of some overall change in trust in institutions. The Eurobarometer survey includes questions about trust in the United Nations (UN) and trust in the European Union (EU), asked in the same exact way. We ran the same specification using the same sample but we created a new trust variable, which takes the value of 1 if an individual trusts either the EU or the UN, and it is zero if the respondent does not trust either institution. (the mean value of the variable $=0.39$ ) The results, displayed in column (4) of Table 10 show

\footnotetext{
${ }^{34}$ It should be kept in mind that although Turkey has been a democratic Republic since 1923, there were a number of interruptions to democracy due to military coups, and the country embodies an increasingly polarized electorate and citizenry, and Turkey is listed as one of the most polarized countries (Lauka, McCoy and Firat 2018, Keyman 2014). Thus, external validity of the results in Table 10 may not be generalizable to other settings where voters are less polarized.
} 
that having an MP who lost immunity in the province has no impact on the propensity to trust the UN or the EU and that political polarization has no influence on trusting these institutions either.

\section{Summary and Conclusion}

Most countries grant Parliamentary immunity to their elected politicians, which typically has two components. First, Members of a Parliamentary body (MPs) are protected with nonliability, which means that they cannot be held accountable for their speeches or for any of their activity related to their job, such as how they cast their votes, propose legislation, and deliver political speech. In addition, MPs are usually provided with inviolability, which prohibits any search and seizure, arrest, and trial for an alleged offense before the end of their term. The goal of inviolability is to protect elected politicians from politically-motivated frivolous charges and to allow them to devote their full attention and effort to their job.

Although there is a sizable literature on the determinants of the behavior and performance of politicians, no previous work analyzed the question of whether Parliamentary immunity has an impact on the effort and performance of elected politicians. This is because, immunity applies to all lawmakers of a country, and variations in the extent and style of immunity can only be observed across countries and not within a country. While there have been cases where an MP's immunity has been revoked by her/his peers in a Parliament, such isolated cases are not suitable for a systematic analysis of the impact of immunity.

We provide the first empirical investigation of the impact of Parliamentary immunity on politician behavior. Turkish Parliament adopted a Constitutional Amendment in 2016, which lifted the immunity of 132 of its 550 Members. Specifically, the amendment, which was approved with bi-partisan support of the government bloc and the main opposition party, (with more than 2/3 support of all MPs) revoked the inviolability of these 132 MPs so that any of them, who had a charge filed against her/him when the amendment was enacted, could be subject to arrest and prosecution related to that charge. These charges covered a whole spectrum of offenses, ranging from violation of election laws to assault, from defamation to fraud, from forgery to terrorism. All MPs continued to have non-liability; i.e., they retained their protection for free political speech and activities in the Parliament.

Using a Difference-in-Differences design, we analyze the extent to which losing Parliamentary immunity impacts MP behavior. We show that the MPs who lost their immunity are not different in observable dimensions (e.g., age, sex, education) from the ones who retained 
it. On the other hand, MPs of the opposition parties were more likely to have lost their immunity. Thus, our analyses focus on the opposition MPs, although the results mirror those obtained from all MPs. We find no evidence that opposition MPs who are more valuable for their party or who have been more active and aggressive before the enactment of the Constitutional Amendment were more likely to lose their immunity.

We investigate MPs’ Parliamentary performance in standard dimensions such as voting behavior, legislation proposals drafted, investigation inquiries filed into the actions of the government, and formal queries posed to the ministers of the cabinet. We also analyze speechrelated activities, such as the number of formal speeches delivered in the Parliament, the length of these speeches (i.e., the number of words), the number of times the MP interrupted the speech of another MP who was a member of the government party, and the number of interruptions targeted towards non-government MPs.

We find that lifting Parliamentary immunity deters the MPs of the opposition parties from engaging in Parliamentary activities such as drafting legislation and initiating investigation inquiries. In addition, losing immunity muffles the opposition party MPs, who deliver fewer and shorter speeches as a result. Similarly, MPs who lose their immunity reduce the number of times they interrupt the speakers on the podium. The loss of immunity also compels the opposition MPs to vote in tandem with the government. These results indicate that losing Parliamentary immunity motivates the MPs to reduce their work effort and keep a lower profile.

A number of robustness analyses show that the results do not emerge because the MPs who lost their immunity altered their attendance to the Parliament. Similarly, we obtain the same results when we drop from the analysis those MPs who have not completed their term due to being convicted and jailed, resigned, or passed away. We also show that the impact of the revocation of immunity is not influenced by the number of charges filed against the MPs. The conclusions of the paper are unaltered when we analyze the sample of opposition MPs who were highly active and outspoken before the enactment of the Constitutional Amendment or who are highly-ranked within their party.

It may be possible for the MPs, whose immunity has been lifted, to turn to their immunity-intact colleagues and ask them to draft or sponsor legislation or to initiate an investigation inquiry on their behalf. If these colleagues comply, or if they independently increase their legislative activity simply in reaction to their peers' loss of immunity, this would imply that the treatment of lifting immunity also had an influence on the MPs in the control 
group, and that our estimates, in part, reflect the increased activity of the MPs who retained their immunity. A number of analyses, however, indicate no evidence for such spillover on the MPs who have retained immunity.

There was a coup attempt in Turkey during the Parliamentary term analyzed. Considering this coup attempt and revocation of the immunity as two separate treatments reveals that the results are not driven by the coup attempt. Similarly, we show that a sequence of executive orders issued by the government (which provided extraordinary authority to the law enforcement and the judicial system) during the period after the coup attempt does not alter the results. Importantly, we show that the results hold during the period before the coup attempt.

We show that after the enactment of the Constitutional Amendment, which paved the way to immunity revocation, the Parliament enacted legislation at a faster rate. The number of days it took to pass a law went down by more than 1.5 days (from an average of 2.2 days), likely because of shorter and fewer debates due to the reduced effort of the opposition MPs.

Because the loss of immunity leads to reduced effort and effectiveness in the Parliament, the MPs who lost their immunity may have lost their appeal to voters. Alternatively, if losing Parliamentary immunity tarnishes an MP's reputation, voters may find it unappealing to support the party which re-nominates the MP for re-election. Along the same lines, party leadership may decide not to nominate such MPs in the following election because of these concerns. We find that opposition MPs whose immunities are revoked are less likely to get re-elected to the Parliament. We further show that this is because the MPs whose immunities are lifted are less likely to be re-nominated by their parties as an MP candidate in the next election. We also show that holding constant immunity status, the number of charges levied against the MPs has no impact on re-nomination or re-election probability, suggesting that the decline in MPs' Parliamentary effectiveness is the driver of these results. Losing immunity has no impact on either re-nomination or re-election probability of the MPs of the government bloc.

Finally, we employ data from the Euro Barometer survey and investigate whether lifting MPs' immunity had an impact on citizen's trust in the Parliament. We find that an individual's propensity to trust the Parliament decreased if an MP who represents the province of the individual lost immunity and if that MP was associated with the same political ideology (right or left of the spectrum) as the individual. In contrast, if an MP who is a member of a political party representing the opposite ideology lost immunity, the propensity to trust the Parliament went up. These effects are driven by the citizens who adhere to right-wing politics. This finding is not an 
artifact of an overall change in people's trust in institutions because revocation of parliamentarians' immunity has no impact on individuals' trust in the UN or the EU.

It should be noted that the loss of immunity did not eliminate the protection of political speech of the MPs. However, those MPs who lost immunity become vulnerable to prosecution for alleged civil and criminal violations, and such vulnerability influenced their tendency to deliver speeches and to speak up and interrupt others, as well as their actions and effort in the Parliament. Taken together, these findings reveal that Member of the Parliament respond to an increase in the price of their behavior (the risk of prosecution), which underscore the significance of Parliamentary immunity in political outcomes. 
Figure 1

Event Study Analysis (All MPs)

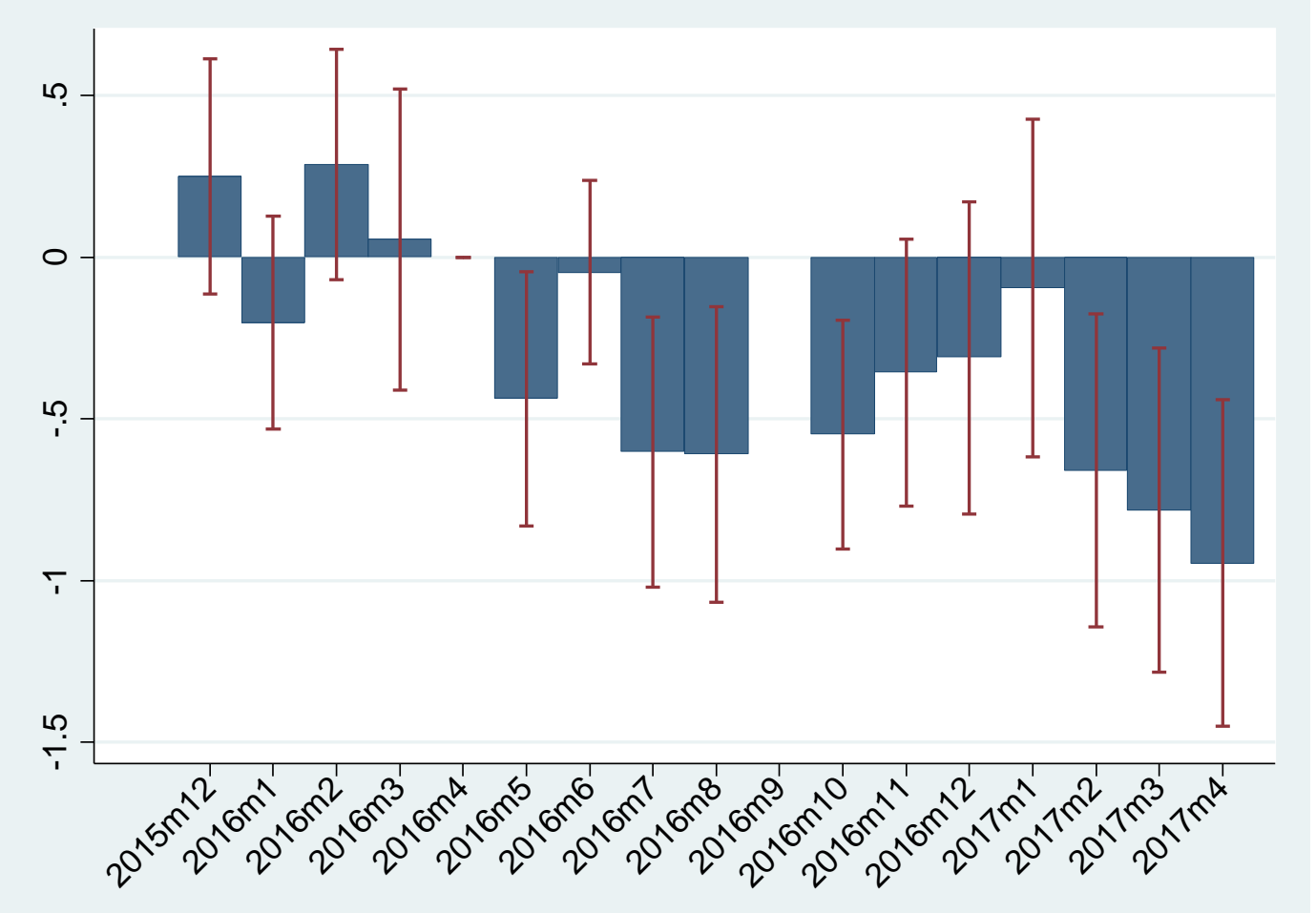

To obtain the figure, we estimate $P C_{i t}=\sum_{t} \gamma_{t}$ Immunity Lifted $_{i} \times m_{t}+\mu_{i}+m_{t}+\varepsilon_{i t}$, where $P C$ is the first principal component of all legislative effort outcomes. $m_{t}$ stands for the indicator function that equals one in month $t$, and Immunity Lifted is a dummy variable for whether an MP's immunity is lifted in May 2016. The bars represent the point estimates of $\gamma_{t}$, and the capped lines are the $95 \%$ confidence intervals. The omitted category is April 2016, i.e., one month before the immunities are lifted. The Parliament was on holiday in September 2016. 
Figure 2

Event Study Analysis (Opposition MPs)

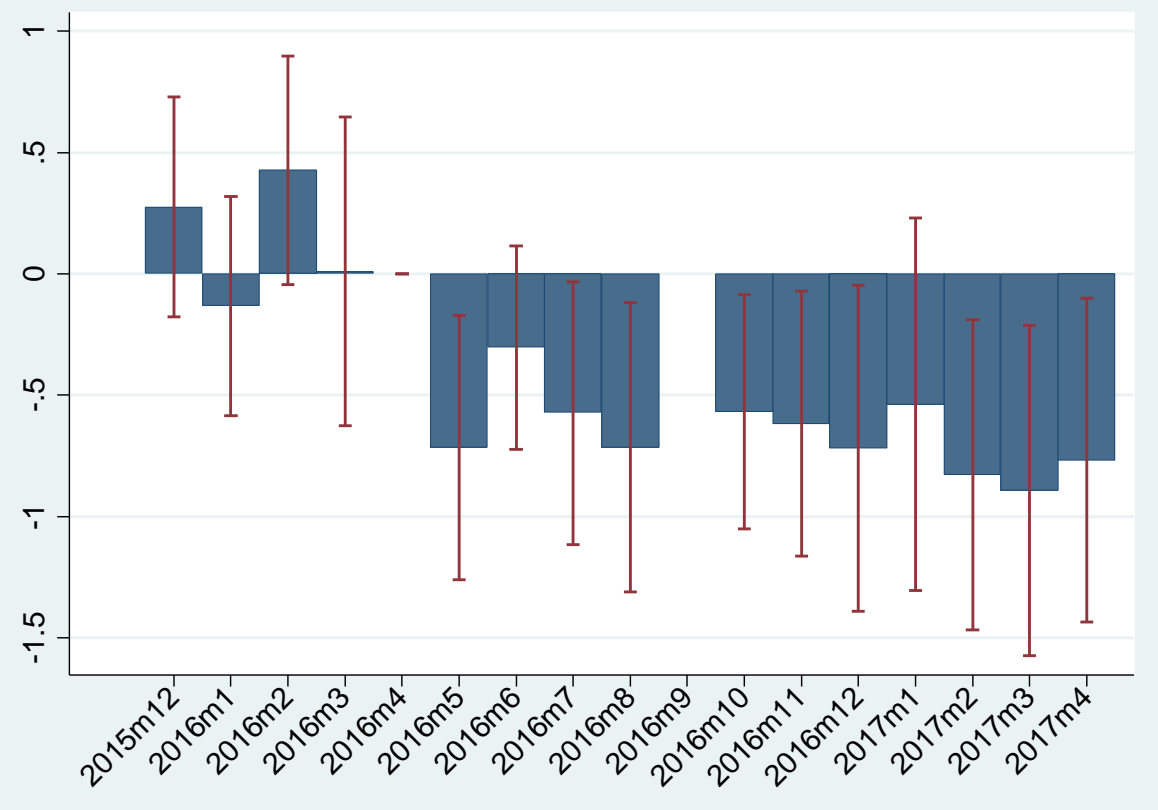

See notes to Figure 1.

Figure 3

Event Study Analysis (Government Bloc MPs)

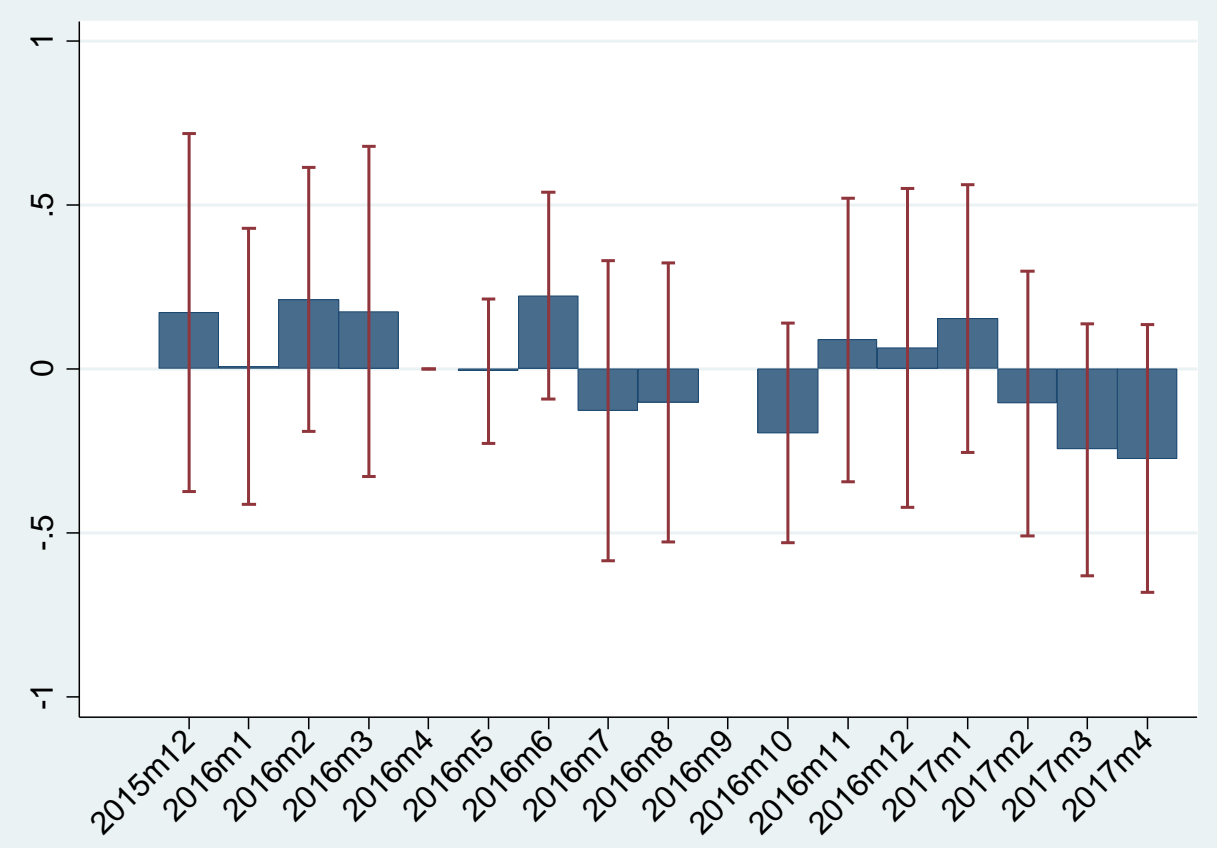

See notes to Figure 1. 
Figure 4

Mean of the Legislative Effort Over Time (Opposition Parties)

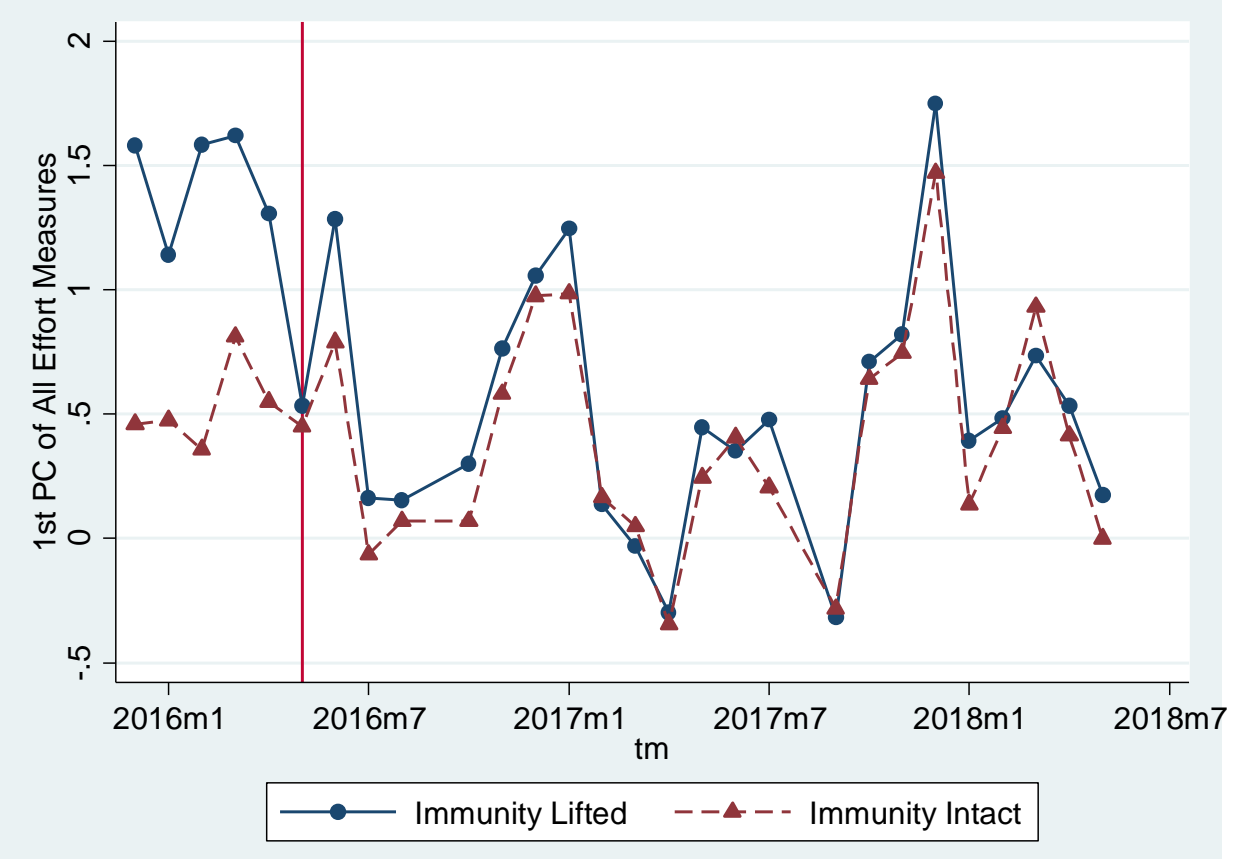

The figure presents the average of the first principal component of all legislative effort outcomes for the opposition party MPs. The blue, solid line (circles) represents the MPs who lost immunity, and the red dashed line (triangles) is for the MPs who retained immunity.

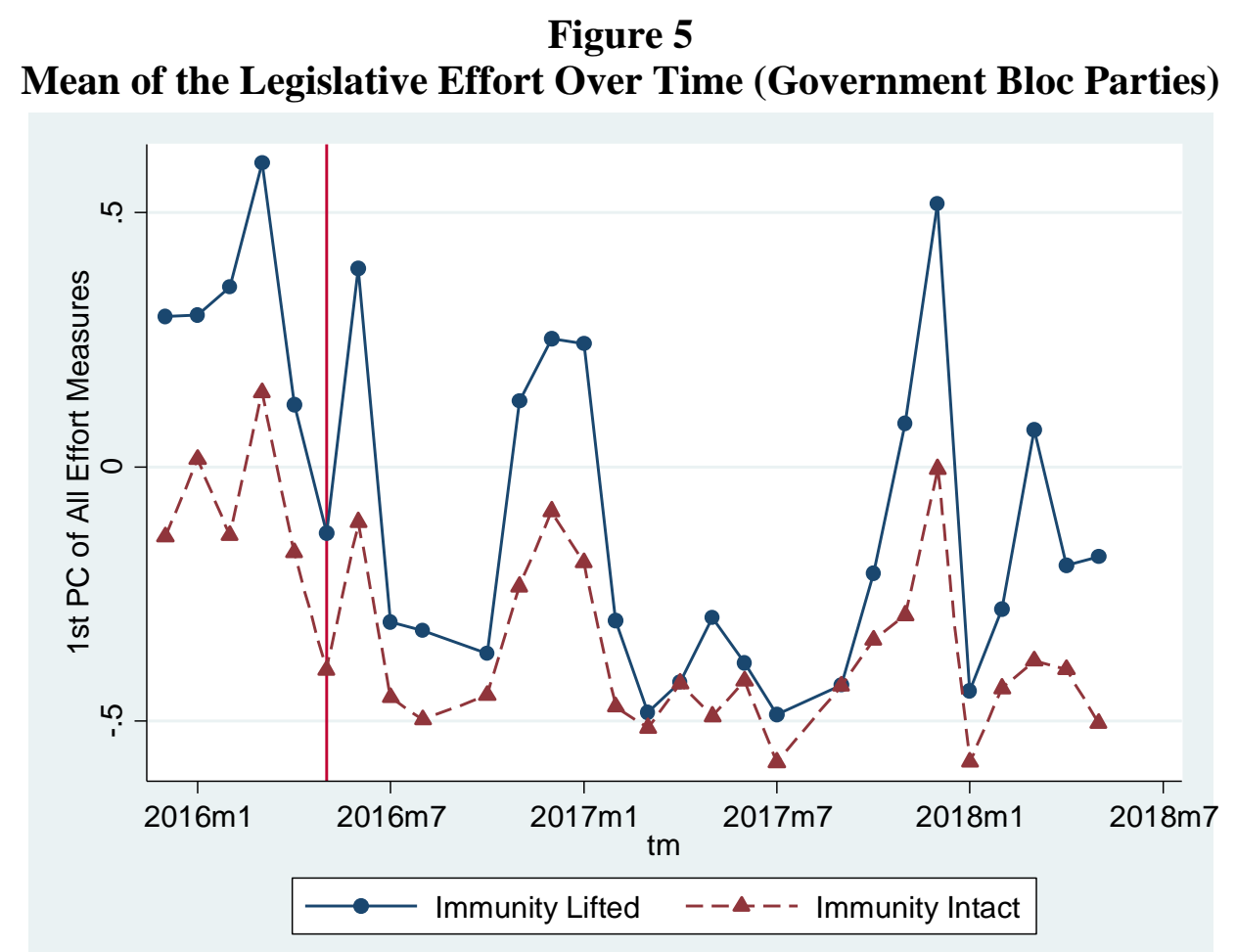

The figure presents the average of the first principal component of all legislative effort outcomes for the government bloc MPs. The blue, solid line (circles) represents the MPs who lost immunity, and the red dashed line (triangles) is for the MPs who retained immunity. 


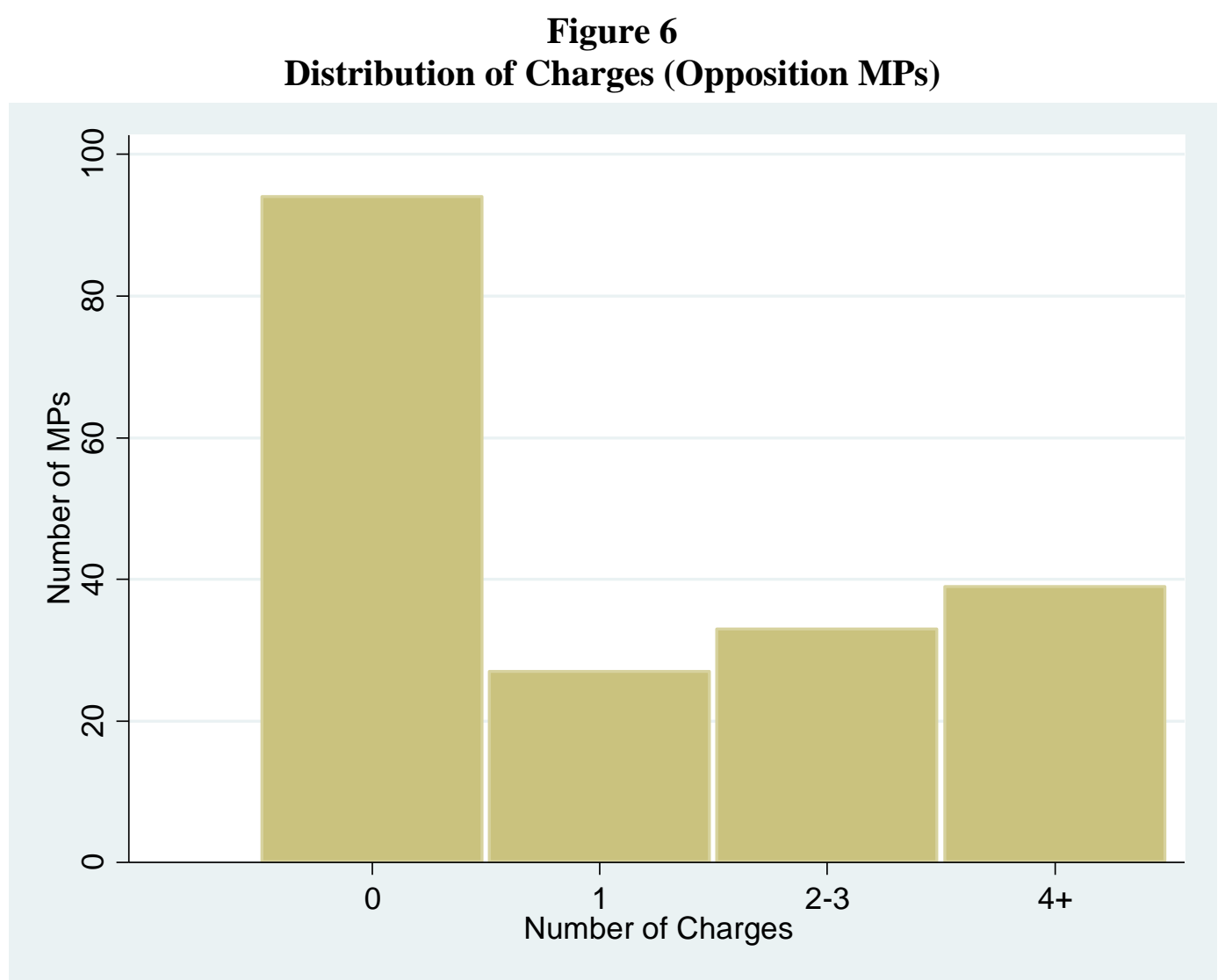

The figure presents the number of charges filed against opposition MPs as of the start of the pre-treatment period.

Table 1

Distribution of MPs by Legislative Immunity Status

\begin{tabular}{lcc|c}
\hline $\begin{array}{l}\text { Political } \\
\text { Party }\end{array}$ & $\begin{array}{c}\text { Number of MPs whose } \\
\text { Immunity is NOT Lifted }\end{array}$ & $\begin{array}{c}\text { Number of MPs whose } \\
\text { Immunity is Lifted }\end{array}$ & Total \\
\hline AKP & 292 & $25(8 \%)$ & 317 \\
MHP & 32 & $8(20 \%)$ & 40 \\
CHP & 80 & $54(40 \%)$ & 134 \\
HDP & 14 & $45(76 \%)$ & 59 \\
\hline Total & 418 & $132(24 \%)$ & 550 \\
\hline
\end{tabular}

AKP (Adalet ve Kalkınma Partisi = Justice and Development Party) is the government party; MHP (Milliyetçi Hareket Partisi $=$ Nationalist Movement Party) is not in the government but is an ally of AKP. CHP (Cumhuriyet Halk Partisi = Republican People's Party) is the main opposition party; HDP (Halkların Demokratik Partisi = People's Democratic Party) is the second-largest opposition party. CHP and HDP constitute the opposition bloc. 
Table 2

Summary Statistics

\begin{tabular}{|c|c|c|c|}
\hline & Description & Mean & Std. Dev. \\
\hline \multicolumn{4}{|l|}{ Legislative Activities of MPs } \\
\hline Speeches & $\begin{array}{l}\text { The number of times per month the MP delivered } \\
\text { a speech at the Parliamentary lectern. }\end{array}$ & 6.75 & 27.74 \\
\hline Words & $\begin{array}{l}\text { The total number of words MP spoke in } \\
\text { Parliamentary speeches in a month. }\end{array}$ & 717.16 & 1792.25 \\
\hline $\begin{array}{l}\text { Interruptions Targeting } \\
\text { Speeches of Gov. MPs }\end{array}$ & $\begin{array}{l}\text { The number of times the MP interrupted the } \\
\text { speech of another MP who was a member of the } \\
\text { government party. }\end{array}$ & 0.70 & 4.18 \\
\hline $\begin{array}{l}\text { Interruptions Targeting } \\
\text { Speeches of Non-Gov. MPs }\end{array}$ & $\begin{array}{l}\text { The number of times the MP interrupted the } \\
\text { speech of another MP who was a member of } \\
\text { opposition parties. }\end{array}$ & 1.05 & 4.91 \\
\hline $\begin{array}{l}\text { \% Votes Against } \\
\text { Government }\end{array}$ & $\begin{array}{l}\text { The percent of times the MP voted against the } \\
\text { position of the governing party. }\end{array}$ & 60.97 & 42.51 \\
\hline Investigation Inquiries Filed & $\begin{array}{l}\text { The number of times the MP initiated an } \\
\text { investigation in the Parliament regarding the } \\
\text { actions of the government or of a cabinet member. }\end{array}$ & 0.17 & 0.99 \\
\hline Drafts of Legislation & The number of bills sponsored by the MP. & 0.13 & 0.92 \\
\hline Formal Queries & $\begin{array}{l}\text { The number of times MP submitted a formal query } \\
\text { to the government to be responded in writing or } \\
\text { orally on the Parliament floor. }\end{array}$ & 1.81 & 19.48 \\
\hline \multicolumn{4}{|l|}{ Treatment Variable } \\
\hline Immunity Lifted & $\begin{array}{l}=1 \text { if MP is among the group of MPs whose } \\
\text { immunities are stripped off in May } 2016 .\end{array}$ & 0.24 & 0.43 \\
\hline \multicolumn{4}{|l|}{ MP Attributes } \\
\hline Age & Age of the MP in May 2016. & 51.93 & 8.57 \\
\hline Female & $=1$ if MP is female. & 0.14 & 0.35 \\
\hline $\mathrm{MA} / \mathrm{PhD}$ & $=1$ if MP has a graduate degree. & 0.41 & 0.49 \\
\hline Re-Elected & $\begin{array}{l}=1 \text { if } \mathrm{MP} \text { is re-elected to the } 27^{\text {th }} \text { Parliamentary } \\
\text { term. }\end{array}$ & 0.49 & 0.50 \\
\hline
\end{tabular}

The unit of observation is an MP-month. The number of observations is 15,317. 
Table 3

The Impact of Losing Immunity on MPs' Legislative Activities

All MPs

Panel A: Speech Outcomes

\begin{tabular}{lcccc}
\hline & $(1)$ & $(2)$ & $(3)$ & $(4)$ \\
\hline & Speeches & Words & $\begin{array}{c}\text { Interruptions } \\
\text { Targeting } \\
\text { Gov. MPs }\end{array}$ & $\begin{array}{c}\text { Interruptions } \\
\text { Targeting } \\
\text { Non-Gov. MPs }\end{array}$ \\
\hline $\begin{array}{lcccc}\text { Immunity Lifted } \\
\quad \times \text { Post }\end{array}$ & -5.89 & -422.19 & $-1.44^{* * *}$ & 0.59 \\
& $(4.72)$ & $(257.76)$ & $(0.43)$ & $(0.47)$ \\
$\mathrm{N}$ & {$[0.24]$} & {$[0.15]$} & {$[0.00]$} & {$[0.24]$} \\
\hline
\end{tabular}

Panel B: Legislative Effort

\begin{tabular}{ccccc}
\hline & $(1)$ & $(2)$ & $(3)$ & $(4)$ \\
\hline & $\%$ Votes & Investigation & Drafts of & Formal \\
& Against Gov. & Inquiries Filed & Legislation & Queries \\
\hline Immunity Lifted & $-3.83^{* * *}$ & $-0.31^{* * *}$ & $-0.37^{* *}$ & 0.95 \\
$\times$ Post & $(1.18)$ & $(0.10)$ & $(0.15)$ & $(1.54)$ \\
& {$[0.00]$} & {$[0.01]$} & {$[0.03]$} & {$[0.54]$} \\
\hline $\mathrm{N}$ & 15,317 & 15,317 & 15,317 & 15,317 \\
\hline
\end{tabular}

Panel C: First Principal Components

\begin{tabular}{cccc}
\hline & $(1)$ & $(2)$ & $(3)$ \\
\hline & $1^{\text {st }}$ PC of & $1^{\text {st }}$ PC of & $1^{\text {st }}$ PC of Effort in \\
& All Effort & Speech & Other Legislative \\
& Measures & Outcomes & Activities \\
\hline Immunity Lifted & $-0.55^{* *}$ & -0.38 & $-0.38^{* * *}$ \\
$\times$ Post & $(0.22)$ & $(0.23)$ & $(0.11)$ \\
& {$[0.03]$} & {$[0.15]$} & {$[0.00]$} \\
\hline $\mathrm{N}$ & 15,317 & 15,317 & 15,317 \\
\hline
\end{tabular}

Immunity Lifted is the treatment indicator that is equal to one if the immunity of the MP was stripped off in May 2016. Post stands for the post-treatment period. Outcomes: Panel A: (1) Number of speeches delivered on the Parliament floor by the MP; (2) Number of words in those speeches; (3) Number of times the MP interrupted the speech of another MP who is a member of the government party; (4) Number of times an MP interrupted the speech of another MP who is a member of the opposition parties. Panel B: (1) \% of the rollcall votes the MP voted the same way as the majority of the government party; (2) the number of times the MP filed an investigation inquiry into the activities of the government (3) the number of bills sponsored by the MP; (4) the number of times MP passed a formal query to the members of the government. Panel C: (1) first principal component of all outcomes in Panels A and B; (2) first principal component of outcomes in Panel A; (3) first principal component of outcomes in Panel B. The unit of observation is an MP-month. All regressions include MP fixed effects and month-by-year dummies. Standard errors, clustered at the MP level, are in parentheses. ***, **, and * indicate statistical significance at $1 \%$, $5 \%$ and $10 \%$ levels. P-values, adjusted for multiple hypothesis testing, are displayed in [brackets]. 
Table 4

The Impact of Losing Immunity on MPs' Legislative Activities --Opposition MPs Panel A: Speech Outcomes

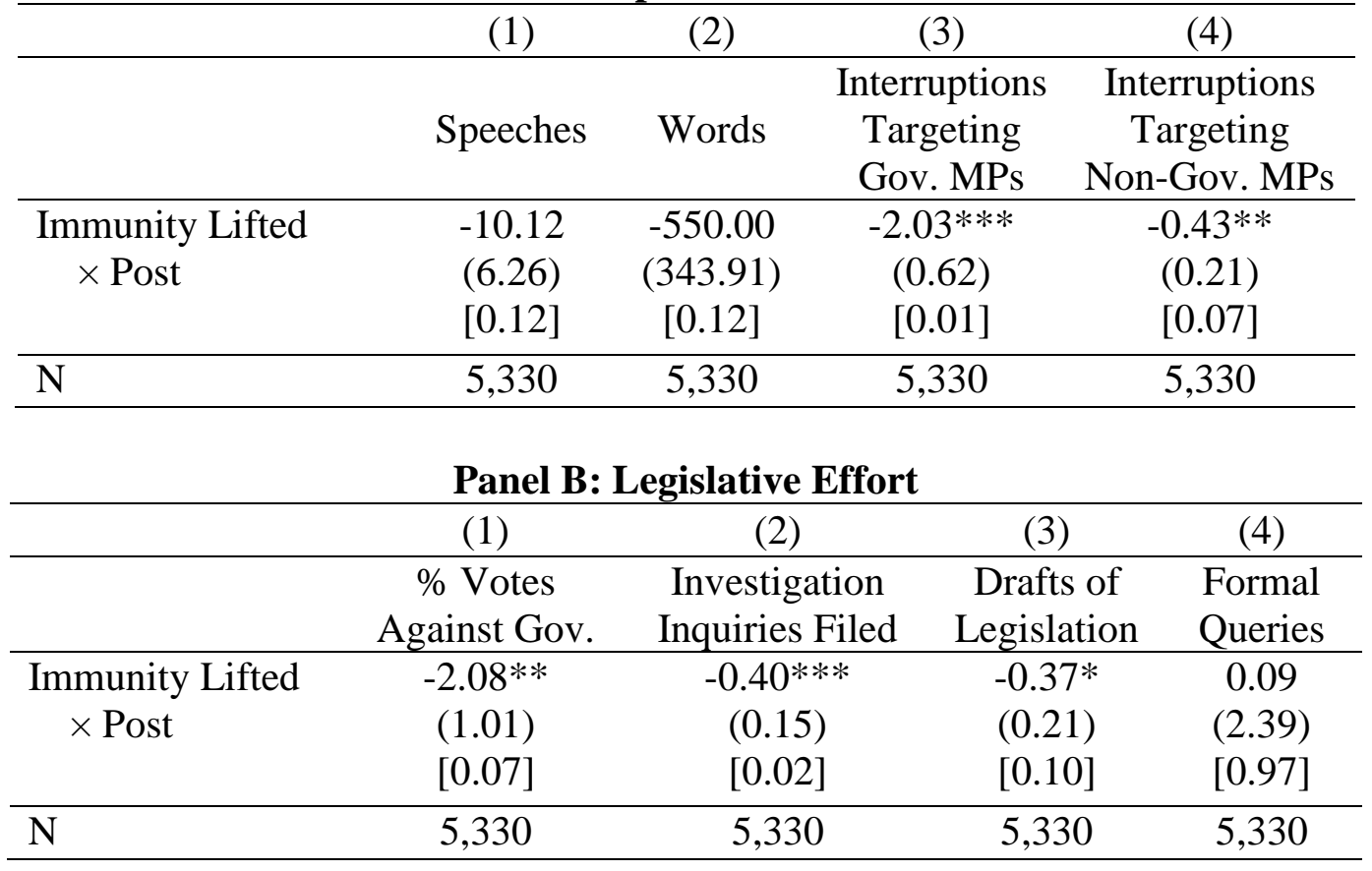

Panel C: First Principal Components

\begin{tabular}{lccc}
\hline & $(1)$ & $(2)$ & $(3)$ \\
\hline & $1^{\text {st }}$ PC of & $1^{\text {st }}$ PC of & $1^{\text {st }}$ PC of Effort in \\
& All Effort & Speech & Other Legislative \\
& Measures & Outcomes & Activities \\
\hline $\begin{array}{l}\text { Immunity Lifted } \\
\times \text { Post }\end{array}$ & $-0.81^{* * *}$ & $-0.64^{* *}$ & $-0.45^{* * *}$ \\
& $(0.30)$ & $(0.31)$ & $(0.17)$ \\
& {$[0.02]$} & {$[0.07]$} & {$[0.02]$} \\
\hline $\mathrm{N}$ & 5,330 & 5,330 & 5,330 \\
\hline
\end{tabular}

Immunity Lifted is the treatment indicator that is equal to one if the immunity of the MP was stripped off in May 2016. Post stands for the post-treatment period. Outcomes: Panel A: (1) Number of speeches delivered on the Parliament floor by the MP; (2) Number of words in those speeches; (3) Number of times the MP interrupted the speech of another MP who is a member of the government party; (4) Number of times an MP interrupted the speech of another MP who is a member of the opposition parties. Panel B: (1) \% of the rollcall votes the MP voted the same way as the majority of the government party; (2) the number of times the MP filed an investigation inquiry into the activities of the government (3) the number of bills sponsored by the MP; (4) the number of times MP passed a formal query to the members of the government. Panel C: (1) first principal component of all outcomes in Panels A and B; (2) first principal component of outcomes in Panel A; (3) first principal component of outcomes in Panel B. The unit of observation is an MP-month. All regressions include MP fixed effects and month-by-year dummies. Standard errors, clustered at the MP level, are in parentheses. ${ }^{* *}, * *$, and * indicate statistical significance at $1 \%$, $5 \%$ and $10 \%$ levels. P-values, adjusted for multiple hypothesis testing, are displayed in [brackets]. 
Table 5

The Impact of Losing Immunity on MPs' Legislative Activities MPs of the Social Democratic Party (CHP) Panel A: Speech Outcomes

\begin{tabular}{lcccc}
\hline & $(1)$ & $(2)$ & $(3)$ & $(4)$ \\
\hline & Speeches & Words & $\begin{array}{c}\text { Interruptions } \\
\text { Targeting } \\
\text { Gov. MPs }\end{array}$ & $\begin{array}{c}\text { Interruptions } \\
\text { Targeting } \\
\text { Non-Gov. MPs }\end{array}$ \\
\hline $\begin{array}{lcccc}\text { Immunity Lifted } \\
\text { × Post }\end{array}$ & $-5.09^{*}$ & $-301.23^{*}$ & $-2.09^{* * *}$ & $-0.27^{* *}$ \\
& $(2.63)$ & $(173.01)$ & $(0.77)$ & $(0.13)$ \\
$\mathrm{N}$ & {$[0.08]$} & {$[0.10]$} & {$[0.02]$} & {$[0.06]$} \\
\hline
\end{tabular}

\section{Panel B: Legislative Effort}

\begin{tabular}{ccccc}
\hline & $(1)$ & $(2)$ & $(3)$ & $(4)$ \\
\hline & \% Votes & Investigation & Drafts of & Formal \\
& Against & Inquiries & Legislation & Queries \\
& Gov. & Filed & . & \\
& -1.41 & $-0.67^{* * *}$ & $-0.81^{* *}$ & 0.94 \\
Immunity Lifted & $(1.38)$ & $(0.23)$ & $(0.35)$ & $(3.93)$ \\
$\times$ Post & {$[0.34]$} & {$[0.02]$} & {$[0.05]$} & {$[0.81]$} \\
\hline $\mathrm{N}$ & 3,745 & 3,745 & 3,745 & 3,745 \\
\hline
\end{tabular}

\section{Panel C: First Principal Components}

\begin{tabular}{cccc}
\hline & $(1)$ & $(2)$ & $(3)$ \\
\hline & $1^{\text {st }}$ PC of & $1^{\text {st }}$ PC of & $1^{\text {st }}$ PC of Effort in \\
& All Effort & Speech & Other Legislative \\
& Measures & Outcomes & Activities \\
\hline Immunity Lifted & $-0.84^{* * *}$ & $-0.45^{* * *}$ & $-0.81^{* * *}$ \\
$\times$ Post & $(0.26)$ & $(0.17)$ & $(0.26)$ \\
& {$[0.01]$} & {$[0.02]$} & {$[0.01]$} \\
\hline $\mathrm{N}$ & 3,745 & 3,745 & 3,745
\end{tabular}

Immunity Lifted is the treatment indicator that is equal to one if the immunity of the MP was stripped off in May 2016. Post stands for the post-treatment period. Outcomes: Panel A: (1) Number of speeches delivered on the Parliament floor by the MP; (2) Number of words in those speeches; (3) Number of times the MP interrupted the speech of another MP who is a member of the government party; (4) Number of times an MP interrupted the speech of another MP who is a member of the opposition parties. Panel B: (1) \% of the rollcall votes the MP voted the same way as the majority of the government party; (2) the number of times the MP filed an investigation inquiry into the activities of the government (3) the number of bills sponsored by the MP; (4) the number of times MP passed a formal query to the members of the government. Panel C: (1) first principal component of all outcomes in Panels A and B; (2) first principal component of outcomes in Panel A; (3) first principal component of outcomes in Panel B. The unit of observation is an MP-month. All regressions include MP fixed effects and month-by-year dummies. Standard errors, clustered at the MP level, are in parentheses. ${ }^{* *}, * *$, and * indicate statistical significance at $1 \%$, $5 \%$ and $10 \%$ levels. P-values, adjusted for multiple hypothesis testing, are displayed in [brackets]. 
Table 6

The Impact of Losing Immunity on MPs' Legislative Activities

Government Bloc MPs (Members of AKP and MHP)

Panel A: Speech Outcomes

\begin{tabular}{lcccc}
\hline & $(1)$ & $(2)$ & $(3)$ & $(4)$ \\
\hline & Speeches & Words & $\begin{array}{c}\text { Interruptions } \\
\text { Targeting } \\
\text { Gov. MPs }\end{array}$ & $\begin{array}{c}\text { Interruptions } \\
\text { Targeting } \\
\text { Non-Gov. MPs }\end{array}$ \\
\hline $\begin{array}{lcccc}\text { Immunity Lifted } \\
\quad \times \text { Post }\end{array}$ & -1.35 & -129.63 & -0.17 & -1.33 \\
& $(2.45)$ & $(148.85)$ & $(0.18)$ & $(1.38)$ \\
$\mathrm{N}$ & {$[0.58]$} & {$[0.58]$} & {$[0.58]$} & {$[0.58]$} \\
\hline
\end{tabular}

\section{Panel B: Legislative Effort}

\begin{tabular}{|c|c|c|c|c|}
\hline & (1) & (2) & (3) & (4) \\
\hline & $\begin{array}{c}\text { \% Votes } \\
\text { Against } \\
\text { Gov. }\end{array}$ & $\begin{array}{l}\text { Investigation } \\
\text { Inquiries } \\
\text { Filed }\end{array}$ & $\begin{array}{l}\text { Drafts of } \\
\text { Legislation }\end{array}$ & $\begin{array}{l}\text { Formal } \\
\text { Queries }\end{array}$ \\
\hline $\begin{array}{l}\text { Immunity Lifted } \\
\times \text { Post }\end{array}$ & $\begin{array}{l}-3.60 \\
(2.98) \\
{[0.58]}\end{array}$ & $\begin{array}{l}-0.06 \\
(0.09) \\
{[0.58]}\end{array}$ & $\begin{array}{c}0.03 \\
(0.04) \\
{[0.58]}\end{array}$ & $\begin{array}{c}0.19 \\
(0.31) \\
{[0.58]}\end{array}$ \\
\hline $\mathrm{N}$ & 9,987 & 9,987 & 9,987 & 9,987 \\
\hline
\end{tabular}

Panel C: First Principal Components

\begin{tabular}{lccc}
\hline & $(1)$ & $(2)$ & $(3)$ \\
\hline & $1^{\text {st }}$ PC of & $1^{\text {st }}$ PC of & $1^{\text {st }}$ PC of Effort in \\
& All Effort & Speech & Other Legislative \\
& Measures & Outcomes & Activities \\
\hline Immunity Lifted & -0.17 & -0.18 & -0.04 \\
$\times$ Post & $(0.13)$ & $(0.16)$ & $(0.08)$ \\
& {$[0.58]$} & {$[0.58]$} & {$[0.58]$} \\
\hline $\mathrm{N}$ & 9,987 & 9,987 & 9,987 \\
\hline
\end{tabular}

Immunity Lifted is the treatment indicator that is equal to one if the immunity of the MP was stripped off in May 2016. Post stands for the post-treatment period. Outcomes: Panel A: (1) Number of speeches delivered on the Parliament floor by the MP; (2) Number of words in those speeches; (3) Number of times the MP interrupted the speech of another MP who is a member of the government party; (4) Number of times an MP interrupted the speech of another MP who is a member of the opposition parties. Panel B: (1) \% of the rollcall votes the MP voted the same way as the majority of the government party; (2) the number of times the MP filed an investigation inquiry into the activities of the government (3) the number of bills sponsored by the MP; (4) the number of times MP passed a formal query to the members of the government. Panel C: (1) first principal component of all outcomes in Panels A and B; (2) first principal component of outcomes in Panel A; (3) first principal component of outcomes in Panel B. The unit of observation is an MP-month. All regressions include MP fixed effects and month-by-year dummies. Standard errors, clustered at the MP level, are in parentheses. ${ }^{* *}, * *$, and * indicate statistical significance at $1 \%$, $5 \%$ and $10 \%$ levels. P-values, adjusted for multiple hypothesis testing, are displayed in [brackets]. 
Table 7

The Impact of Losing Immunity on MPs’ Legislative Activities Including the Number of Charges against the MP (Opposition MPs) Panel A: Speech Outcomes

\begin{tabular}{lcccc}
\hline & $(1)$ & $(2)$ & $(3)$ & $(4)$ \\
\hline Speeches & Words & $\begin{array}{c}\text { Interruptions } \\
\text { Targeting } \\
\text { Gov. MPs }\end{array}$ & $\begin{array}{c}\text { Interruptions } \\
\text { Targeting } \\
\text { Non-Gov. MPs }\end{array}$ \\
\hline $\begin{array}{cccc}\text { Immunity Lifted } \\
\times \text { Post }\end{array}$ & $-7.36^{*}$ & $-417.96^{*}$ & $-1.98^{* * *}$ & $-0.34^{* *}$ \\
Charges $\times$ Post & $(3.86)$ & $(228.47)$ & $(0.58)$ & $(0.14)$ \\
& {$[0.08]$} & {$[0.08]$} & {$[0.01]$} & {$[0.03]$} \\
$\mathrm{N}$ & -0.48 & -23.20 & -0.01 & -0.02 \\
& $(0.64)$ & $(34.36)$ & $(0.04)$ & $(0.02)$ \\
\hline
\end{tabular}

Panel B: Legislative Effort

\begin{tabular}{lcccc}
\hline & $(1)$ & $(2)$ & $(3)$ & $(4)$ \\
\hline & $\begin{array}{c}\text { \% Votes } \\
\text { Against } \\
\text { Gov. }\end{array}$ & $\begin{array}{c}\text { Investigation } \\
\text { Inquiries } \\
\text { Filed }\end{array}$ & $\begin{array}{c}\text { Drafts of } \\
\text { Legislation }\end{array}$ & $\begin{array}{c}\text { Formal } \\
\text { Queries }\end{array}$ \\
& -1.70 & $-0.48^{* * *}$ & $-0.48^{* *}$ & 0.25 \\
Immunity Lifted & $(1.08)$ & $(0.17)$ & $(0.24)$ & $(2.65)$ \\
$\times$ Post & {$[0.13]$} & {$[0.01]$} & {$[0.07]$} & {$[0.93]$} \\
& $-0.07^{* *}$ & $0.01^{* *}$ & $0.02^{* *}$ & -0.03 \\
Charges $\times$ Post & $(0.03)$ & $(0.01)$ & $(0.01)$ & $(0.05)$ \\
\hline $\mathrm{N}$ & 5,330 & 5,330 & 5,330 & 5,330 \\
\hline
\end{tabular}

Panel C: First Principal Components

\begin{tabular}{lccc}
\hline & $(1)$ & $(2)$ & $(3)$ \\
\hline & $1^{\text {st }}$ PC of & $1^{\text {st }}$ PC of & $1^{\text {st }}$ PC of Effort in \\
& All Effort & Speech & Other Legislative \\
& Measures & Outcomes & Activities \\
\hline Immunity Lifted & $-0.76^{* * *}$ & $-0.53^{* * *}$ & $-0.55^{* * *}$ \\
$\times$ Post & $(0.23)$ & $(0.20)$ & $(0.19)$ \\
& {$[0.01]$} & {$[0.02]$} & {$[0.01]$} \\
Charges $\times$ Post & -0.01 & -0.02 & $0.02^{* * *}$ \\
& $(0.03)$ & $(0.03)$ & $(0.01)$ \\
\hline $\mathrm{N}$ & 5,330 & 5,330 & 5,330
\end{tabular}

See notes to Table 4. The results pertain to the same specification and the sample as in Table 4, with the addition of the interaction between the Post dummy and the number of charges against the MP. 
Table 8

The Impact of Losing Immunity on MPs' Legislative Activities During the Period before the Coup Attempt (Opposition MPs) Panel A: Speech Outcomes

\begin{tabular}{lcccc}
\hline & $(1)$ & $(2)$ & $(3)$ & $(4)$ \\
\hline & Speeches & Words & $\begin{array}{c}\text { Interruptions } \\
\text { Targeting } \\
\text { Gov. MPs }\end{array}$ & $\begin{array}{c}\text { Interruptions } \\
\text { Targeting } \\
\text { Non-Gov. MPs }\end{array}$ \\
\hline $\begin{array}{lcccc}\text { Immunity Lifted } \\
\quad \times \text { Post }\end{array}$ & -4.26 & -285.83 & $-1.68^{* * *}$ & -0.36 \\
& $(3.81)$ & $(218.63)$ & $(0.56)$ & $(0.24)$ \\
$\mathrm{N}$ & {$[0.27]$} & {$[0.24]$} & {$[0.01]$} & {$[0.17]$} \\
\hline
\end{tabular}

\section{Panel B: Legislative Effort}

\begin{tabular}{ccccc}
\hline & $(1)$ & $(2)$ & $(3)$ & $(4)$ \\
\hline & \% Votes & Investigation & Drafts of & Formal \\
& Against & Inquiries & $\begin{array}{c}\text { Legislation } \\
\text { Queries }\end{array}$ & Quev \\
& Gov. & Filed & & \\
& $-2.91^{* *}$ & $-0.34^{* *}$ & $-0.52^{* *}$ & -0.70 \\
Immunity Lifted & $(1.16)$ & $(0.17)$ & $(0.23)$ & $(0.59)$ \\
$\times$ Post & {$[0.04]$} & {$[0.08]$} & {$[0.06]$} & {$[0.26]$} \\
\hline $\mathrm{N}$ & 1,351 & 1,351 & 1,351 & 1,351 \\
\hline
\end{tabular}

\section{Panel C: First Principal Components}

\begin{tabular}{cccc}
\hline & $(1)$ & $(2)$ & $(3)$ \\
\hline & $1^{\text {st }}$ PC of & $1^{\text {st }}$ PC of & $1^{\text {st }}$ PC of Effort in \\
& All Effort & Speech & Other Legislative \\
& Measures & Outcomes & Activities \\
\hline Immunity Lifted & $-0.63^{* * *}$ & $-0.39^{*}$ & $-0.52^{* * *}$ \\
$\times$ Post & $(0.20)$ & $(0.20)$ & $(0.16)$ \\
& {$[0.01]$} & {$[0.08]$} & {$[0.01]$} \\
\hline $\mathrm{N}$ & 1,351 & 1,351 & 1,351 \\
\hline
\end{tabular}

Immunity Lifted is the treatment indicator that is equal to one if the immunity of the MP was stripped off in May 2016. Post stands for the post-treatment period. Outcomes: Panel A: (1) Number of speeches delivered on the Parliament floor by the MP; (2) Number of words in those speeches; (3) Number of times the MP interrupted the speech of another MP who is a member of the government party; (4) Number of times an MP interrupted the speech of another MP who is a member of the opposition parties. Panel B: (1) \% of the rollcall votes the MP voted the same way as the majority of the government party; (2) the number of times the MP filed an investigation inquiry into the activities of the government (3) the number of bills sponsored by the MP; (4) the number of times MP passed a formal query to the members of the government. Panel C: (1) first principal component of all outcomes in Panels A and B; (2) first principal component of outcomes in Panel A; (3) first principal component of outcomes in Panel B. The unit of observation is an MP-month. All regressions include MP fixed effects and month-by-year dummies. Standard errors, clustered at the MP level, are in parentheses. ${ }^{* *}, * *$, and * indicate statistical significance at $1 \%$, $5 \%$ and $10 \%$ levels. P-values, adjusted for multiple hypothesis testing, are displayed in [brackets]. 
Table 9

The Impact of Losing Immunity on Re-Election and Re-Nomination Probability

\begin{tabular}{lcccc}
\hline & $\begin{array}{c}\text { Gov. } \\
\text { Bloc }\end{array}$ & $\begin{array}{c}\text { Opposition } \\
\text { Bloc }\end{array}$ & $\begin{array}{c}\text { Gov. } \\
\text { Bloc }\end{array}$ & $\begin{array}{c}\text { Opposition } \\
\text { Bloc }\end{array}$ \\
\hline & $(1)$ & $(2)$ & $(3)$ & $(4)$ \\
\hline \multicolumn{2}{c}{ Re-Elected to the $27^{\text {th }}$} & \multicolumn{2}{c}{ Re-Nominated for the 27 } \\
Parliament & \multicolumn{2}{c}{ Parliament } \\
\hline Immunity Lifted & -0.01 & $-0.19^{* *}$ & -0.08 & $-0.16^{*}$ \\
Charges & $(0.13)$ & $(0.09)$ & $(0.12)$ & $(0.09)$ \\
Age & -0.02 & 0.01 & -0.02 & 0.01 \\
& $(0.05)$ & $(0.02)$ & $(0.04)$ & $(0.02)$ \\
Female & $-0.01^{* * *}$ & $-0.01^{* * *}$ & $-0.01^{* * *}$ & $-0.01^{* * *}$ \\
& $(0.00)$ & $(0.00)$ & $(0.00)$ & $(0.00)$ \\
MA/PhD & -0.06 & $-0.19 *$ & -0.06 & $-0.20^{* *}$ \\
& $(0.09)$ & $(0.10)$ & $(0.09)$ & $(0.10)$ \\
\hline $\mathrm{N}$ & $0.09 *$ & 0.07 & 0.08 & 0.04 \\
\hline Party FEs & $(0.05)$ & $(0.08)$ & $(0.05)$ & $(0.08)$ \\
\hline
\end{tabular}

Immunity Lifted is the treatment indicator that is equal to one if the immunity of the MP was stripped off in May 2016. Charges represents the number of charges against the MP. Outcomes are dummies for whether the MP is reelected to the $27^{\text {th }}$ Parliamentary term (columns 1-2) and for whether the MP is re-nominated by her/his party (columns 3-4). All regressions include party fixed-effects. Robust standard errors are in parentheses. ***, **, and * indicate statistical significance at $1 \%, 5 \%$ and $10 \%$ levels. 
Table 10

Impact of Lifting MPs' Immunity on Citizens' Trust in the Parliament

\begin{tabular}{|c|c|c|c|c|}
\hline & $\begin{array}{c}\text { (1) } \\
\text { Trust the } \\
\text { Turkish } \\
\text { Parliament }\end{array}$ & $\begin{array}{c}\text { (2) } \\
\text { Trust the } \\
\text { Turkish } \\
\text { Parliament }\end{array}$ & $\begin{array}{c}\text { (3) } \\
\text { Trust the } \\
\text { Turkish } \\
\text { Parliament }\end{array}$ & $\begin{array}{c}\text { (4) } \\
\text { Trust the } \\
\text { EU or } \\
\text { UN }\end{array}$ \\
\hline $\begin{array}{l}\text { Immunity of MP(s) from } \\
\text { the Province is Lifted }\end{array}$ & $\begin{array}{l}-0.04 \\
(0.10) \\
\{0.60\}\end{array}$ & & & \\
\hline $\begin{array}{l}\text { Politically Compatible MP } \\
\text { of the Province Lost Immunity }\end{array}$ & & $\begin{array}{l}-0.09 \\
(0.10) \\
\{0.35\}\end{array}$ & & \\
\hline $\begin{array}{l}\text { Rival MP of the Province } \\
\text { Lost Immunity }\end{array}$ & & $\begin{array}{l}0.22 * * \\
(0.10) \\
\{0.04\}\end{array}$ & & \\
\hline $\begin{array}{l}\text { Ideologically Right-Wing Citizen } \\
\text { × Government MP's } \\
\text { Immunity is Lifted }\end{array}$ & & & $\begin{array}{l}-0.21^{*} \\
(0.15) \\
\{0.10\}\end{array}$ & $\begin{array}{l}-0.18 \\
(0.17) \\
\{0.38\}\end{array}$ \\
\hline $\begin{array}{l}\text { Ideologically Right-Wing Citizen } \\
\times \text { Opposition. MP’s } \\
\text { Immunity is Lifted }\end{array}$ & & & $\begin{array}{l}0.34^{*} \\
(0.22) \\
\{0.08\}\end{array}$ & $\begin{array}{l}-0.12 \\
(0.22) \\
\{0.61\}\end{array}$ \\
\hline $\begin{array}{l}\text { Ideologically Left-Wing Citizen } \\
\times \text { Government MP's } \\
\text { Immunity is Lifted }\end{array}$ & & & $\begin{array}{l}0.11 \\
(0.14) \\
\{0.48\}\end{array}$ & $\begin{array}{l}-0.31 \\
(0.16) \\
\{0.12\}\end{array}$ \\
\hline $\begin{array}{l}\text { Ideologically Left-Wing Citizen } \\
\text { × Opposition MP’s } \\
\text { Immunity is Lifted }\end{array}$ & & & $\begin{array}{c}0.43 \\
(0.24) \\
\{0.26\}\end{array}$ & $\begin{array}{c}0.07 \\
(0.25) \\
\{0.83\}\end{array}$ \\
\hline $\mathrm{N}$ & 1,677 & 1,677 & 1,677 & 1677 \\
\hline Mean of the Outcome & 0.58 & 0.58 & 0.58 & 0.39 \\
\hline
\end{tabular}

The outcome variable in columns 1-3 is an indicator that takes the value of one if the individual trusts the Turkish Parliament. The outcome in column 4 is a dummy that takes the value of one if the individual trusts the UN or EU. Regressions include individual characteristics, which are age and its square, whether the individual has a college degree, is married, female, employed, owns a car, owns a house, and whether the individual had difficulty in paying bills in the past year, and the size of the household. We also control for a post dummy, an indicator for whether the individual is on the left of the ideological spectrum and its interaction with the Post dummy, as well as province fixed effects and interactions of each province fixed effects with the Left dummy. Standard errors, reported in parentheses, are clustered at the province level (26 provinces). P-values using the wild-t bootstrap procedure described in Cameron and Miller (2015) are reported in \{brackets\}. 


\section{References}

Acemoglu, D., J. Robinson, and R. Torvik. (2013). "Why Do Voters Dismantle Checks and Balances?” Review of Economic Studies 80, pp. 845-875.

Aydin-Duzgit, S. (2019). “The Islamist-Secularist Divide and Turkey’s Descent into Severe Polarization.” Chapter 1 in Democracies Divided: The Global Challenge of Political

Polarization, eds. T. Carothers and A. O’Dohonue. Brookings Institution Press, Washington, D.C.

Benjamini, Y., and D. Yekutieli. (2001). "The Control of the False Discovery Rate in Multiple Testing Under Dependency.” Annals of Statistics 1165-1188.

Cameron, C., and D. Miller (2015). “A Practitioner’s Guide to Cluster-Robust Inference.” Journal of Human Resources 50(2), pp. 317-372.

de Chaisemartin, C., and X. D’Haultfoeuille. (2020). “Two-Way Fixed Effects Estimators with Heterogeneous Treatment Effects.” American Economic Review 110(9), pp. 2964-2996.

Chang, Eric C., Miriam Golden, and Seth Hill, 2010. "Legislative malfeasance and Political Accountability, World Politics; 62(2): 177-220.

Corman, Hope, and Naci Mocan. (2000). “A Time-Series Analysis of Crime, Deterrence, and Drug Abuse in New York City.” American Economic Review 90 (3): 584-604.

Di Tella, R., and E. Schargrodsky. (2004). "Do Police Reduce Crime? Estimates Using the Allocation of Police Forces After a Terrorist Attack.” American Economic Review 94 (1), pp. 115-133.

Dal Bó, E., and M. Rossi. (2011). “Term Length and the Effort of Politicians.” The Review of Economic Studies 78(4), pp. 1237-1263.

Dal Bó, E., P. Dal Bó and Rafael Di Tella. 2006. “'Plata o Plamo?’: Bribe and Punishment in a Theory of Political Influence,” American Political Science Review, 100(1): 41-53.

Daniele Gianmarco, Sergio Galletta, and Benny Geys, 2020. “Abondon Ship? Party Brands and Politicians’ responses to a Political Scandal.” Journal of Public Economics, 184:104172

Ferraz, C. and F. Finan. (2008). "Exposing Corrupt Politicians: The Effects of Brazil’s Publicly Released Audits on Electoral Outcomes.” Quarterly Journal of Economics 123(2), pp.703745.

Garz, M., and J. Sörensen. (2017). “Politicians Under Investigation: The News Media’s Effect on the Likelihood of Resignation.” Journal of Public Economics 153, pp. 82-91.

Goodman-Bacon, A. (2021). "Difference-in-Differences with Variation in Treatment Timing." Journal of Econometrics, < https://doi.org/10.1016/j.jeconom.2021.03.014>.

Harmon, N., R. Fisman, and E. Kamenica. (2019). "Peer Effects in Legislative Voting.” American Economic Journal: Applied Economics 11(4), pp. 156-80.

Keyman, F. (2014). “The AK Party: Dominant Party, New Turkey and Polarization.” Insight Turkey 16(2), pp. 19-31. 
Kotakorpi K, Poutvaara P. (2011). "Pay for Politicians and Candidate Selection: An Empirical Analysis.” Journal of Public Economics 95(7-8), pp. 877-885.

Lauka, A., J. McCoy, and R. Firat. (2018). "Mass Partisan Polarization: Measuring a Relational Concept.” American Behavioral Scientist 62(1), pp. 107-126.

Lizzeri, A., and N. Persico. (2005). "A Drawback of Electoral Competition.” Journal of the European Economic Association 3(4), pp. 1318-1348.

Lizzeri, A., and N. Persico. (2001). "The Provision of Public Goods under Alternative Electoral Incentives.” American Economic Review 91(1), pp. 225-239.

McGee, S. (2001). "Rules on Parliamentary Immunity in the European Parliament and the Member States of the European Union." European Centre for Parliamentary Research and Documentation (ECPRD), Brussels.

Mocan, N., and D. Altindag. (2013). "Salaries and Work Effort: An Analysis of the European Union Parliamentarians.” Economic Journal 123, pp. 1130-1167.

Newson, R. (2010). “Frequentist q-values for Multiple-test Procedures.” Stata Journal 10(4), pp. 568-584.

Neziroğlu, İ. (Ed.) (2015). “The Grand National Assembly of Turkey.” GNAT Press Publications and Public Relations Department Printing House, Ankara.

Persson, T, G. Roland, and G. Tabellini. (1997). "Separation of Powers and Political Accountability.” The Quarterly Journal of Economics 112(4), pp. 1163-1202.

Persson, T., and G. Tabellini. (2004). "Constitutions and Economic Policy.” Journal of Economic Perspectives 18 (1), pp. 75-98.

Peters, John G. and Susan Welch. 1980.” The Effects of Charges of Corruption on Voting Behavior in Congressional Elections.” American Political Science Review, 74(3): 697-708.

Reddy, K., M. Schularick, and V. Skereta. (2020). “Immunity.” International Economic Review 61(2) pp. 531-56.

Saia, A. (2018). "Random Interactions in the Chamber: Legislators' Behavior and Political Distance.” Journal of Public Economics 164(C), pp. 225-240.

Schelling, T. (1980). "The Strategy of Conflict." Harvard University Press. Cambridge and London.

Simes, J. (1986). “An Improved Bonferroni Procedure for Multiple Tests of Significance.” Biometrika 73(3), pp. 751-754.

Snyder Jr., J., and D. Strömberg. (2010). “Press Coverage and Political Accountability.” Journal of Political Economy 118(2), pp. 355-408.

Washington, E. (2008). "Female Socialization: How Daughters Affect Their Legislator Fathers.” American Economic Review 98(1), pp. 311-32.

Welch, Susan and John Hibbing, 1997. "The Effects of Charges of Corruption on Voting Behavior in Congressional Elections, 1982-1990" The Journal of Politics, 59(1): 226-239. Wigley, S. (2009). "Parliamentary Immunity in Democratizing Countries: The Case of Turkey.” Human Rights Quarterly 31, pp. 567-591. 
Wigley, S. (2003). “Parliamentary Immunity: Protecting Democracy or Protecting Corruption?” The Journal of Political Philosophy 11(1), pp. 23-40. 


\section{APPENDIX}

\section{Appendix Section 1: Various Robustness Analyses}

\section{Appendix Figure AF1 \\ The Number of Executive Orders by Month}

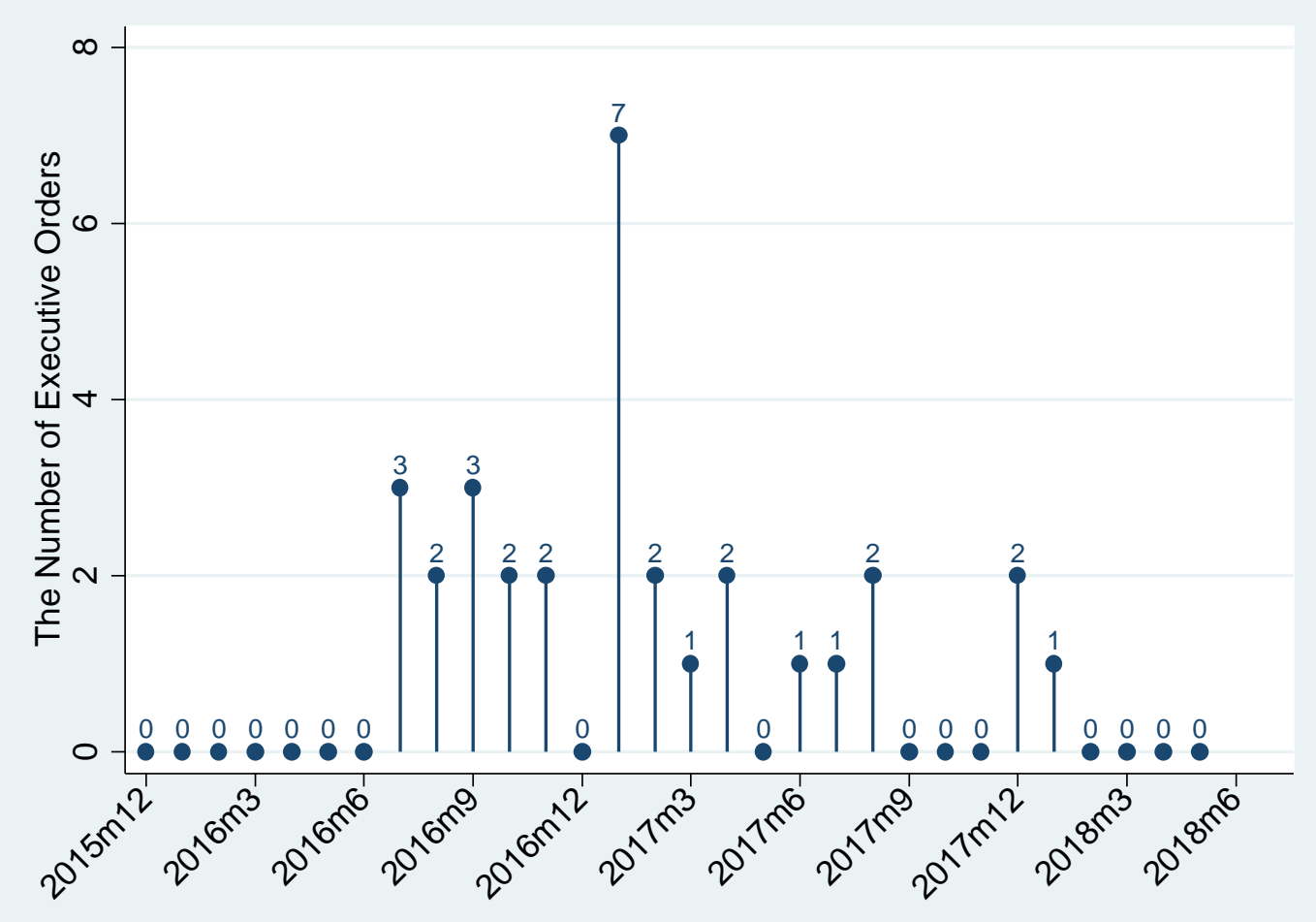

In late July 2016, after the coup attempt, the government declared a state of emergency which allowed it to issue executive orders and bypass the Parliamentary approval process to investigate the coup organizers and collaborators. The figure presents the number of such executive orders over time. 


\section{Appendix Table A1 \\ The Relationship between MP Attributes and Immunity Status}

\begin{tabular}{lcc} 
Explanatory Variable & $\begin{array}{c}\text { Whole Sample } \\
(1)\end{array}$ & $\begin{array}{c}\text { Opposition Parties } \\
(2)\end{array}$ \\
\hline \multirow{3}{*}{ Age in May 2016 } & & \\
& -0.002 & $-0.006^{*}$ \\
& $(0.002)$ & $(0.004)$ \\
& {$[0.58]$} & {$[0.33]$} \\
MA/PhD & & \\
& -0.040 & 0.005 \\
& $(0.037)$ & $(0.078)$ \\
Female & {$[0.58]$} & {$[0.95]$} \\
& & \\
& 0.037 & -0.046 \\
& $(0.053)$ & $(0.086)$ \\
& {$[0.58]$} & {$[0.79]$}
\end{tabular}

Opposition Party Member $\quad 0.421 * * *$

(0.039)

[0.00]

Each cell presents the estimate of $\beta_{1}$ from a separate regression of the following form: Immunity Lifted Im $_{i}=\beta_{0}+$ $\beta_{1} A_{i}+\varepsilon_{i}$, where $A$ stands for an MP attribute listed in column (1). The unit of observation is an MP. The number of MPs is 550 in the whole sample and 193 in the sample of opposition parties (CHP and HDP). Standard errors, clustered at the MP level are in (parentheses). P-values, adjusted for multiple hypothesis testing, are displayed in [brackets]. 
Appendix Table A2

\section{Unconditional Difference-in-Differences Estimates}

Panel A: All MPs

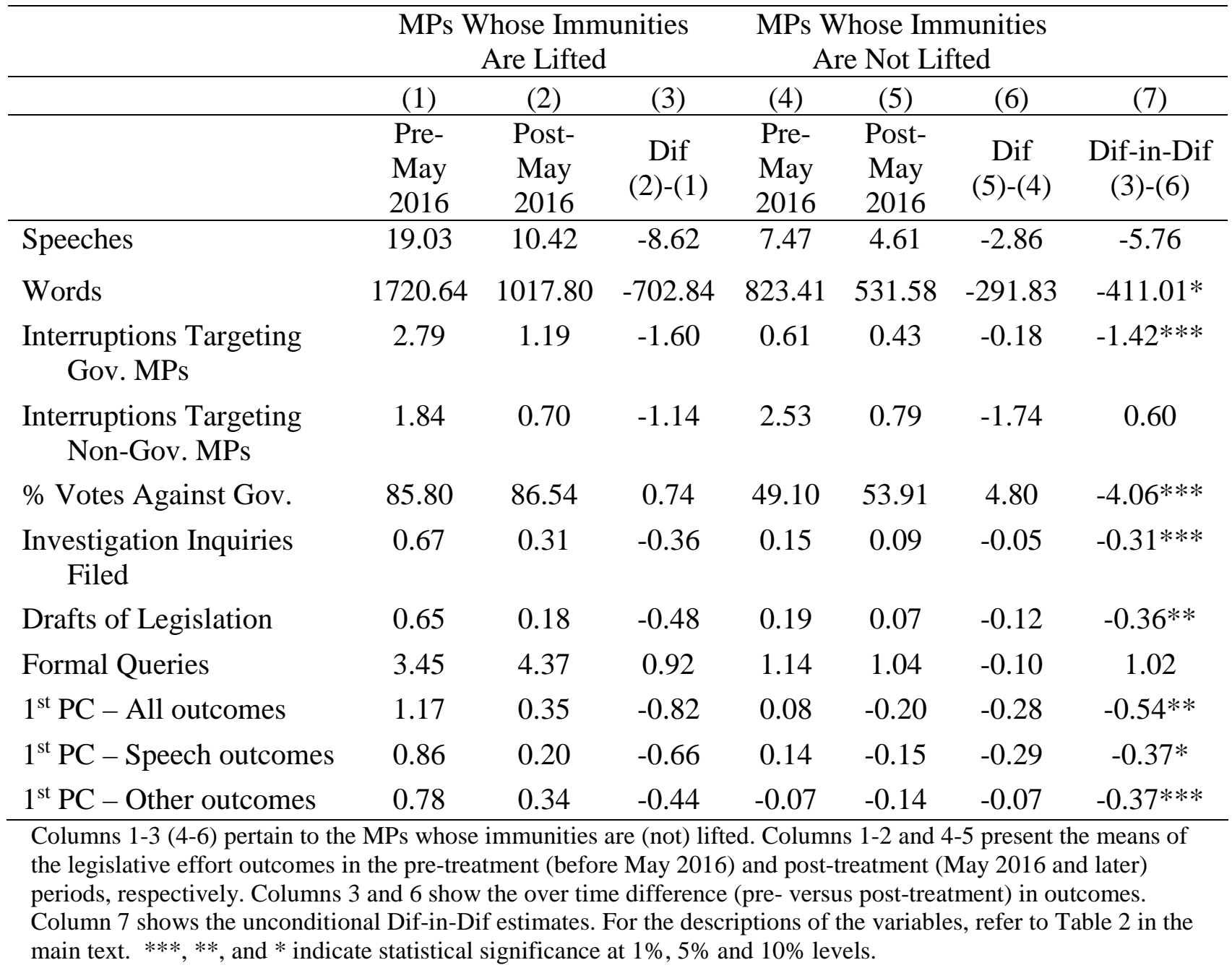




\section{Appendix Table A2 \\ Unconditional Difference-in-Differences Estimates}

Panel B: Opposition MPs

\begin{tabular}{|c|c|c|c|c|c|c|c|}
\hline & \multicolumn{3}{|c|}{$\begin{array}{l}\text { Opposition MPs Whose } \\
\text { Immunities Are Lifted }\end{array}$} & \multicolumn{3}{|c|}{$\begin{array}{l}\text { Opposition MPs Whose } \\
\text { Immunities Are Not Lifted }\end{array}$} & \multirow[b]{2}{*}{ (7) } \\
\hline & (1) & (2) & (3) & (4) & (5) & (6) & \\
\hline & $\begin{array}{l}\text { Pre- } \\
\text { May } \\
2016\end{array}$ & $\begin{array}{l}\text { Post- } \\
\text { May } \\
2016\end{array}$ & $\begin{array}{c}\text { Dif } \\
(2)-(1)\end{array}$ & $\begin{array}{l}\text { Pre- } \\
\text { May } \\
2016\end{array}$ & $\begin{array}{l}\text { Post- } \\
\text { May } \\
2016\end{array}$ & $\begin{array}{c}\text { Dif } \\
(5)-(4)\end{array}$ & $\begin{array}{l}\text { Dif-in-Dif } \\
\text { (3)-(6) }\end{array}$ \\
\hline Speeches & 21.10 & 11.33 & -9.78 & 7.77 & 7.92 & 0.15 & -9.93 \\
\hline Words & 1944.38 & 1154.59 & -789.79 & 1262.40 & 1006.46 & -255.93 & -533.86 \\
\hline $\begin{array}{l}\text { Interruptions Targeting } \\
\text { Gov. MPs }\end{array}$ & 3.53 & 1.54 & -1.99 & 1.62 & 1.63 & 0.01 & $-2.00 * * *$ \\
\hline $\begin{array}{l}\text { Interruptions Targeting } \\
\text { Non-Gov. MPs }\end{array}$ & 0.73 & 0.40 & -0.32 & 0.33 & 0.43 & 0.10 & $-0.42 * *$ \\
\hline \% Votes Against Gov. & 96.79 & 97.45 & 0.65 & 94.06 & 96.85 & 2.78 & $-2.13 * *$ \\
\hline $\begin{array}{l}\text { Investigation Inquiries } \\
\text { Filed }\end{array}$ & 0.85 & 0.41 & -0.44 & 0.41 & 0.37 & -0.05 & $-0.39 * * *$ \\
\hline Drafts of Legislation & 0.85 & 0.23 & -0.62 & 0.50 & 0.24 & -0.26 & $-0.36 *$ \\
\hline Formal Queries & 4.46 & 5.81 & 1.35 & 3.27 & 4.45 & 1.18 & 0.17 \\
\hline $1^{\text {st }} \mathrm{PC}-$ All outcomes & 1.45 & 0.52 & -0.93 & 0.53 & 0.39 & -0.14 & $-0.79 * * *$ \\
\hline $1^{\text {st }} \mathrm{PC}-$ Speech outcomes & 0.98 & 0.28 & -0.70 & 0.24 & 0.17 & -0.07 & $-0.63^{* *}$ \\
\hline $1^{\text {st }} \mathrm{PC}$ - Other outcomes & 1.09 & 0.54 & -0.55 & 0.58 & 0.47 & -0.11 & $-0.44^{* * *}$ \\
\hline
\end{tabular}


Appendix Table A3

Interruptions by Party

\begin{tabular}{l|cccc}
\hline & $\begin{array}{c}\text { Share of times an } \\
\text { AKP MP's Speech }\end{array}$ & $\begin{array}{c}\text { Share of times a } \\
\text { CHP MP's Speech }\end{array}$ & $\begin{array}{c}\text { Share of times an } \\
\text { MHP MP's Speech }\end{array}$ & $\begin{array}{c}\text { Share of times an } \\
\text { HDP MP's Speech }\end{array}$ \\
\hline $\begin{array}{l}\text { A. is interrupted by } \\
\text { AKP MPs }\end{array}$ & 0.027 & 0.267 & 0.028 & 0.202 \\
$\begin{array}{l}\text { C.is interrupted by } \\
\ldots \text { is interrupted by } \\
\text { MHP MPs } \\
\ldots \text { is interrupted by }\end{array}$ & 0.275 & 0.036 & 0.017 & 0.010 \\
HDP MPs & 0.024 & 0.010 & 0.006 & 0.006 \\
\hline
\end{tabular}

The entries are the shares of all interruptions. The shares add up to 1.

Appendix Table A4

The Impact of Losing Immunity on Being Interrupted while Delivering Speeches

Whole Sample Opposition Bloc Government Bloc

(CHP \& HDP)

(AKP \& MHP)

(1)

(2)

(3)

\begin{tabular}{|c|c|c|c|}
\hline & $\begin{array}{l}\text { No. Times Interrupted } \\
\text { by Gov. Bloc }\end{array}$ & $\begin{array}{l}\text { No. Times Interrupted } \\
\text { by Gov. Bloc }\end{array}$ & $\begin{array}{l}\text { No. Times Interrupted } \\
\text { by Gov. Bloc }\end{array}$ \\
\hline $\begin{array}{l}\text { Immunity Lifted } \\
\times \text { Post }\end{array}$ & $\begin{array}{c}-3.71 * * * \\
(1.00)\end{array}$ & $\begin{array}{c}-3.43 * * \\
(1.42)\end{array}$ & $\begin{array}{l}-0.90 \\
(0.57)\end{array}$ \\
\hline $\mathrm{N}$ & 15317 & 5330 & 9987 \\
\hline Mean of outcome & 0.99 & 2.42 & 0.22 \\
\hline
\end{tabular}


Appendix Table A5

Log of the Outcomes (Opposition MPs)

(1)

\begin{tabular}{lcccc}
\hline & Speeches & Words & $\begin{array}{c}\text { Interruptions } \\
\text { Targeting } \\
\text { Gov. MPs }\end{array}$ & $\begin{array}{c}\text { Interruptions } \\
\text { Targeting } \\
\text { Non-Gov. MPs }\end{array}$ \\
\hline $\begin{array}{l}\text { Immunity Lifted } \\
\times \text { Post }\end{array}$ & -0.14 & 0.04 & $-0.25 * * *$ & $-0.12 * * *$ \\
& $(0.10)$ & $(0.24)$ & $(0.07)$ & $(0.04)$ \\
$\mathrm{N}$ & {$[0.23]$} & {$[0.88]$} & {$[0.00]$} & {$[0.01]$} \\
\hline
\end{tabular}

\section{Panel B: Legislative Effort}

\begin{tabular}{ccccc}
\hline & $(1)$ & $(2)$ & $(3)$ & $(4)$ \\
\hline & \% Votes & Investigation & Drafts of & Formal \\
& Against Gov. & Inquiries Filed & Legislation & Queries \\
\hline Immunity Lifted & $-0.04^{* *}$ & $-0.09^{* *}$ & -0.04 & -0.02 \\
$\times$ Post & $(0.02)$ & $(0.04)$ & $(0.04)$ & $(0.07)$ \\
& {$[0.06]$} & {$[0.06]$} & {$[0.51]$} & {$[0.81]$} \\
\hline $\mathrm{N}$ & 5,330 & 5,330 & 5,330 & 5,330 \\
\hline
\end{tabular}

Panel C: First Principal Components

\begin{tabular}{lccc}
\hline & $(1)$ & $(2)$ & $(3)$ \\
\hline & $1^{\text {st }}$ PC of & $1^{\text {st }}$ PC of & $1^{\text {st }}$ PC of Effort in \\
& All Effort & Speech & Other Legislative \\
& Measures & Outcomes & Activities \\
\hline Immunity Lifted & $-0.13^{* *}$ & $-0.13^{* *}$ & $-0.08^{*}$ \\
$\times$ Post & $(0.06)$ & $(0.06)$ & $(0.04)$ \\
& {$[0.06]$} & {$[0.06]$} & {$[0.10]$} \\
\hline $\mathrm{N}$ & 5,330 & 5,330 & 5,330 \\
\hline
\end{tabular}

The table presents results from the same specification as Table 4, except that the left-hand side variables are the natural logarithms of one plus the outcomes. 


\begin{tabular}{|c|c|c|c|c|}
\hline \multicolumn{5}{|c|}{$\begin{array}{c}\text { Appendix Table A6 } \\
\text { The Impact of Losing Immunity on MPs' Legislative Activities } \\
\text { Controlling for the Interactions of Personal Attributes and the Post-Treatment Du } \\
\text { Panel A: Speech Outcomes }\end{array}$} \\
\hline & $(1)$ & $(2)$ & (3) & (4) \\
\hline & Speeches & Words & $\begin{array}{l}\text { Interruptions } \\
\text { Targeting } \\
\text { Gov. MPs }\end{array}$ & $\begin{array}{l}\text { Interruptions } \\
\text { Targeting } \\
\text { Non-Gov. MPs }\end{array}$ \\
\hline $\begin{array}{l}\text { Immunity Lifted } \\
\times \text { Post }\end{array}$ & $\begin{array}{l}-8.70^{*} \\
(4.94) \\
{[0.10]}\end{array}$ & $\begin{array}{l}-473.76 * \\
(277.72) \\
{[0.10]}\end{array}$ & $\begin{array}{c}-1.93 * * * \\
(0.58) \\
{[0.01]}\end{array}$ & $\begin{array}{l}-0.39 * * \\
(0.17) \\
{[0.04]}\end{array}$ \\
\hline $\mathrm{N}$ & 5,330 & 5,330 & 5,330 & 5,330 \\
\hline
\end{tabular}

Panel B: Legislative Effort

\begin{tabular}{|c|c|c|c|c|}
\hline & (1) & (2) & (3) & (4) \\
\hline & $\begin{array}{c}\text { \% Votes } \\
\text { Against } \\
\text { Gov. }\end{array}$ & $\begin{array}{l}\text { Investigation } \\
\text { Inquiries } \\
\text { Filed } \\
\end{array}$ & $\begin{array}{c}\text { Drafts of } \\
\text { Legislation }\end{array}$ & $\begin{array}{l}\text { Formal } \\
\text { Queries }\end{array}$ \\
\hline $\begin{array}{l}\text { Immunity Lifted } \\
\times \text { Post }\end{array}$ & $\begin{array}{c}-2.06 * * \\
(0.96) \\
{[0.05]}\end{array}$ & $\begin{array}{c}-0.39 * * * \\
(0.15) \\
{[0.02]} \\
\end{array}$ & $\begin{array}{l}-0.38^{*} \\
(0.22) \\
{[0.10]} \\
\end{array}$ & $\begin{array}{c}0.07 \\
(2.31) \\
{[0.97]} \\
\end{array}$ \\
\hline $\mathrm{N}$ & 5,330 & 5,330 & 5,330 & 5,330 \\
\hline
\end{tabular}

Panel C: First Principal Components

\begin{tabular}{cccc}
\hline & $(1)$ & $(2)$ & $(3)$ \\
\hline & $1^{\text {st }}$ PC of & $1^{\text {st }}$ PC of & $1^{\text {st }}$ PC of Effort in \\
& All Effort & Speech & Other Legislative \\
& Measures & Outcomes & Activities \\
\hline Immunity Lifted & $-0.75^{* * *}$ & $-0.57 * *$ & $-0.45^{* * *}$ \\
$\times$ Post & $(0.26)$ & $(0.25)$ & $(0.17)$ \\
& {$[0.02]$} & {$[0.04]$} & {$[0.02]$} \\
\hline $\mathrm{N}$ & 5,330 & 5,330 & 5,330 \\
\hline
\end{tabular}

See notes to Table 4.

The results pertain to the same specification and the sample as in Table 4, with the addition of the interaction between Post dummy and MP attributes: Age, Female, and MA/PhD. 


\section{Appendix Table A7 \\ The Impact of Losing Immunity on MPs' Attendance to the Parliament}

\begin{tabular}{lcc}
\hline & Whole Sample & Opposition Parties \\
\hline & $(1)$ & $(2)$ \\
\hline & Days Attended & Days Attended \\
\hline Immunity Lifted & $0.39 * * *$ & 0.05 \\
$\times$ Post & $(0.06)$ & $(0.05)$ \\
\hline $\mathrm{N}$ & 15,317 & 5,330 \\
\hline
\end{tabular}

Immunity Lifted is the treatment indicator that is equal to one if the immunity of the MP (Member of the Parliament) was stripped off in May 2016. Post stands for the post-treatment period. Columns 1 and 2 pertain to the whole sample of MPs and opposition party MPs, respectively. The outcome is the number of days on which the MP attended the meetings in Parliament. The unit of observation is an MP-month. All regressions include MP fixed effects and month-by-year dummies. Standard errors, clustered at the MP level, are in parentheses. ${ }^{* * *}$, **, and * indicate statistical significance at $1 \%, 5 \%$ and $10 \%$ levels. 


Appendix Table A8
The Impact of Losing Immunity on MPs' Legislative Activities
(Opposition MPs who served continuously in the $\mathbf{2 6}^{\text {th }}$ Parliament)
Panel A: Speech Outcomes

Panel B: Legislative Effort

\begin{tabular}{|c|c|c|c|c|}
\hline & (1) & (2) & (3) & (4) \\
\hline & $\begin{array}{c}\text { \% Votes } \\
\text { Against } \\
\text { Gov. }\end{array}$ & $\begin{array}{c}\text { Investigation } \\
\text { Inquiries } \\
\text { Filed } \\
\end{array}$ & $\begin{array}{c}\text { Drafts of } \\
\text { Legislation }\end{array}$ & $\begin{array}{l}\text { Formal } \\
\text { Queries }\end{array}$ \\
\hline $\begin{array}{l}\text { Immunity Lifted } \\
\times \text { Post }\end{array}$ & $\begin{array}{l}-2.05 * \\
(1.07) \\
{[0.08]}\end{array}$ & $\begin{array}{c}-0.41 * * \\
(0.16) \\
{[0.02]}\end{array}$ & $\begin{array}{l}-0.44^{*} \\
(0.23) \\
{[0.08]} \\
\end{array}$ & $\begin{array}{c}0.22 \\
(2.63) \\
{[0.93]} \\
\end{array}$ \\
\hline $\mathrm{N}$ & 4,977 & 4,977 & 4,977 & 4,977 \\
\hline
\end{tabular}

Panel C: First Principal Components

\begin{tabular}{cccc}
\hline & $(1)$ & $(2)$ & $(3)$ \\
\hline & $1^{\text {st }}$ PC of & $1^{\text {st }}$ PC of & $1^{\text {st }}$ PC of Effort in \\
& All Effort & Speech & Other Legislative \\
& Measures & Outcomes & Activities \\
\hline Immunity Lifted & $-0.56^{* * *}$ & $-0.34^{* * *}$ & $-0.49 * * *$ \\
$\times$ Post & $(0.18)$ & $(0.12)$ & $(0.18)$ \\
& {$[0.01]$} & {$[0.02]$} & {$[0.02]$} \\
\hline $\mathrm{N}$ & 4,977 & 4,977 & 4,977 \\
\hline
\end{tabular}

See notes to Table 4. The results pertain to the same specification and the sample as in Table 4, but 15 opposition MPs who stopped attending the Parliament are dropped. One of these MPs has resigned; the other 14 stopped attending because they were arrested or convicted following the revocation of their immunity. 


\begin{tabular}{ccccc}
$\begin{array}{c}\text { Appendix Table A9 } \\
\text { The Impact of Losing Immunity on Opposition MPs' Legislative Activities } \\
\text { Controlling for the Impact of the Post-Coup Period } \\
\text { Panel A: Speech Outcomes }\end{array}$ \\
\hline & $(1)$ & $(2)$ & $(3)$ & $(4)$ \\
\hline & Speeches & Words & $\begin{array}{c}\text { Thterruptions } \\
\text { Targeting }\end{array}$ & $\begin{array}{c}\text { Interruptions } \\
\text { Targeting }\end{array}$ \\
& & & Gov. MPs & Non-Gov. MPs \\
\hline $\begin{array}{c}\text { Immunity Lifted } \\
\text { × Post Treatment }\end{array}$ & -4.26 & -285.83 & $-1.68^{* * *}$ & $-0.36 * * *$ \\
& $(3.73)$ & $(210.77)$ & $(0.47)$ & $(0.10)$ \\
Immunity Lifted & $\{0.60\}$ & $\{0.40\}$ & $\{0.06\}$ & $\{0.03\}$ \\
$\quad \times$ Post Coup & $-6.43^{*}$ & -290.01 & -0.38 & -0.07 \\
\hline $\mathrm{N}$ & $(3.62)$ & $(187.72)$ & $(0.28)$ & $(0.10)$ \\
\hline
\end{tabular}

\section{Panel B: Legislative Effort}

\begin{tabular}{|c|c|c|c|c|}
\hline & (1) & (2) & (3) & (4) \\
\hline & $\begin{array}{c}\text { \% Votes } \\
\text { Against } \\
\text { Gov. }\end{array}$ & $\begin{array}{l}\text { Investigation } \\
\text { Inquiries } \\
\text { Filed }\end{array}$ & $\begin{array}{c}\text { Drafts of } \\
\text { Legislation }\end{array}$ & $\begin{array}{l}\text { Formal } \\
\text { Queries }\end{array}$ \\
\hline $\begin{array}{l}\text { Immunity Lifted } \\
\text { × Post Treatment }\end{array}$ & $\begin{array}{l}-2.91 * \\
(1.67) \\
\{0.20\}\end{array}$ & $\begin{array}{c}-0.34^{* * *} \\
(0.02) \\
\{0.02\}\end{array}$ & $\begin{array}{c}-0.52 * * \\
(0.20) \\
\{0.17\}\end{array}$ & $\begin{array}{l}-0.70 \\
(0.59) \\
\{0.44\}\end{array}$ \\
\hline $\begin{array}{l}\text { Immunity Lifted } \\
\times \text { Post Coup }\end{array}$ & $\begin{array}{c}0.92^{* * *} \\
(0.29)\end{array}$ & $\begin{array}{l}-0.06 \\
(0.04)\end{array}$ & $\begin{array}{c}0.16^{* * * *} \\
(0.03)\end{array}$ & $\begin{array}{c}0.86 \\
(0.86)\end{array}$ \\
\hline $\mathrm{N}$ & 5,330 & 5,330 & 5,330 & 5,330 \\
\hline
\end{tabular}

Panel C: First Principal Components

\begin{tabular}{cccc}
\hline & $(1)$ & $(2)$ & $(3)$ \\
\hline & $1^{\text {st }}$ PC of & $1^{\text {st }}$ PC of & $1^{\text {st }}$ PC of Effort in \\
& All Effort & Speech & Other Legislative \\
& Measures & Outcomes & Activities \\
\hline Immunity Lifted & $-0.63^{* * *}$ & $-0.39^{*}$ & $-0.52^{* * *}$ \\
$\times$ Post Treatment & $(0.18)$ & $(0.19)$ & $(0.10)$ \\
& $\{0.05\}$ & $\{0.08\}$ & $\{0.07\}$ \\
Immunity Lifted & -0.20 & -0.28 & $0.08^{* *}$ \\
$\quad \times$ Post Coup & $(0.16)$ & $(0.17)$ & $(0.04)$ \\
\hline $\mathrm{N}$ & 5,330 & 5,330 & 5,330 \\
\hline
\end{tabular}

See notes to Table 4. The results pertain to the same specification and the sample as in Table 4, with the addition of the interaction of Immunity Lifted and Post Coup dummy, where the latter variable equals one for the period after the coup attempt. The p-values that are obtained from the wild t bootstrap method are presented in \{curly brackets. 


\section{Appendix Table A10}

The Impact of Losing Immunity on MPs' Legislative Activities Controlling for the Impact of Executive Orders Panel A: Speech Outcomes

\begin{tabular}{lcccc}
\hline & $(1)$ & $(2)$ & $(3)$ & $(4)$ \\
\hline & Speeches & Words & $\begin{array}{c}\text { Interruptions } \\
\text { Targeting } \\
\text { Gov. MPs }\end{array}$ & $\begin{array}{c}\text { Interruptions } \\
\text { Targeting } \\
\text { Non-Gov. MPs }\end{array}$ \\
\hline Immunity Lifted & -9.76 & -549.22 & $-1.96^{* * *}$ & $-0.40^{*}$ \\
$\quad \times$ Post & $(6.13)$ & $(335.09)$ & $(0.60)$ & $(0.21)$ \\
& {$[0.12]$} & {$[0.12]$} & {$[0.01]$} & {$[0.09]$} \\
Immunity Lifted & -2.03 & -4.45 & -0.40 & -0.17 \\
$\quad \times$ Exec. Orders & $(1.58)$ & $(103.70)$ & $(0.36)$ & $(0.15)$ \\
\hline $\mathrm{N}$ & 5,330 & 5,330 & 5,330 & 5,330 \\
\hline
\end{tabular}

Panel B: Legislative Effort

\begin{tabular}{|c|c|c|c|c|}
\hline & (1) & (2) & (3) & (4) \\
\hline & $\begin{array}{c}\text { \% Votes } \\
\text { Against } \\
\text { Gov. }\end{array}$ & $\begin{array}{l}\text { Investigation } \\
\text { Inquiries } \\
\text { Filed }\end{array}$ & $\begin{array}{l}\text { Drafts of } \\
\text { Legislation }\end{array}$ & $\begin{array}{l}\text { Formal } \\
\text { Queries }\end{array}$ \\
\hline $\begin{array}{l}\text { Immunity Lifted } \\
\times \text { Post }\end{array}$ & $\begin{array}{c}-2.09 * * \\
(1.01) \\
{[0.07]}\end{array}$ & $\begin{array}{c}-0.42 * * * \\
(0.15) \\
{[0.02]}\end{array}$ & $\begin{array}{l}-0.38^{*} \\
(0.21) \\
{[0.09]}\end{array}$ & $\begin{array}{c}0.04 \\
(2.23) \\
{[0.99]}\end{array}$ \\
\hline $\begin{array}{l}\text { Immunity Lifted } \\
\times \text { Exec. Orders } \\
\end{array}$ & $\begin{array}{c}0.05 \\
(0.36) \\
\end{array}$ & $\begin{array}{c}0.11 \\
(0.10) \\
\end{array}$ & $\begin{array}{c}0.06 \\
(0.04)\end{array}$ & $\begin{array}{c}0.31 \\
(1.15) \\
\end{array}$ \\
\hline $\mathrm{N}$ & 5,330 & 5,330 & 5,330 & 5,330 \\
\hline
\end{tabular}

Panel C: First Principal Components

\begin{tabular}{cccc}
\hline & $(1)$ & $(2)$ & $(3)$ \\
\hline & $1^{\text {st }}$ PC of & $1^{\text {st }}$ PC of & $1^{\text {st }}$ PC of Effort in \\
& All Effort & Speech & Other Legislative \\
& Measures & Outcomes & Activities \\
\hline Immunity Lifted & $-0.81^{* * *}$ & $-0.62^{* *}$ & $-0.47^{* * *}$ \\
$\times$ Post & $(0.29)$ & $(0.30)$ & $(0.17)$ \\
& {$[0.02]$} & {$[0.07]$} & {$[0.02]$} \\
Immunity Lifted & -0.04 & -0.10 & 0.11 \\
$\quad \times$ Exec. Orders & $(0.10)$ & $(0.09)$ & $(0.10)$ \\
\hline $\mathrm{N}$ & 5,330 & 5,330 & 5,330 \\
\hline
\end{tabular}

See notes to Table 4. The results pertain to the same specification and the sample as in Table 4, with the addition of the interaction of Immunity Lifted and Executive Orders, where the latter variable represents the number of executive orders issues each month following the coup attempt (see Appendix Figure AF1). 
Appendix Table A11

The Impact of Losing Immunity on MPs' Legislative Activities During the Period before the Coup Attempt (All MPs)

Panel A: Speech Outcomes

\begin{tabular}{|c|c|c|c|c|}
\hline & (1) & (2) & (3) & (4) \\
\hline & Speeches & Words & $\begin{array}{lr}\text { nterruptions } & \text { I } \\
\text { Targeting } & \\
\text { Gov. MPs } & \text { N }\end{array}$ & $\begin{array}{l}\text { Interruptions } \\
\text { Targeting } \\
\text { Non-Gov. MPs }\end{array}$ \\
\hline $\begin{array}{l}\text { Immunity Lifted } \\
\times \text { Post }\end{array}$ & $\begin{array}{l}-2.19 \\
(2.97) \\
{[0.56]}\end{array}$ & $\begin{array}{c}-157.24 \\
(165.76) \\
{[0.47]}\end{array}$ & $\begin{array}{c}-0.79 * * \\
(0.35) \\
{[0.06]}\end{array}$ & $\begin{array}{c}0.42 \\
(0.36) \\
{[0.45]}\end{array}$ \\
\hline $\mathrm{N}$ & 3,850 & 3,850 & 3,850 & 3,850 \\
\hline \multicolumn{5}{|c|}{ Panel B: Legislative Effort } \\
\hline & (1) & (2) & (3) & (4) \\
\hline & $\begin{array}{c}\text { \% Votes } \\
\text { Against } \\
\text { Gov. }\end{array}$ & $\begin{array}{l}\text { Investigation } \\
\text { Inquiries } \\
\text { Filed }\end{array}$ & $\begin{array}{l}\text { Drafts of } \\
\text { Legislation }\end{array}$ & $\begin{array}{l}\text { Formal } \\
\text { Queries }\end{array}$ \\
\hline $\begin{array}{l}\text { Immunity Lifted } \\
\times \text { Post }\end{array}$ & $\begin{array}{l}-0.38 \\
(1.34) \\
{[0.78]}\end{array}$ & $\begin{array}{l}-0.20 * * \\
(0.09) \\
{[0.06]}\end{array}$ & $\begin{array}{l}-0.38^{* *} \\
(0.16) \\
{[0.06]}\end{array}$ & $\begin{array}{c}0.14 \\
(0.39) \\
{[0.78]}\end{array}$ \\
\hline $\mathrm{N}$ & 3,850 & 3,850 & 3,850 & 3,850 \\
\hline
\end{tabular}

Panel C: First Principal Components

\begin{tabular}{lccc}
\hline & $(1)$ & $(2)$ & $(3)$ \\
\hline & $1^{\text {st }}$ PC of & $1^{\text {st }}$ PC of & $1^{\text {st }}$ PC of Effort in \\
& All Effort & Speech & Other Legislative \\
& Measures & Outcomes & Activities \\
\hline Immunity Lifted & $-0.32^{* *}$ & -0.15 & $-0.32^{* * *}$ \\
$\times$ Post & $(0.15)$ & $(0.15)$ & $(0.11)$ \\
& {$[0.06]$} & {$[0.47]$} & {$[0.03]$} \\
\hline $\mathrm{N}$ & 3,850 & 3,850 & 3,850 \\
\hline
\end{tabular}

Immunity Lifted is the treatment indicator which is equal to one if the immunity of the MP was stripped off in May 2016. Post stands for the post-treatment period. Outcomes: Panel A: (1) Number of speeches delivered on the Parliament floor by the MP; (2) Number of words in those speeches; (3) Number of times the MP interrupted the speech of another MP who is a member of the government party; (4) Number of times an MP interrupted the speech of another MP who is a member of the opposition parties. Panel B: (1) \% of the rollcall votes the MP voted the same way as the majority of the government party; (2) the number of times the MP filed an investigation inquiry into the activities of the government (3) the number of bills sponsored by the MP; (4) the number of times MP passed a formal query to the members of the government. Panel C: (1) first principal component of all outcomes in Panels A and B; (2) first principal component of outcomes in Panel A; (3) first principal component of outcomes in Panel B. The unit of observation is an MP-month. All regressions include MP fixed effects and month-by-year dummies. Standard errors, clustered at the MP level, are in parentheses. $* * *, * *$, and * indicate statistical significance at $1 \%$, $5 \%$ and $10 \%$ levels. P-values, adjusted for multiple hypothesis testing, are displayed in [brackets]. 


\section{Appendix Section 2: Have Outspoken “Troublemaker” MPs been Targeted?}

The estimates in the paper have a causal interpretation if the MPs in the treatment group and those in the control group are counterfactuals to one another. That average MP characteristics, such as age, sex, and education, do not depend on their immunity status (see Appendix Table A1) is reassuring. However, as shown in the Panels of Appendix Table A2, those MPs who lost their immunity were more active in Parliament before the enactment of the Constitutional Amendment in May 2016. It can be argued that the MPs who were more outspoken and more active in the Parliament could have been targeted for having their immunity being lifted. That is, charges could have been filed against these MPs by their political opponents to pave the way to lift their immunity.

Note that, in this scenario, some MPs have personal attributes that make them formidable and fiery opposition members (who speak more and interrupt others more frequently, who file investigation inquiries against the government more often, and so on). At the same time, these character attributes make them more likely targets for immunity revocation. In this case, we would underestimate the impact of immunity on MPs' activities, and the results reported in Table 4 would be biased towards zero.

Nevertheless, to investigate the validity of this conjecture, we used the $1^{\text {st }}$ Principal Component ( $1^{\text {st }} \mathrm{PC}$ ) of all eight activities (see Panel C of Tables 3-6). For each MP, we calculated the average value of the $1^{\text {st }}$ PC over the months until May 2016, which represents a summary of the Parliamentary activity of each MP until the enactment of the Constitutional Amendment. Ranking all 550 MPs of the Parliament by this average enables us to order them by the intensity of their Parliamentary activities before the "treatment." There are 138 MPs in the top quartile (550/4) of this activity distribution. Of these, 79 MPs are members of the opposition parties, and 43 of them (54\%) lost their immunity. There are 137 MPs in the second quartile of pre-treatment activity. Fifty-six percent of these (77 MPs) are members of the opposition parties, and 35 of the 77 lost their immunity. Similarly, there are 37 opposition MPs in the $3^{\text {rd }}$ quartile, and 21 of them (58\%) lost their immunity.

This information, which is displayed in Appendix Table A12 (and also graphically below the table), indicates that the proportion of the opposition MPs who lost their immunity is similar between the three quartiles of Parliamentary pre-activity distribution. Put differently, opposition MPs who are more outspoken, aggressive, and active (those who are in the top quartile of pretreatment Parliamentary activity) have not lost their Parliamentary immunity disproportionally. 
Note that there are no opposition MPs in the bottom quartile of the activity distribution, which is partly the reflection that there are 85 percent more government bloc MPs in the Parliament in comparison to the number of opposition MPs (357 vs. 193), but also because opposition MPs have been more active in the Parliament. ${ }^{35}$

Appendix Table A13 presents the estimation results obtained from the sample of the opposition MPs who were most active (i.e., in the top quartile of the activity distribution) before the enactment of the Constitutional amendment. The results are consistent with the ones reported in Table 4 and indicate that revocation of immunity has muted these MPs as well and reduced their effort in Parliament. The coefficient estimates are larger in Appendix Table A13, but the mean values of the outcomes are also proportionately larger because the MPs in this sample are more active than the rest of the MPs.

\section{Are "More Valuable MPs" of the Opposition Parties Targeted?}

In the closed-list proportional representation election system used in Turkey, voters cast their votes for political parties and not for the candidates. Each party submits a list of " $N$ " candidates in a given province (which is an election district), where $\mathrm{N}$ is the number of contested MP seats. Parties announce the rank of their candidates in descending order, where candidate Number 1 (Number $\mathrm{N}$ ) is the first (last) person who would be an MP from that party in that province. The vote share of each party determines the number of MP seats won by that party in that province, which in turn determines who on the party list becomes an MP. Parties typically rank their more senior and important/valuable candidates higher on their list as higher-ranked candidates are more likely to get elected. For example, party leaders are ranked at the top of the party list in their respective provinces.

Appendix Table A14 and the graphs below the table present the distribution of the 193 opposition MPs by their immunity status and their rank on their party ticket in their province. Seventy-six MPs were ranked at the top of their lists. Thirty-nine MPs of this group lost immunity (51\%), and 37 MPs (49\%) retained it. Of the 39 MPs who were ranked second, 21 lost

\footnotetext{
${ }^{35}$ A regression of whether an opposition MP's immunity is lifted on an indicator of whether that MP was in the top quartile of the pre-treatment activity distribution and party fixed effects generated a coefficient of 0.05 (se=0.07). When we included two indicators for being in the top quartile of the activity distribution and for being in the second quartile, the estimates were $-0.02(\mathrm{se}=0.10)$ and -0.11 (se $=0.10)$, respectively.
} 
immunity, and 18 retained it. Half of those who are ranked third or lower on their party ticket lost immunity (39/78), while the other half retained it. Thus, there is no indication that higherranked opposition MPs have been targeted. ${ }^{36}$

Appendix Table A15 displays the results of the performance regressions in the sample of top-ranked opposition MPs. The impact of losing immunity is always negative. The magnitudes of the point estimates are similar to those obtained from the full sample of opposition MPs reported in Table 4, although the precision of the estimates is lower, likely because of the small sample size. This finding indicates that MPs, who are top-ranked on their party tickets and who are party leaders in their respective cities, respond to the loss of immunity no differently than other MPs.

${ }^{36}$ A regression of immunity status on an indicator of whether an opposition MP was at the top of the party ticket generated a coefficient of 0.00 (se=0.07). When we included two indicators for being ranked at the top of the ticket and as the second candidate on the ticket, the estimates were $0.01(\mathrm{se}=0.08)$ and 0.04 (se=0.10), respectively. 
Appendix Table A12

Distribution of Opposition MPs by Immunity Status and Pre-Treatment Activity

\begin{tabular}{lcccc}
\hline & $\begin{array}{c}\text { Top } \\
\text { Quartile }\end{array}$ & $\begin{array}{c}\text { Second } \\
\text { Quartile }\end{array}$ & $\begin{array}{c}\text { Third } \\
\text { Quartile }\end{array}$ & $\begin{array}{c}\text { Bottom } \\
\text { Quartile }\end{array}$ \\
\hline Immunity Lifted & 43 & 35 & 21 & 0 \\
Immunity Retained & 36 & 42 & 16 & 0 \\
\hline $\begin{array}{l}\text { Number of Opposition } \\
\text { MPs in the Quartile }\end{array}$ & 79 & 77 & 37 & 0 \\
\hline
\end{tabular}

Activity is measured by the $1^{\text {st }}$ Principle Component of all 8 outcomes, averaged during the pre-treatment period (before May 2016). The ranking of all 550 MPs enables the determination of the MPs within the quartiles of the Activity distribution.
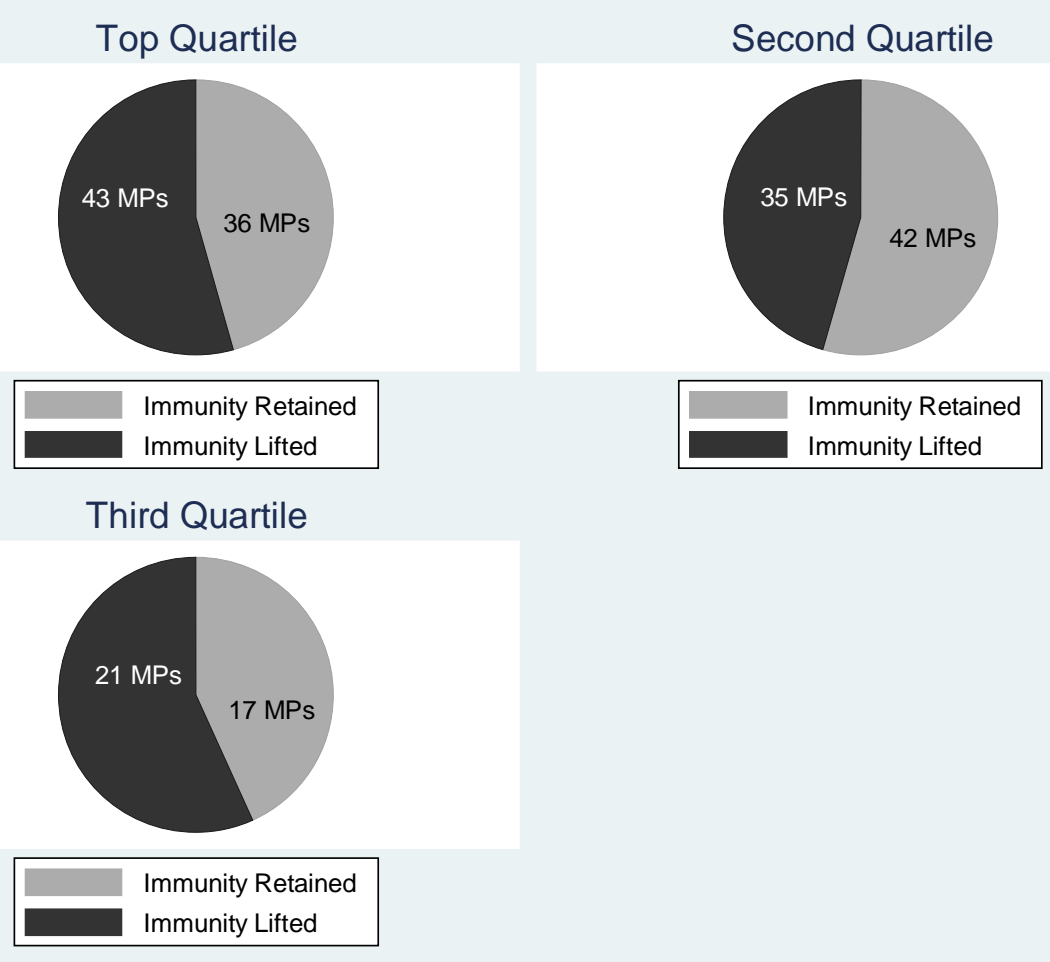


\begin{tabular}{|c|c|c|c|c|}
\hline $\begin{array}{l}\text { The Impact of I } \\
\text { Opposition MPs in the Top }\end{array}$ & $\begin{array}{r}\text { Appe } \\
\text { osing Imm } \\
\text { uartile in } 1 \\
\text { Panel A: }\end{array}$ & $\begin{array}{l}\text { dix Table } \\
\text { Inity on M } \\
\text { le Distribu } \\
\text { Speech Ou }\end{array}$ & $\begin{array}{l}13 \\
\text { s' Legislative } \\
\text { on of Pre-Tr } \\
\text { omes }\end{array}$ & $\begin{array}{l}\text { Activities } \\
\text { atment Period Ac }\end{array}$ \\
\hline & (1) & (2) & (3) & (4) \\
\hline & Speeches & Words & $\begin{array}{l}\text { Interruptions } \\
\text { Targeting } \\
\text { Gov. MPs } \\
\end{array}$ & $\begin{array}{c}\text { Interruptions } \\
\text { Targeting } \\
\text { Non-Gov. MPs }\end{array}$ \\
\hline $\begin{array}{l}\text { Immunity Lifted } \\
\times \text { Post }\end{array}$ & $\begin{array}{c}-24.43^{*} \\
(14.17) \\
{[0.11]}\end{array}$ & $\begin{array}{c}-1414.53^{*} \\
(758.52) \\
{[0.10]}\end{array}$ & $\begin{array}{c}-4.65 * * * \\
(1.32) \\
{[0.01]}\end{array}$ & $\begin{array}{c}-0.98 * * \\
(0.48) \\
{[0.08]}\end{array}$ \\
\hline $\mathrm{N}$ & 2,188 & 2,188 & 2,188 & 2,188 \\
\hline Mean of the Outcome & 21.61 & 2045.13 & 3.70 & 0.94 \\
\hline
\end{tabular}

Panel B: Legislative Effort

\begin{tabular}{lcccc}
\hline & $(1)$ & $(2)$ & $(3)$ & $(4)$ \\
\hline & $\begin{array}{l}\text { \% Votes } \\
\text { Against } \\
\text { Gov. }\end{array}$ & $\begin{array}{c}\text { Investigation } \\
\text { Inquiries } \\
\text { Filed }\end{array}$ & $\begin{array}{c}\text { Drafts of } \\
\text { Legislation }\end{array}$ & $\begin{array}{c}\text { Formal } \\
\text { Queries }\end{array}$ \\
\hline Immunity Lifted & -1.61 & $-0.95^{* * *}$ & $-0.76^{*}$ & -0.58 \\
$\times$ Post & $(2.00)$ & $(0.32)$ & $(0.45)$ & $(5.65)$ \\
& {$[0.46]$} & {$[0.02]$} & {$[0.11]$} & {$[0.92]$} \\
\hline $\mathrm{N}$ & 2,188 & 2,188 & 2,188 & 2,188 \\
\hline Mean of the Outcome & 96.07 & 0.81 & 0.59 & 9.59 \\
\hline
\end{tabular}

Panel C: First Principal Components

\begin{tabular}{lccc}
\hline & $(1)$ & $(2)$ & $(3)$ \\
\hline & $1^{\text {st }}$ PC of & $1^{\text {st }}$ PC of & $1^{\text {st }}$ PC of Effort in \\
& All Effort & Speech & Other Legislative \\
& Measures & Outcomes & Activities \\
\hline Immunity Lifted & $-1.91^{* * *}$ & $-1.54^{* *}$ & $-1.01^{* * *}$ \\
$\times$ Post & $(0.65)$ & $(0.68)$ & $(0.36)$ \\
& {$[0.02]$} & {$[0.06]$} & {$[0.02]$} \\
\hline $\mathrm{N}$ & 2,188 & 2,188 & 2,188 \\
\hline Mean of the Outcome & 1.47 & 1.06 & 1.07 \\
\hline
\end{tabular}

See notes to Table 4. The results pertain to the same specification and the sample as in Table 4. The sample contains opposition MPs who are in the top quartile of the pre-treatment period activity distribution. There are 79 opposition MPs in the sample, 43 of which are treated by immunity revocation. Activity is measured by the $1^{\text {st }}$ Principle Component of all 8 outcomes, averaged during the pre-treatment period. 


\section{Appendix Table A14}

Distribution of Opposition MPs by Immunity Status and Rank on Their Parties' Tickets

\begin{tabular}{lcccc}
\hline & $\begin{array}{c}\text { Top } \\
\text { Ranked }\end{array}$ & $\begin{array}{c}\text { Second } \\
\text { Ranked }\end{array}$ & $\begin{array}{c}\text { Third } \\
\text { Ranked }\end{array}$ & $\begin{array}{c}\text { Ranked } 4^{\text {th }} \\
\text { or Lower }\end{array}$ \\
\hline Immunity Lifted & 39 & 21 & 16 & 23 \\
Immunity Retained & 37 & 18 & 12 & 27 \\
\hline Total MPs & 76 & 39 & 28 & 50 \\
\hline
\end{tabular}

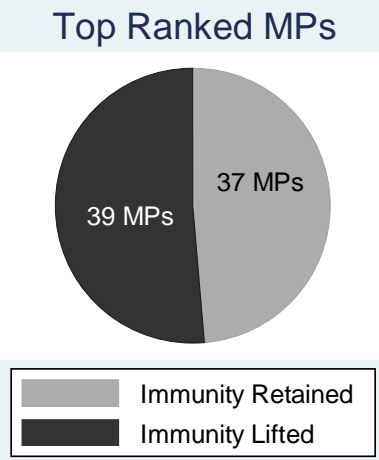

Third Ranked MPs

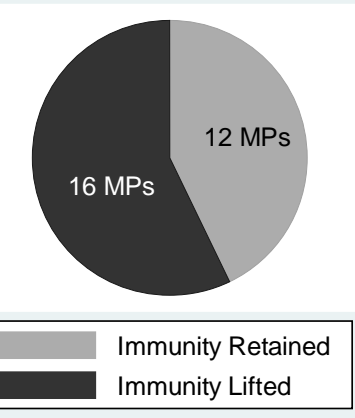

Second Ranked MPs

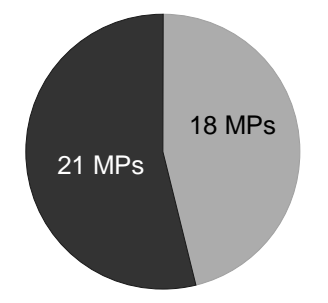

Immunity Retained Immunity Lifted

MPs Ranked 4th or Lower

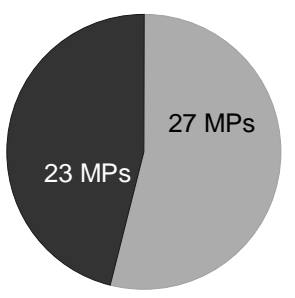

Immunity Retained

Immunity Lifted 
Appendix Table A15

The Impact of Losing Immunity on MPs’ Legislative Activities

Top Ranked Opposition MPs

Panel A: Speech Outcomes

\begin{tabular}{lcccc}
\hline & $(1)$ & $(2)$ & $(3)$ & $(4)$ \\
\hline & Speeches & Words & $\begin{array}{c}\text { Interruptions } \\
\text { Targeting } \\
\text { Gov. MPs }\end{array}$ & $\begin{array}{c}\text { Interruptions } \\
\text { Targeting } \\
\text { Non-Gov. MPs }\end{array}$ \\
\hline $\begin{array}{lcccc}\text { Immunity Lifted } \\
\times \text { Post }\end{array}$ & -17.30 & -1106.39 & $-2.77^{* *}$ & -0.71 \\
& $(15.20)$ & $(822.49)$ & $(1.24)$ & $(0.51)$ \\
\hline $\mathrm{N}$ & {$[0.27]$} & {$[0.22]$} & {$[0.14]$} & {$[0.22]$} \\
\hline Mean of the Outcome & 12,092 & 2,092 & 2,092 & 2,092 \\
\hline
\end{tabular}

Panel B: Legislative Effort

\begin{tabular}{lcccc}
\hline & $(1)$ & $(2)$ & $(3)$ & $(4)$ \\
\hline & $\begin{array}{c}\text { \% Votes } \\
\text { Against } \\
\text { Gov. }\end{array}$ & $\begin{array}{c}\text { Investigation } \\
\text { Inquiries } \\
\text { Filed }\end{array}$ & $\begin{array}{c}\text { Drafts of } \\
\text { Legislation }\end{array}$ & $\begin{array}{c}\text { Formal } \\
\text { Queries }\end{array}$ \\
\hline Immunity Lifted & -2.69 & $-0.50^{* *}$ & $-0.44^{*}$ & -3.67 \\
$\times$ Post & $(1.93)$ & $(0.24)$ & $(0.25)$ & $(3.29)$ \\
& {$[0.22]$} & {$[0.14]$} & {$[0.18]$} & {$[0.27]$} \\
\hline $\mathrm{N}$ & 2,092 & 2,092 & 2,092 & 2,092 \\
\hline Mean of the Outcome & 96.73 & 0.42 & 0.30 & 4.98 \\
\hline
\end{tabular}

Panel C: First Principal Components

\begin{tabular}{lccc}
\hline & $(1)$ & $(2)$ & $(3)$ \\
\hline & $1^{\text {st }}$ PC of & $1^{\text {st }}$ PC of & $1^{\text {st }}$ PC of Effort in \\
& All Effort & Speech & Other Legislative \\
& Measures & Outcomes & Activities \\
\hline $\begin{array}{l}\text { Immunity Lifted } \\
\times \text { Post }\end{array}$ & $-1.29^{*}$ & -1.07 & $-0.66^{* *}$ \\
& $(0.68)$ & $(0.74)$ & $(0.29)$ \\
& {$[0.17]$} & {$[0.22]$} & {$[0.14]$} \\
\hline $\mathrm{N}$ & 2,092 & 2,092 & 2,092 \\
\hline Mean of the Outcome & 0.63 & 0.40 & 0.55 \\
\hline
\end{tabular}

See notes to Table 4. The results pertain to the same specification and the sample as in Table 4. The sample contains opposition MPs who are in the top-ranked in their parties' tickets. There are 76 such opposition MPs in the sample, 39 of which are treated by immunity revocation. 
Appendix Table A16

Models that Account for MPs' Pre-treatment Level Parliamentary Activity

Panel A: Speech Outcomes

\begin{tabular}{ccccc}
\hline & $(1)$ & $(2)$ & $(3)$ & $(4)$ \\
\hline & Speeches & Words & $\begin{array}{c}\text { Interruptions } \\
\text { Targeting Gov. MPs }\end{array}$ & $\begin{array}{c}\text { Interruptions Targeting } \\
\text { Non-Gov. MPs }\end{array}$ \\
\hline Immunity lifted & -9.53 & -505.52 & $-1.92^{* * *}$ & $-0.41^{* *}$ \\
$\quad \times$ Post & $(5.91)$ & $(321.36)$ & $(0.58)$ & $(0.20)$ \\
& {$[0.13]$} & {$[0.13]$} & {$[0.01]$} & {$[0.07]$} \\
Pre-activity 25-50 & $14.84^{*}$ & $1292.44^{* * *}$ & $2.94^{* * *}$ & 0.42 \\
$\quad \times$ Post & $(7.82)$ & $(421.15)$ & $(0.75)$ & $(0.26)$ \\
Pre-activity 50-75 & $12.77^{*}$ & $948.25^{* *}$ & $2.59^{* * *}$ & 0.38 \\
$\quad \times$ Post & $(7.27)$ & $(393.82)$ & $(0.70)$ & $(0.25)$ \\
\hline $\mathrm{N}$ & 5330 & 5330 & 5330 & 5330 \\
\hline
\end{tabular}

Panel B: Legislative Effort

\begin{tabular}{lcccc}
\hline & $(1)$ & $(2)$ & $(3)$ & $(4)$ \\
\hline & \% Votes Against & Investigation & Drafts of & Formal \\
& Gov. & Inquiries Filed & Legislation & Queries \\
\hline Immunity lifted & $-2.08^{* *}$ & $-0.38^{* * *}$ & $-0.32^{*}$ & -0.21 \\
$\quad \times$ Post & $(0.97)$ & $(0.13)$ & $(0.19)$ & $(2.13)$ \\
& {$[0.07]$} & {$[0.02]$} & {$[0.12]$} & {$[0.92]$} \\
Pre-activity 25-50 & $-4.19^{* * *}$ & $0.59^{* * *}$ & $1.06^{* * *}$ & -2.69 \\
$\quad \times$ Post & $(1.06)$ & $(0.18)$ & $(0.24)$ & $(2.93)$ \\
Pre-activity 50-75 & $-2.16^{*}$ & $0.44^{* * *}$ & $0.97^{* * *}$ & -1.95 \\
$\quad \times$ Post & $(1.18)$ & $(0.16)$ & $(0.23)$ & $(2.61)$ \\
\hline $\mathrm{N}$ & 5330 & 5330 & 5330 & 5330 \\
\hline
\end{tabular}

Panel C: First Principal Components

\begin{tabular}{lccc}
\hline & $(1)$ & $(2)$ & $(3)$ \\
\hline & $1^{\text {st }}$ PC of & $1^{\text {st }}$ PC of & $1^{\text {st }}$ PC of Effort in \\
& All Effort & Speech & Other Legislative \\
& Measures & Outcomes & Activities \\
\hline Immunity lifted & $-0.76^{* * *}$ & $-0.60^{* *}$ & $-0.42^{* * *}$ \\
$\times$ post & $(0.28)$ & $(0.29)$ & $(0.16)$ \\
& {$[0.02]$} & {$[0.07]$} & {$[0.02]$} \\
Pre-activity 25-50 & $1.43^{* * *}$ & $1.07^{* * *}$ & $0.81^{* * *}$ \\
$\quad \times$ post & $(0.36)$ & $(0.38)$ & $(0.19)$ \\
Pre-activity 50-75 & $1.20^{* * *}$ & $0.88^{* *}$ & $0.70^{* * *}$ \\
$\quad \times$ post & $(0.34)$ & $(0.35)$ & $(0.19)$ \\
\hline $\mathrm{N}$ & 5330 & 5330 & 5330 \\
\hline
\end{tabular}

See notes to Table 4. The results pertain to the same specification and the sample as in Table 4, except that indicators that represent the interactions of MP's pre-treatment activity (see Appendix Table A12) with Post are included as control variables. 


\section{Appendix Section 3: Analyses of SUTVA Violations. Have the MPs who Retained Their Immunity Been Impacted by Those who Lost Immunity?}

To investigate whether the MPs who retained their immunity have adjusted their parliamentary activity in response to their colleagues' loss of immunity, we first focus on opposition MPs who retained their immunity, and we analyze whether the intensity of the parliamentary activities of these MPs (who are in the control group) have been positively impacted by having peers from the same party who lost immunity. We proxy the extra workload imposed (outsourced) on each MP (i) by the variable \% Immunity-Losing Peersipjt, which is calculated in each province for each party as (MPs who Lost Immunity from a Party \& Province $)_{p j}$ / (Total Number of MPs from the Party \& Province) $)_{p j}$, where $p$ and $j$ represent parties and provinces, respectively. ${ }^{37} \%$ Immunity-Losing Peersipjt is zero for all MPs in the control group until the enactment of the Constitutional Amendment. It then switches to a positive value if MP $i$ herself/himself retained immunity but has same-party colleagues from the same province who lost immunity. ${ }^{38}$ The reason for considering spillovers between MPs of a given party of the same province is that these MPs arguably would be concerned with the issues related to their province and that they could have a stronger rapport between them. We, however, also consider peer effects at the national level (see footnote 39 below).

Appendix Table A17 below displays the results obtained from a regression, which is the same as equation (1), except that the sample includes only the untreated MPs, and that instead of Immunity Lifted $\times$ Post variable, we include \% Immunity-Losing Peersipjt as the key explanatory variable. The sample contains 2,616 MP-month observations generated by those MPs who retained their immunity. As described above, \% Immunity-Losing Peers is zero for everyone until the Constitutional Amendment. The variable varies both between provinces and between parties after the enactment of the Constitutional Amendment. Most of the estimated coefficients in Appendix Table A17 are negative (as opposed to being positive), and none is different from zero. As shown in Panel C, aggregate indicators are not impacted either. Thus, the results

\footnotetext{
${ }^{37}$ For example, if an opposition party has 4 MPs from a city and if one of these MP's lost immunity, the variable takes the value of $1 / 4$ for the three MPs who retained immunity. If no MP lost immunity from that party in a city, the value of the variable for all MPs of that part from that city is equal to zero, reflecting no extra workload.

${ }^{38}$ In other words, this variable is the same as the product of the post-treatment dummy and the percent of immunity-losing MPs from the same city and province.
} 
indicate that having same-party colleagues who lost immunity has no impact on the work effort of those MPs who retained their immunity.

We also estimated an alternative specification, which utilizes all opposition MPs (those who lost immunity, as well as those who retained immunity). Thus, the sample used in this specification is identical to the one employed in the benchmark model (Table 4). We estimated the same specification as Equation (1), but we added a second "treatment," which is relevant only for those who are in the control group. Specifically, we estimated

$$
\begin{aligned}
Y_{\text {ipjt }}= & \gamma_{0}+\gamma_{1} \text { Immunity Lifted }_{\text {ipj }} \times \text { Post }_{t}+\gamma_{2} \% \text { Immunity }- \text { Losing Peers }_{\text {ipjt }}+ \\
& +\mu_{i}+m_{t}+\omega_{\text {ipjt }}
\end{aligned}
$$

where, as discussed earlier, \% Immunity-Losing Peers Iipjt $_{\text {is }}$ equal to zero for all MPs before the enactment of the Constitutional Amendment. It also equals zero after the amendment if the MP has lost his/her immunity (if Immunity Lifted=1), but it takes positive values if the MP has retained immunity and if she/he has peers who lost immunity. Thus, $\gamma_{1}$ represents the impact of losing immunity, and $\gamma_{2}$ is the impact of the extent of having peers from the same province and same party who lost immunity on those MPs who themselves retained immunity.

The results, which are reported in Appendix Table A18 below, reveal that potential extra workload, which could have been shouldered by the MPs who retained their immunity, has no impact on these MPs' parliamentary activities. This is because the coefficients of \% ImmunityLosing Peers are always very small and never statistically different from zero, indicating that the behavior of the MPs in the control group is not influenced by the extent to which their peers lose immunity. On the other hand, the coefficients of Immunity Lifted $\times$ Post are similar in magnitude and in statistical significance to those reported in Table 4. Thus, the results in Appendix Tables A17 and A18 indicate that lifting parliamentary immunity had an impact on the behavior of those MPs whose immunities have been lifted but that it had no spillover effects on those who retained their immunity. ${ }^{39}$

\footnotetext{
${ }^{39}$ The formulation of the variable \%Immunity-Losing Peers assumes that the MPs of a given party, who are elected from a particular province, share the extra workload created by the loss of immunity of colleague(s) who are also from the same party and the same province. Alternatively, it is also possible that colleagues of a given party pick up the slack regardless of whether those who lost immunity are from their own province. Therefore, we also calculated the variable \% Immunity-Losing Peers Ip $_{\text {at }}$ at the parliament level. This means that in each party, MPs who are in the control group (i.e., those who retained immunity) are assigned the same value, which is the ratio of those who lost immunity from their party to the total number of MPs in that party. With the proviso that in this formulation \% Immunity-
} 
Finally, we ran aggregate regressions at the party level. Here each political party contributes one observation per month, where the outcome variables are the 11 performance measures of the MPs of the party, averaged at the party level as shown by Equation (A2)

$$
Y_{p t}=\delta_{0}+\delta_{1} \% \text { Immunity Lifted }_{p} \times \text { Post }_{t}+\lambda_{p}+\delta_{2} \lambda_{p} \mathrm{x} t+v_{p t}
$$

where \% Immunity Lifted Im $_{p}$ is the proportion of the MPs who lost their immunity in party $p$. The regressions also include party fixed effects and a separate time trend for each party. The sample consists of 112 party-month observations ( 4 political parties $\times 28$ months). Under the assumption of complete outsourcing, the proportion of MPs who lost immunity from a party should have no impact on that party's Parliamentary activities, and $\delta_{1}$ should be zero. Similarly, under the hypothesis that MPs whose immunity are lifted are not impacted, while their immunity-intact peers increased their effort is true, then $\delta_{1}$ should be positive and significant. The results are displayed in Appendix Table A19. Party activities listed in Panel B are not impacted by MPs’ losing immunity, although the impact on \% Votes Against Government is large. The estimates on party-level speech-related outcomes, displayed in Panel A, are negative and statistically significant, and the same is true for the average of speech-related outcomes (Panel C, column 2) as well as the average of all eight outcomes (Panel C, column 1). Thus, consistent with the results presented in Tables A15 and A16, the results of Appendix Table A19 also indicate that there is no compelling evidence of notable shifting of Parliamentary activities from immunity-losing to immunity-retaining MPs.

Losing Peers suffers from lack of variation, consistent with the results of Appendix Tables A17 and A18, the impact of the \% Immunity-Losing Peers was not different from zero. 
Appendix Table A17

Spillover Impact on the Opposition MPs Who Retained Their Immunity Panel A: Speech Outcomes

\begin{tabular}{lcccc}
\hline & $(1)$ & $(2)$ & $(3)$ & $(4)$ \\
\hline Speeches & Words & $\begin{array}{c}\text { Interruptions } \\
\text { Targeting } \\
\text { Gov. MPs }\end{array}$ & $\begin{array}{c}\text { Interruptions } \\
\text { Targeting } \\
\text { Non-Gov. MPs }\end{array}$ \\
\hline $\begin{array}{l}\text { \% Immunity Lifted from } \\
\text { same Province \& Party }\end{array}$ & 1.83 & 25.82 & -0.94 & 0.18 \\
$\mathrm{~N}$ & 2616 & $(316.43)$ & $(1.40)$ & $(0.31)$ \\
\hline
\end{tabular}

Panel B: Legislative Effort

\begin{tabular}{lcccc}
\hline & $(1)$ & $(2)$ & $(3)$ & $(4)$ \\
\hline & $\begin{array}{c}\text { \% Votes } \\
\text { Against } \\
\text { Gov. }\end{array}$ & $\begin{array}{c}\text { Investigation } \\
\text { Inquiries } \\
\text { Filed }\end{array}$ & $\begin{array}{c}\text { Drafts of } \\
\text { Legislation }\end{array}$ & $\begin{array}{c}\text { Formal } \\
\text { Queries }\end{array}$ \\
\hline \% Immunity Lifted from & -3.85 & -0.25 & -0.45 & -6.95 \\
same Province \& Party & $(4.02)$ & $(0.30)$ & $(0.30)$ & $(7.03)$ \\
\hline $\mathrm{N}$ & 2616 & 2616 & 2616 & 2616 \\
\hline
\end{tabular}

Panel C: First Principal Components

\begin{tabular}{lccc}
\hline & $(1)$ & $(2)$ & $(3)$ \\
\hline & $1^{\text {st }}$ PC of & $1^{\text {st }}$ PC of & $1^{\text {st }}$ PC of Effort in \\
& All Effort & Speech & Other Legislative \\
& Measures & Outcomes & Activities \\
\hline \% Immunity Lifted from & -0.34 & -0.04 & -0.62 \\
same Province \& Party & $(0.39)$ & $(0.27)$ & $(0.46)$ \\
\hline $\mathrm{N}$ & 2616 & 2616 & 2616 \\
\hline
\end{tabular}

Only the opposition MPs who retained their immunity enter into the regressions. The specification is same as equation (1), except that instead of Immunity Lifted $\times$ Post, we include \% Immunity Lifted From Same City \& Party. This variable measures the share of MPs that also represent the same city and party as the MP. In the pre-treatment period, this variable is equal to zero. All regressions include MP fixed effects and month-by-year dummies. Standard errors, clustered at the MP level, are in parentheses. ${ }^{* * *}, * *$, and * indicate statistical significance at $1 \%, 5 \%$ and $10 \%$ levels. 


\begin{tabular}{|c|c|c|c|c|}
\hline \multicolumn{5}{|c|}{$\begin{array}{c}\text { Appendix Table A18 } \\
\text { The Impact of Losing Immunity on Opposition MPs' Legis } \\
\text { Controlling for Potential Spillover Impacts } \\
\text { Panel A: Speech Outcomes }\end{array}$} \\
\hline & $(1)$ & $(2)$ & (3) & $(4)$ \\
\hline & Speeches & Words & $\begin{array}{c}\text { Interruptions } \\
\text { Targeting } \\
\text { Gov. MPs }\end{array}$ & $\begin{array}{c}\text { Interruptions } \\
\text { Targeting } \\
\text { Non-Gov. MPs }\end{array}$ \\
\hline $\begin{array}{l}\text { Immunity Lifted } \\
\times \text { Post }\end{array}$ & $\begin{array}{l}-9.56 \\
(6.50) \\
{[0.16]}\end{array}$ & $\begin{array}{c}-533.14 \\
(358.60) \\
{[0.16]}\end{array}$ & $\begin{array}{c}-2.29 * * * \\
(0.84) \\
{[0.03]}\end{array}$ & $\begin{array}{l}-0.38 \\
(0.24) \\
{[0.16]}\end{array}$ \\
\hline $\begin{array}{l}\text { \% Immunity Lifted from } \\
\text { same Province \& Party }\end{array}$ & $\begin{array}{c}2.00 \\
(4.07)\end{array}$ & $\begin{array}{c}60.52 \\
(330.56)\end{array}$ & $\begin{array}{l}-0.93 \\
(1.38)\end{array}$ & $\begin{array}{c}0.18 \\
(0.31) \\
\end{array}$ \\
\hline $\mathrm{N}$ & 5330 & 5330 & 5330 & 5330 \\
\hline
\end{tabular}

Panel B: Legislative Effort

\begin{tabular}{lcccc}
\hline & $(1)$ & $(2)$ & $(3)$ & $(4)$ \\
\hline & $\begin{array}{c}\text { \% Votes } \\
\text { Against } \\
\text { Gov. }\end{array}$ & $\begin{array}{c}\text { Investigation } \\
\text { Inquiries } \\
\text { Filed }\end{array}$ & $\begin{array}{c}\text { Drafts of } \\
\text { Legislation }\end{array}$ & $\begin{array}{c}\text { Formal } \\
\text { Queries }\end{array}$ \\
& $-3.12^{*}$ & $-0.47^{* *}$ & $-0.49^{* *}$ & -1.81 \\
Immunity Lifted & $(1.75)$ & $(0.18)$ & $(0.21)$ & $(3.73)$ \\
$\times$ Post & {$[0.12]$} & {$[0.03]$} & {$[0.05]$} & {$[0.63]$} \\
& -3.73 & -0.25 & -0.43 & -6.82 \\
\% Immunity Lifted from & $(4.00)$ & $(0.30)$ & $(0.30)$ & $(6.90)$ \\
$\quad$ same Province \& Party & 5330 & 5330 & 5330 & 5330 \\
\hline $\mathrm{N}$ & & & & \\
\hline
\end{tabular}

Panel C: First Principal Components

\begin{tabular}{lccc}
\hline & $(1)$ & $(2)$ & $(3)$ \\
\hline & $1^{\text {st }}$ PC of & $1^{\text {st }}$ PC of & $1^{\text {st }}$ PC of Effort in \\
& All Effort & Speech & Other Legislative \\
& Measures & Outcomes & Activities \\
\hline Immunity Lifted & $-0.90^{* * *}$ & $-0.65^{* *}$ & $-0.62^{* *}$ \\
$\times$ Post & $(0.34)$ & $(0.33)$ & $(0.24)$ \\
& {$[0.03]$} & {$[0.09]$} & {$[0.03]$} \\
\% Immunity Lifted from & -0.31 & -0.02 & -0.60 \\
same Province \& Party & $(0.39)$ & $(0.27)$ & $(0.45)$ \\
\hline $\mathrm{N}$ & 5330 & 5330 & 5330 \\
\hline
\end{tabular}

Only the opposition MPs enter into the regressions. The specification is the same as equation (1), except that we additionally include \% Immunity Lifted From Same City \& Party. This variable measures the share of the MP's peers who also represent the same city and party as the MP. In the pre-treatment period, this variable is equal to zero. All regressions include MP fixed effects and month-by-year dummies. Standard errors, clustered at the MP level, are in parentheses. ***, **, and * indicate statistical significance at $1 \%, 5 \%$ and $10 \%$ levels. P-values, adjusted for multiple hypothesis testing, are displayed in [brackets]. 


\section{Appendix Table A19 \\ Party Level Regressions}

Panel A: Speech Outcomes

\begin{tabular}{lcccc}
\hline & $(1)$ & $(2)$ & $(3)$ & $(4)$ \\
\hline & & & Interruptions \\
& Speeches & Words & $\begin{array}{c}\text { Targeting } \\
\text { Gov. MPs }\end{array}$ & $\begin{array}{c}\text { Targeting } \\
\text { Non-Gov. MPs }\end{array}$ \\
& & & $-0.02^{* * *}$ & $-0.01^{* * *}$ \\
$\begin{array}{c}\text { \% Immunity Lifted } \\
\times \text { Post }\end{array}$ & $-0.16^{* * *}$ & $-14.32^{* * *}$ & $(0.01)$ & $(0.00)$ \\
\hline $\mathrm{N}$ & $(0.04)$ & $(4.12)$ & 112 & 112 \\
\hline
\end{tabular}

Panel B: Legislative Effort

\begin{tabular}{lcccc}
\hline & $(1)$ & $(2)$ & $(3)$ & $(4)$ \\
\hline & \% Votes & Investigation & Drafts of & Formal \\
& Against & Inquiries & Fegislation & Queries \\
& Gov. & Filed & Led & \\
\hline $\begin{array}{c}\text { \% Immunity Lifted } \\
\text { × Post }\end{array}$ & 0.00 & $-0.00^{* * *}$ & $-0.00^{* * *}$ & $-0.03^{* * *}$ \\
\hline $\mathrm{N}$ & $(0.02)$ & $(0.00)$ & $(0.00)$ & $(0.01)$ \\
\hline
\end{tabular}

\section{Panel C: First Principal Components}

\begin{tabular}{cccc}
\hline & $(1)$ & $(2)$ & $(3)$ \\
\hline & $1^{\text {st }}$ PC of & $1^{\text {st }}$ PC of & $1^{\text {st }}$ PC of Effort in \\
& All Effort & Speech & Other Legislative \\
& Measures & Outcomes & Activities \\
\hline $\begin{array}{c}\text { \% Immunity Lifted } \\
\times \text { Post }\end{array}$ & $-0.01^{* * *}$ & $-0.01^{* * *}$ & $-0.01^{* * *}$ \\
\hline $\mathrm{N}$ & $(0.00)$ & $(0.00)$ & $(0.00)$ \\
\hline
\end{tabular}

The unit of observation is a party-month. \% Immunity Lifted measures the percent of MPs whose immunity is lifted in May 2016 from that party. Post stands for the post-treatment period. Outcomes are the averages for the party. Panel A: (1) Number of speeches delivered on the Parliament floor by the MP; (2) Number of words in those speeches; (3) Number of times the MP interrupted the speech of another MP who is a member of the government party; (4) Number of times an MP interrupted the speech of another MP who is a member of the opposition parties. Panel B: (1) \% of the rollcall votes the MP voted the same way as the majority of the government party; (2) the number of times the MP filed an investigation inquiry into the activities of the government (3) the number of bills sponsored by the MP; (4) the number of times MP passed a formal query to the members of the government. Panel C: (1) first principal component of all outcomes in Panels A and B; (2) first principal component of outcomes in Panel A; (3) first principal component of outcomes in Panel B. All regressions include party fixed effects and linear party-specific trends. Robust standard errors are in parentheses. ***, **, and * indicate statistical significance at $1 \%, 5 \%$ and $10 \%$ levels. 


\section{Appendix Section 4: Are the Months of May and June Different?}

We investigated whether the months of May and June of 2016 (the two months between the Constitutional Amendment and the coup attempt) were different from previous years’ May and June in terms of the workload of the Parliament. Analyzing the number of days the Parliament was in session each month since the beginning of the $22^{\text {nd }}$ Parliament in 2002 (when AKP first came to power), we find there was no drop in the workload in May or June 2016. Specifically, the Parliament was in session for 13 days in May 2016 and 15 days in June 2016, whereas the average days in session for the period of 2003-2017 was 12 days for May and 11.6 days for June.

We also analyzed seasonality in general. The summary of this analysis is presented in Appendix Figure AF2, where we display the coefficients of 10 monthly dummies and their 95 percent confidence intervals in comparison to the left-out category of August and September, during which the Parliament is usually closed for the Summer vacation. ${ }^{40}$ The dependent variable is the number of session days each month, and the regression has 162 observations, spanning January 2003 - June 2016. As the figure demonstrates, the workload of the Parliament is rather evenly distributed throughout the year, with the exception of the month of December in which the Parliament is in session for a larger number of days, generally because of the budget discussions for the upcoming year.

40 Between January 2003 and June 2016 (the period between the formation of the first AKP government and the coup attempt, the average number of days in which the Parliament held sessions is 11.9 in January, 12.6 in February, 12.8 in March, 12.4 in April, 11.7 in May, 11.6 in June, 8.4 in July, 11.3 in October, 12.8 in November and 16.1 in December. On the other hand, the average number of session days in August is 1.9, and it is 2.6 in September. 


\section{Appendix Figure AF2}

\section{Average Days the Parliament is in Session by Month 2003-2016}

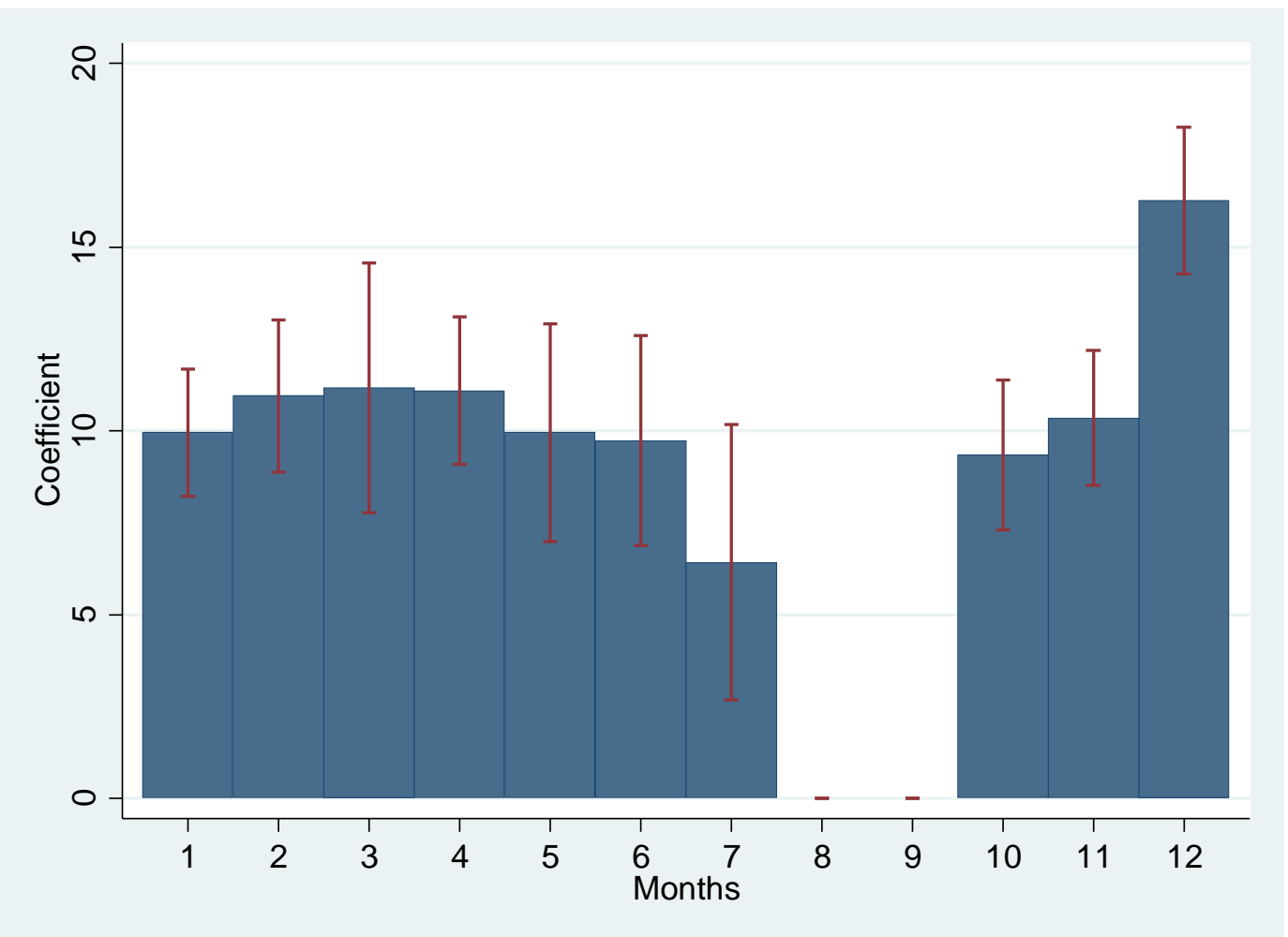

The figure displays the coefficients of ten monthly dummies and their 95 percent confidence intervals in comparison to the left-out category of the months of August and September, during which the Parliament is usually closed for the summer vacation. The dependent variable is the number of days per month in which the Parliament was in session. The regression has 162 observations, spanning January 2003 - June 2016. 


\section{Appendix Section 5: The Impact on the Speed of Legislation}

The $26^{\text {th }}$ Parliament analyzed in this paper passed 491 laws. The majority of these were laws that ratify international treaties. Specifically, when the government signs a treaty with a foreign nation or an international organization, the treaty becomes effective if the Parliament ratifies it, i.e., when the Parliament votes to agree with its clauses. The overwhelming majority of these treaties are approved in the Parliament with no discussion and with the unanimous support of all MPs, including those of the opposition parties. ${ }^{41}$ Of the 491 laws passed, 383 were ratifications of international agreements and treaties. The remaining 108 laws were about domestic issues.

Appendix Figures AF3 and AF4 present the average number of days it took in the Parliament each month to ratify treaties and to pass laws. The vertical axes measure the average number of days the laws or international treaties were discussed before being approved by the Parliament. Each dot corresponds to a month with at least one law/treaty being passed/ratified, and the numbers next to the dots represent the number of laws/treaties passed/ratified in that month. The solid vertical line marks the end of the pre-treatment period (April 2016), and the dashed vertical line indicates the coup attempt (July 2016).

As Appendix Figure AF3 reveals, on average, international treaties are discussed and ratified in one day. Appendix Figure AF4, on the other hand, shows that there is variation in the speed with which laws are passed. For example, two laws were passed in February 2016, and the average speed of legislation was about five days. In March 2016, three additional laws were passed, and the average number of days of the debate was three between these two laws. As the figure makes it clear, laws were passed very quickly in some months of 2017: the average was about 1.5 days in February 2017. There are also outliers. For example, two laws were passed in December 2016 and in January 2017. In both cases, the average duration was seven days. ${ }^{42}$

\footnotetext{
${ }^{41}$ Examples of such ratification include "The law regarding the Parliament's endorsement of the Defense Cooperation Agreement between the Republic of Turkey and the Federal Republic of Somalia" and "The law regarding the Parliament's endorsement of our participation in the protocols of the amendments to the Convention on the International Hydrography Organization.”

${ }^{42}$ These week-long Parliamentary debates at the end of a year is observed because these are laws related to the next year's budget, which involve a lot of detail and debate. The unusually high debate days in
} 
To formally investigate the impact of the Constitutional Amendment, which allowed lifting MP immunities, we used the data presented in Appendix Figures AF3 and AF4 and ran regressions of the following form:

(A3) Days $_{i m y}=\pi_{1}$ Post Treatment $m y+\pi_{2}$ PostCoup $p_{m y}+\theta_{m}+\kappa_{y}+\varepsilon_{\text {imy }}$, where $i, m$, and $y$ are indices for laws, months, and years, respectively. Days $s_{\text {imy }}$ stands for the number of days it took the Parliament to pass law $i$ (which was passed in month $m$ of year $y$ ). Post Treatment represents the period after the Constitutional Amendment. Post Coup is equal to one for the months following the coup attempt in July 2016. We also control for the month and year dummies in the regression, represented by $\mu_{m}$ and $\gamma_{y}$, respectively.

The results are presented in Appendix Table A20. Columns (1)- (3) display the results where the speed of ratification of treaties is analyzed. Columns (4) -(6) use the sample that employs domestic laws. Consistent with Appendix Figure AF3, Appendix Table A20 shows that the Constitutional Amendment had no impact on the speed of ratifications. On the other hand, the coefficient of the Post-Treatment is about -1.6 in column (6). This indicates that the enactment of the Constitutional amendment reduced the number of days it took to pass laws by more than a day and a half, where the average is 2.2 days. Put differently, after the Parliamentary action, which lifted the immunity of some MPs, the laws are passed 1.5 days faster than before, presumably because of shorter and/or fewer debates in the Parliament. Although the increase in the speed with which legislators pass laws makes the Parliament more efficient, if the quality of these laws is lower (in their comprehensiveness or in the propensity to be challenged in courts) in comparison to the quality that would have been observed had these laws been enacted slower, and with more deliberation, the welfare implications are unclear.

January 2017 was due to the discussions regarding another Constitutional Amendment that ultimately resulted in Turkey switching to a Presidential system. 


\section{Appendix Figure AF3}

The Speed with which International Treaties are Ratified

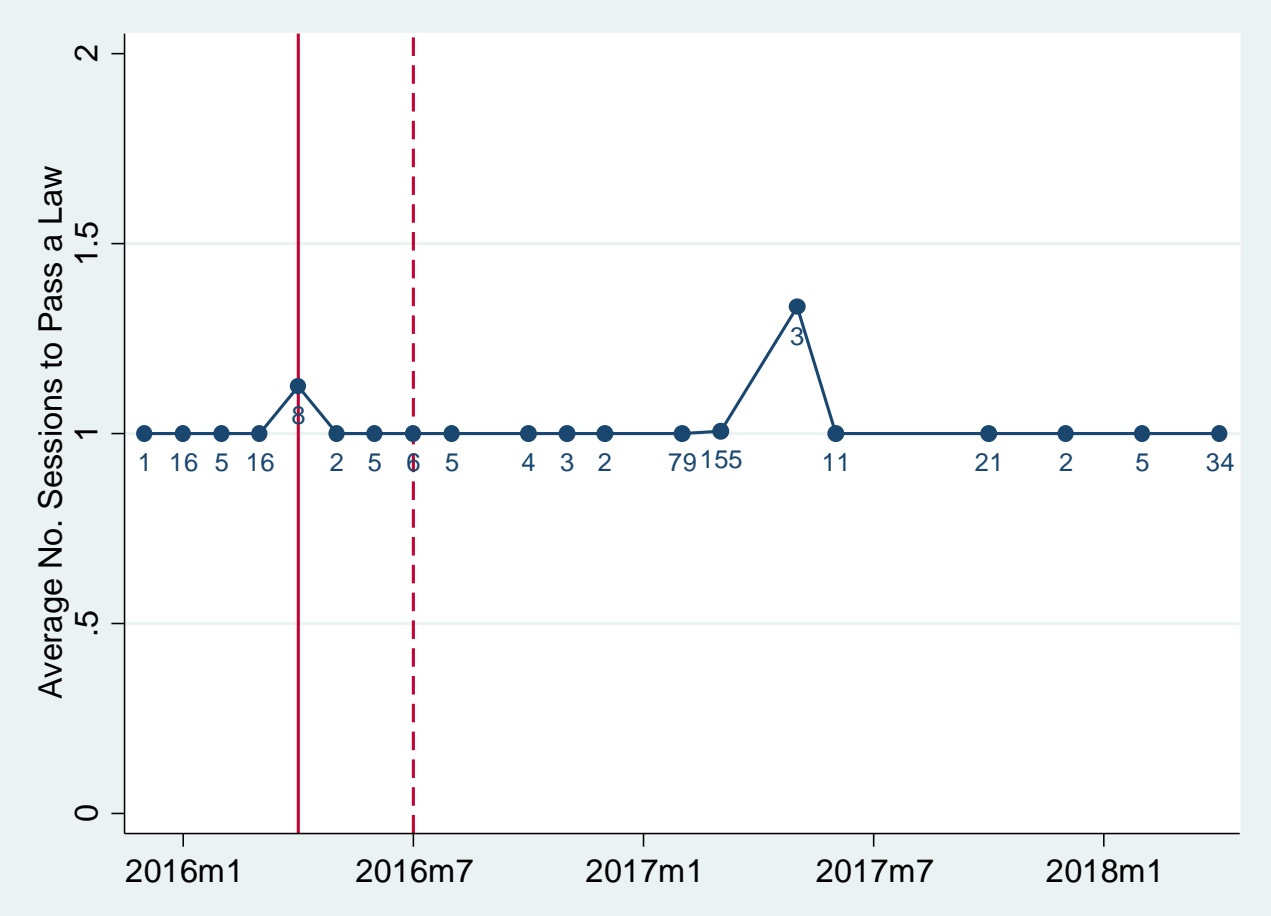

The vertical axis measures the average number of days the ratifications were discussed before being approved by the Parliament. Each month corresponds to a month with at least one ratification, and the number below the dots represents the number of ratifications in that month. The solid red vertical line marks the end of the pre-treatment period (April 2016), and the dashed vertical red line indicates the coup attempt (July 2016). 


\section{Appendix Figure AF4 \\ The Speed with which Laws are Passed}

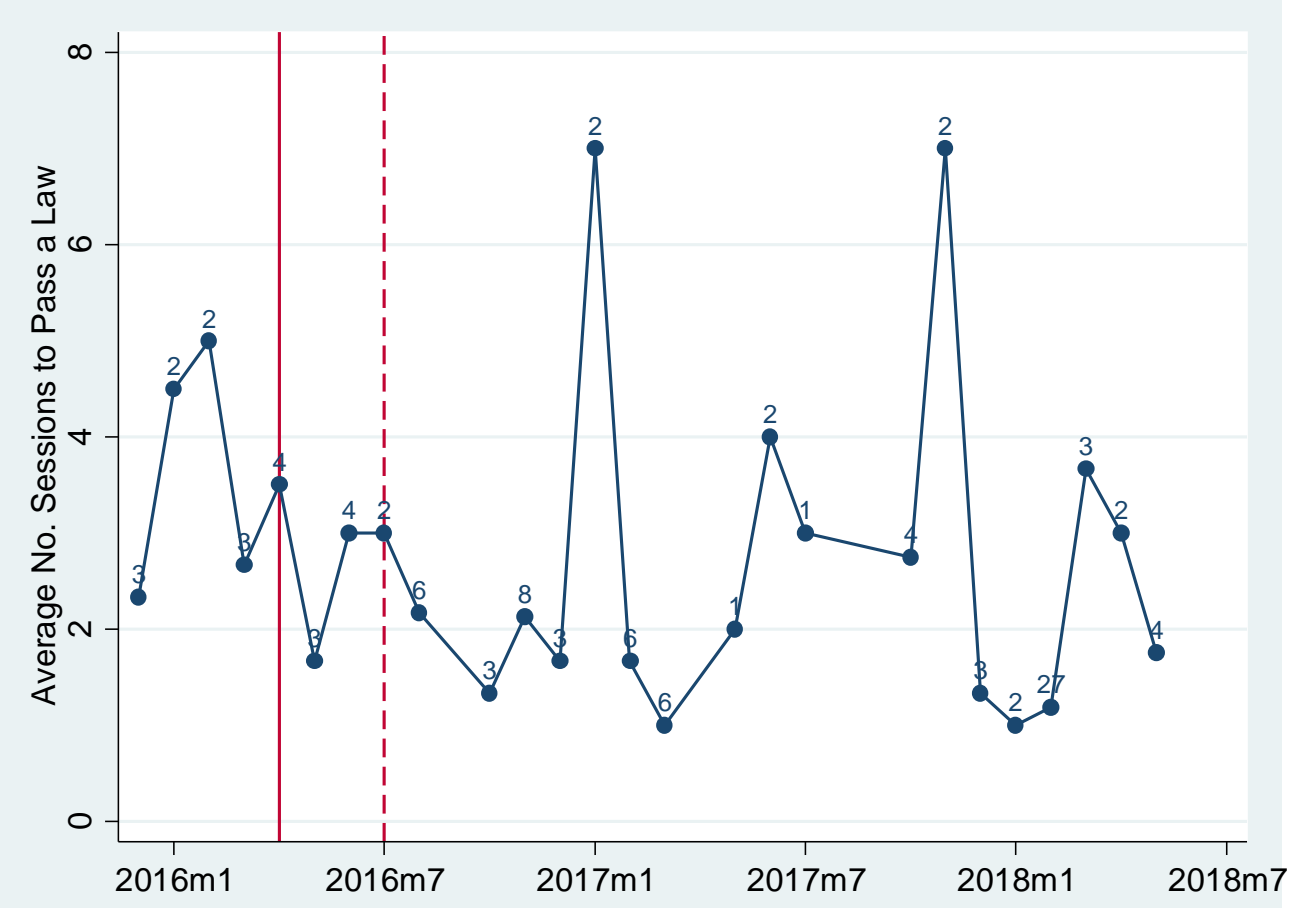

The vertical axis measures the average number of days the laws were discussed before being approved by the Parliament. Each month corresponds to a month with at least one law, and the number next to the dots represents the number of laws in that month. The solid red vertical line marks the end of the pre-treatment period (April 2016), and the dashed vertical red line indicates the coup attempt (July 2016).

Appendix Table A20

The Impact of the Constitutional Amendment on the Speed with which Laws Are Passed

\begin{tabular}{lcccccc}
\hline & \multicolumn{3}{c}{ Ratifications } & \multicolumn{3}{c}{ Laws } \\
\hline & $(1)$ & $(2)$ & $(3)$ & $(4)$ & $(5)$ & $(6)$ \\
\hline Post-Amendment & -0.02 & -0.12 & -0.19 & $-1.39 * * *$ & $-1.93^{*}$ & $-1.64^{+}$ \\
& $(0.02)$ & $(0.07)$ & $(0.12)$ & $(0.53)$ & $(1.15)$ & $(1.07)$ \\
Post-Coup & & & 0.11 & & & -0.52 \\
& & & $(0.08)$ & & & $(1.30)$ \\
\hline $\mathrm{N}$ & 383 & 383 & 383 & 108 & 108 & 108 \\
\hline Year \& Month FEs & No & Yes & Yes & No & Yes & Yes \\
\hline Mean of Y & 1.01 & 1.01 & 1.01 & 2.22 & 2.22 & 2.22 \\
\hline
\end{tabular}

The unit of observation is a piece of legislation. The outcome is the number of parliamentary sessions (days) it took to pass this legislation. Post-Treatment (Post-Coup) indicates May 2016 (July 2016) and later. Ratification stands for whether the legislation is for ratification of an international treaty. Robust standard errors are presented in parentheses. ${ }^{* *}, * *$, and $*$ indicate statistical significance at $1 \%, 5 \%$ and $10 \%$ levels. The coefficient, denoted by + , is significant at $13 \%$. 


\section{Appendix Section 6: Trust in Institutions}

\section{Appendix Figure AF5 \\ Provinces in the Eurobarometer Turkey Sample and Whether MPs from that Province Lost Immunity}

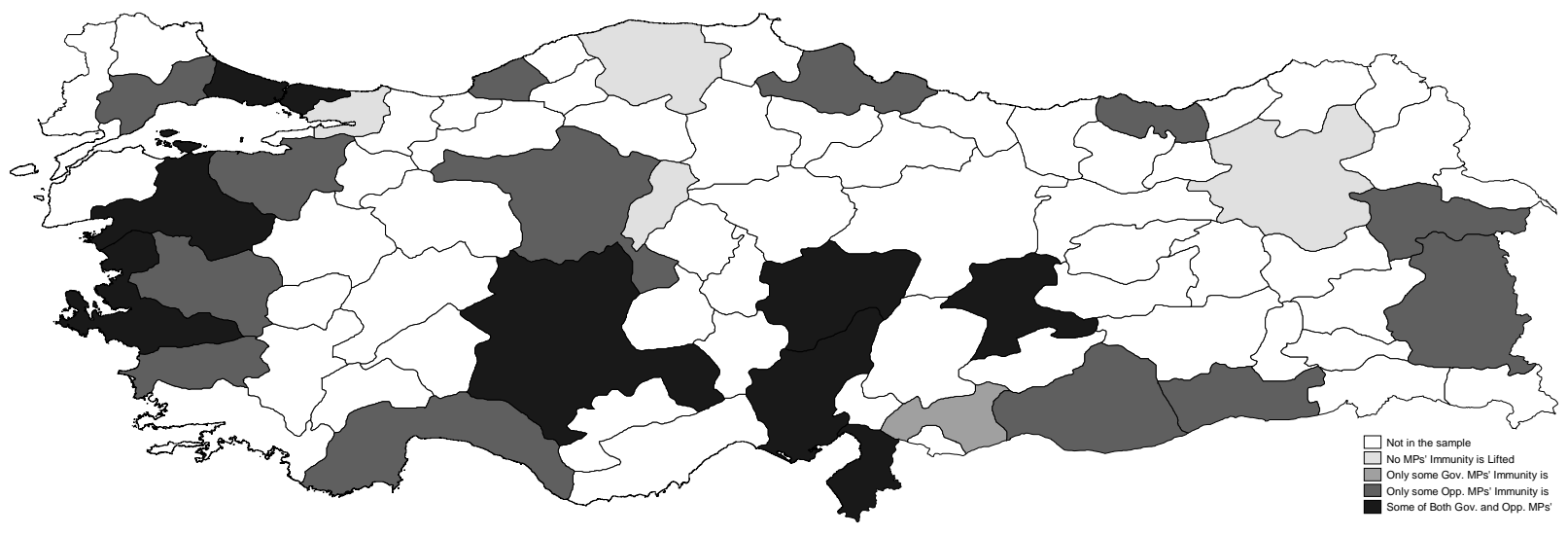

White: Not sampled in Eurobarometer

Light Gray: No MPs of this province lost immunity

Medium Gray: Some government bloc MPs but no opposition MPs of this province lost immunity

Dark Gray: Some opposition MPs but no government bloc MPs of this province lost immunity

Black: Some of both government and opposition bloc MPs of this province lost immunity 
Appendix Table A21

Provinces in the Eurobarometer Turkey Sample and Whether MPs from that Province Lost Immunity

\begin{tabular}{lcc}
\hline & $\begin{array}{c}=1 \text { if Some Gov. } \\
\text { Bloc MPs' } \\
\text { Immunity is Lifted }\end{array}$ & $\begin{array}{c}=1 \text { if Some Opp. } \\
\text { Bloc MPs' } \\
\text { Immunity is Lifted }\end{array}$ \\
\hline Adana & 1 & 1 \\
Agri & 0 & 1 \\
Ankara & 0 & 1 \\
Antalya & 0 & 1 \\
Aydin & 0 & 1 \\
Balikesir & 1 & 1 \\
Bursa & 0 & 1 \\
Erzurum & 0 & 0 \\
Gaziantep & 1 & 0 \\
Hatay & 1 & 1 \\
Istanbul & 1 & 1 \\
Izmir & 1 & 1 \\
Kastamonu & 0 & 0 \\
Kayseri & 1 & 1 \\
Kirikkale & 0 & 0 \\
Kocaeli & 0 & 0 \\
Konya & 1 & 1 \\
Malatya & 1 & 1 \\
Manisa & 0 & 1 \\
Mardin & 0 & 1 \\
Samsun & 0 & 1 \\
Sanliurfa & 0 & 1 \\
Tekirdag & 0 & 1 \\
Trabzon & 0 & 1 \\
Van & 0 & 1 \\
Zonguldak & 0 & 1 \\
\hline
\end{tabular}

